UNIVERSIDADE DE SÃO PAULO

ESCOLA DE ENGENHARIA DE LORENA

BRUNO DAL ROVERE CONTESINI

INVESTIGAÇÃO DA INFLUÊNCIA DE PARÂMETROS LUMINOSOS NO DESENVOLVIMENTO DE CULTIVOS DA MICROALGA MARINHA Chlorella minutissima 
BRUNO DAL ROVERE CONTESINI

\title{
INVESTIGAÇÃO DA INFLUÊNCIA DE PARÂMETROS LUMINOSOS NO DESENVOLVIMENTO DE CULTIVOS DA MICROALGA MARINHA Chlorella minutissima
}

\begin{abstract}
Dissertação apresentada à Escola de Engenharia de Lorena da Universidade de São Paulo para obtenção do título de Mestre em Ciências do Programa de PósGraduação em Engenharia Química na área de desenvolvimento de produtos e processos.
\end{abstract}

Orientador: Prof. Dr. Messias Borges Silva

Versão corrigida

Lorena

2019 
AUTORIZO A REPRODUÇÃO E DIVULGAÇÃO TOTAL OU PARCIAL DESTE TRABALHO, POR QUALQUER MEIO CONVENCIONAL OU ELETROONICO, PARA FINS DE ESTUDO E PESQUISA, DESDE QUE CITADA A FONTE

Ficha catalográfica elaborada pelo Sistema Automatizado da Escola de Engenharia de Lorena, com os dados fornecidos pelo(a) autor(a)

Contesini, Bruno dal Rovere

Investigação da influência de parâmetros luminosos no desenvolvimento de cultivos da microalga marinha Chlorella minutissima / Bruno dal Rovere Contesini; orientador Messias Borges Silva - Versão Corrigida. Lorena, 2019.

$119 \mathrm{p}$.

Dissertação (Mestrado em Ciências - Programa de Pós Graduação em Engenharia Química na Área de Desenvolvimento de Produtos e Processos) - Escola de Engenharia de Lorena da Universidade de São Paulo. 2019

1. Biofotônica. 2. Biomassa. 3. Lipídios. 4. Chlorella minutissima. 5. Planejamento de experimentos. I. Título. II. Silva, Messias Borges, orient. 
Aos meus pais, Kátia e Vagner, a minha irmã Júlia, a todos os amigos e familiares que, de alguma forma, participaram da elaboração dessas páginas e, em especial, dedico este trabalho ao meu falecido avô, Arnaldo, cujo último sonho em vida era acompanhar minha formação acadêmica, sonho que o tempo não me deu a oportunidade de realizar. 



\section{AGRADECIMENTO}

Agradeço primeiramente aos meus pais Kátia e Vagner a á minha irmã Júlia por todo o apoio e a compreensão durante as longas horas de dedicação a este trabalho.

A todos os familiares que ao longo da minha vida sempre torceram e contribuíram com o meu sucesso, assim como aos amigos Brayan Puosso, Diego Pappalardo, Ligia Cortez e Karoline Prates.

Ao meu orientador e amigo, Prof. Dr. Messias Borges Silva, que emprestou a mim ao longo destes anos de formação acadêmica não apenas seus valiosos conselhos técnicos e científicos, mas também seu zelo, sua amizade e seu carinho, típicos de uma relação que ultrapassa a de orientador e aluno, caminhando na direção de algo quase familiar.

Agradeço também aos amigos que a Escola de Engenharia de Lorena trouxe para a minha vida, destaque ao Lucas Zardini, Felipe Torres, Luciana Silvestrini, Paloma Salviano, Nian Freire e Juliana Rodrigues.

Especial lembrança a Graziela Ferraz que, nos momentos de desespero na tentativa de conduzir as vidas acadêmica e corporativa, esteve sempre disposta a ceder a mim a motivação que ora me faltasse para prosseguir.

A Dulcinete Palma, por constituír por tantos anos a minha base de sustentação no município de Lorena, tornando-se a amiga que o tempo jamais afastará da minha vida.

Às alunas de Iniciação Científica Letícia Silva e Amanda Dias, bem como à Isabella Fernanda de Oliveira que trabalharam ao meu lado durante todas as etapas desse trabalho e que tanto contribuíram para que ele fosse bemsucedido.

Aos meus colegas do Laboratório de Engenharia de Microalgas da Escola de Engenharia de Lorena Mateus Amaral, Savienne Zorn, Carla Loures, Guilherme Pedro, Eduardo Bredda e Victor Marino, bem como a todos os alunos de Iniciação Científica e aos estagiários que por lá passaram, emprestando-nos um imprescindível apoio. 
A todos os professores que passaram pelos meus anos de formação desde os tempos de educação infantil, em especial aos professores parceiros do Laboratório de Engenharia de Microalgas da Escola de Engenharia de Lorena e aos membros da banca examinadora do presente trabalho Profa. Dra. Ivonete Ávila, Profa. Dra. Talita Martins Lacerda, Prof. Dr. Arnaldo Márcio Ramalho Prata, Profa. Dra. Daniela Helena Pelegrine Guimarães, Prof. Dr. João Paulo Alves Silva e Profa. Dra. Eliana Vieira Canettieri.

A todos os funcionários da Escola de Engenharia de Lorena que, cada qual com o seu importante trabalho, permitem que a universidade cumpra brilhantemente o seu papel com a sociedade, e a todos os demais que, direta ou indiretamente, contribuíram com a execução do presente trabalho. 
"Pode-se encontrar a felicidade nas horas mais sombrias, se a pessoa se lembrar de acender a luz". 



\section{RESUMO}

CONTESINI, B. D. R. Investigação da influência de parâmetros luminosos no desenvolvimento de cultivos da microalga marinha Chlorella minutissima. 2019. 119 p. Dissertação (Mestrado em Ciências) - Escola de Engenharia de Lorena, Universidade de São Paulo, Lorena, 2019.

O presente trabalho compreende a execução de 16 experimentos, realizados em duplicata, visando avaliar a influência de fatores, tais como iluminância, concentração de $\mathrm{NaH}_{2} \mathrm{PO}_{4} \cdot \mathrm{H}_{2} \mathrm{O}$, concentração de $\mathrm{NaNO}_{3}$, fotoperíodo e comprimento de onda, além da interação entre a iluminância e os demais fatores, na produção de biomassa e lipídios pela microalga marinha Chlorella minutissima. Os experimentos estiveram dispostos em 2 arranjos ortogonais L8 de Taguchi, cada um dos quais recebeu dados obtidos em experimentos com diferentes comprimentos de onda ( $470 \mathrm{~nm}$, além da luz branca), nos quais eram variados, em dois níveis, a iluminância (26 klx e $13 \mathrm{klx}$ ), as concentrações de $\mathrm{NaH}_{2} \mathrm{PO}_{4} \cdot \mathrm{H}_{2} \mathrm{O}$ (5 mg/L e $15 \mathrm{mg} / \mathrm{L}$ ) e $\mathrm{NaNO}_{3}(45 \mathrm{mg} / \mathrm{L}$ e $75 \mathrm{mg} / \mathrm{L}$ ) e o fotoperíodo (12: 12 horas claro: escuro e 8 ciclos diários de 2: 1 horas claro: escuro). Os experimentos se processaram em reatores de vidro com formato de prisma de base quadrada com volume útil de 1,1 L, isolados da influência da luminosidade externa. Para a luz branca, o melhor resultado para a produção de biomassa foi de $1300 \mathrm{mg} / \mathrm{L}$, ao passo que o melhor resultado para o teor lipídico foi de $22,75 \%$ em relação à biomassa seca. Para a luz de comprimento de onda equivalente a $470 \mathrm{~nm}$, o melhor resultado para a produção de biomassa foi de $1270 \mathrm{mg} / \mathrm{L}$, ao passo que o melhor resultado para o teor lipídico foi de 19,03\% em relação à biomassa seca.

Palavras-chave: Biofotônica. Biomassa. Lipídios. Microalgas marinhas. Chlorella minutissima. Planejamento de experimentos. Taguchi. 


\begin{abstract}
CONTESINI, B. D. R. Investigation of the influence of luminous parameters on the development of marine microalgae Chlorella minutissima. 2019. 119 p. Dissertation (Master of Science) - Escola de Engenharia de Lorena, Universidade de São Paulo, Lorena, 2019.

This work comprises the execution of 16 experiments, performed in duplicate, in order to evaluate the influence of factors such as illuminance, $\mathrm{NaH}_{2} \mathrm{PO}_{4} \cdot \mathrm{H}_{2} \mathrm{O}$ concentration, $\mathrm{NaNO}_{3}$ concentration, photoperiod and wavelength, in addition to the interaction between the illuminance and the other factors, in the production of biomass and lipids by the marine microalgae Chlorella minutissima. The experiments were arranged in 2 Taguchi's $L_{8}$ orthogonal arrays, each of which received data obtained in experiments with different wavelengths $(470 \mathrm{~nm}$, in addition to the white light), in which the illuminance (26 klx and $13 \mathrm{klx}$ ), the $\mathrm{NaH}_{2} \mathrm{PO}_{4} . \mathrm{H}_{2} \mathrm{O}(5 \mathrm{mg} / \mathrm{L}$ and $15 \mathrm{mg} / \mathrm{L})$ and $\mathrm{NaNO}_{3}(45 \mathrm{mg} / \mathrm{L}$ and $75 \mathrm{mg} / \mathrm{L})$ concentrations and the photoperiod (12: 12 hours light: dark and 8 daily cycles of 2: 1 hours light: dark) were varied, in two levels. The experiments were performed in quadrangular prism glass reactors with a useful volume of $1.1 \mathrm{~L}$, isolated from the influence of external luminosity. For white light, the best result for biomass production was $1300 \mathrm{mg} / \mathrm{L}$, while the best result of lipid content was $22,75 \%$ in relation to the dry biomass. For light with a wavelength of $470 \mathrm{~nm}$, the best result for biomass production was $1270 \mathrm{mg} / \mathrm{L}$, while the best result of lipid content was $19,03 \%$ in relation to the dry biomass.
\end{abstract}

Keywords: Biophotonics. Biomass. Lipids Marine microalgae. Chlorella minutíssima. Design of experiments. Taguchi. 


\section{LISTA DE ABREVIATURAS}
ANOVA Análise de Variância
B/G Razão entre a taxa de irradiação do vermelho e do verde
B/R Razão entre a taxa de irradiação do azul e do vermelho
D Desejabilidade Global
$d_{i} \quad$ Desejabilidade individuas da i-ésima resposta
DOE Planejamento de Experimentos
EEL-USP Escola de Engenharia de Lorena - Universidade de São Paulo
EIA Energy Information Administration
gl Graus de Liberdade
R/FR Razão entre a taxa de irradiação do vermelho e do vermelho distante
S/N Razão Sinal-Ruído
SQ Soma dos Quadrados
SQM Soma Média dos Quadrados
Hmáx Taxa de crescimento específico máxima 


\section{LISTA DE FIGURAS}

Figura 1 - Consumo de energia por combustível previsto até $2040 \ldots \ldots \ldots \ldots \ldots . . . . .26$

Figura 2 - Células de Chlorella minutissima vistas através de microscópio...... 31

Figura 3 - Diferentes técnicas de colheita e recuperação de biomassa após o cultivo.

Figura 4 - Processo de extração lipídica via solventes em células de microalgas, dividido em etapas......

Figura 5 - Decomposição da luz por um prisma.

Figura 6 - Espectro eletromagnético com ênfase na região do visível.

Figura 7 - Efeito da intensidade luminosa na taxa de crescimento específica de microalgas.

Figura 8 - Taxas de fluxo de fótons no espectro visível em diferentes profundidades de águas límpidas (linhas azuis) e na presença de fitoplânctons (linhas verdes). 48

Figura 9 - Fases do Planejamento de Experimentos. 51

Figura 10 - Representação esquemática de um processo. 52

Figura 11 - Fluxograma das principais etapas da pesquisa. 55

Figura 12 - Esquema da estrutura de manutenção de cepas de microalgas.... 56

Figura 13 - Esquema dos fotobiorreatores empregados para o cultivo da

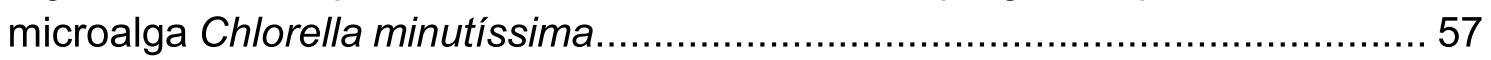

Figura 14 - Vista lateral aberta dos fotobiorreatores usados no trabalho.......... 58

Figura 15 - Vista superior segmentada dos fotobiorreatores. 58

Figura 16 - Desenho técnico mecânico da estrutura dos fotobiorreatores empregados no trabalho 59

Figura 17 - Meio de cultivo recém inoculado.

Figura 18 - Espectro de absorção da clorofila a e da clorofila b. 63

Figura 19 - Biomassa após operação de floculação. 64

Figura 20 - Biomassa filtrada à vácuo 64 
Figura 21 - Esquema para rompimento da parede celular em banho de ultrassom

Figura 22 - Gráfico linear correspondente ao arranjo ortogonal $L_{8}$ de Taguchi. 68

Figura 23 - Gráficos dos efeitos dos fatores no que diz respeito à média de biomassa, em cultivos submetidos à luz branca.

Figura 24 - Gráficos dos efeitos dos fatores no que diz respeito à $\mathrm{S} / \mathrm{N}$ da produção de biomassa, em cultivos submetidos à luz branca.

Figura 25 - Gráfico da interação entre a iluminância e a concentração de $\mathrm{NaH}_{2} \mathrm{PO}_{4} \cdot \mathrm{H}_{2} \mathrm{O}$, para a produção de biomassa, no que diz respeito à média em cultivos submetidos à luz branca 75

Figura 26 - Gráfico da interação entre a iluminância e a concentração de $\mathrm{NaNO}_{3}$, para a produção de biomassa no que diz respeito à média em cultivos submetidos à luz branca. 76

Figura 27 - Gráfico da interação entre a iluminância e o fotoperíodo, para a produção de biomassa, no que diz respeito à média em cultivos submetidos à luz branca.

Figura 28 - Gráfico da interação entre a iluminância e a concentração de $\mathrm{NaH}_{2} \mathrm{PO}_{4} \cdot \mathrm{H}_{2} \mathrm{O}$, para a produção de biomassa, no que diz respeito à $\mathrm{S} / \mathrm{N}$ em cultivos submetidos à luz branca.

Figura 29 - Gráfico da interação entre a iluminância e a concentração de $\mathrm{NaNO}_{3}$, para a produção de biomassa, no que diz respeito à $\mathrm{S} / \mathrm{N}$ em cultivos submetidos à luz branca. 78

Figura 30 - Gráfico da interação entre a iluminância e o fotoperíodo, para a produção de biomassa, no que diz respeito à $\mathrm{S} / \mathrm{N}$ em cultivos submetidos à luz branca. 78

Figura 31 - Gráficos dos efeitos dos fatores no que diz respeito à média do teor lipídico em cultivos submetidos à luz branca.

Figura 32 - Gráficos dos efeitos dos fatores no que diz respeito à $\mathrm{S} / \mathrm{N}$ do teor lipídico, em cultivos submetidos à luz branca.

Figura 33 - Gráfico da interação entre a iluminância e a concentração de $\mathrm{NaH}_{2} \mathrm{PO}_{4} \cdot \mathrm{H}_{2} \mathrm{O}$, para o teor lipídico, no que diz respeito à média em cultivos submetidos à luz branca.

Figura 34 - Gráfico da interação entre a iluminância e a concentração de $\mathrm{NaNO}_{3}$, para o teor lipídico, no que diz respeito à média em cultivos submetidos à luz branca. 
Figura 35 - Gráfico da interação entre a iluminância e o fotoperíodo, para o teor lipídico, no que diz respeito à média em cultivos submetidos à luz branca....... 83

Figura 36 - Gráfico da interação entre a iluminância e a concentração de $\mathrm{NaH}_{2} \mathrm{PO}_{4} \cdot \mathrm{H}_{2} \mathrm{O}$, para o teor lipídico, no que diz respeito à $\mathrm{S} / \mathrm{N}$ em cultivos submetidos à luz branca.

Figura 37 - Gráfico da interação entre a iluminância e a concentração de $\mathrm{NaNO}_{3}$, para o teor lipídico, no que diz respeito à $\mathrm{S} / \mathrm{N}$ em cultivos submetidos à luz branca. 85

Figura 38 - Gráfico da interação entre a iluminância e o fotoperíodo, para o teor lipídico, no que diz respeito à $\mathrm{S} / \mathrm{N}$ em cultivos submetidos à luz branca. 85

Figura 39 - Gráfico de otimização simultânea das variáveis de resposta, em cultivos submetidos à luz branca.

Figura 40 - Gráficos dos efeitos dos fatores no que diz respeito à média de biomassa, em cultivos submetidos à luz azul.

Figura 41 - Gráficos dos efeitos dos fatores no que diz respeito à $S / N$ da produção de biomassa, em cultivos submetidos à luz azul.............................. 90

Figura 42 - Gráfico da interação entre a iluminância e a concentração de $\mathrm{NaH}_{2} \mathrm{PO}_{4} \cdot \mathrm{H}_{2} \mathrm{O}$, para a produção de biomassa, no que diz respeito à média em cultivos submetidos à luz azul.

Figura 43 - Gráfico da interação entre a iluminância e a concentração de $\mathrm{NaNO}_{3}$, para a produção de biomassa no que diz respeito à média em cultivos submetidos à luz azul. 92

Figura 44 - Gráfico da interação entre a iluminância e o fotoperíodo, para a produção de biomassa, no que diz respeito à média em cultivos submetidos à luz azul

Figura 45 - Gráfico da interação entre a iluminância e a concentração de $\mathrm{NaH}_{2} \mathrm{PO}_{4} \cdot \mathrm{H}_{2} \mathrm{O}$, para a produção de biomassa, no que diz respeito à $\mathrm{S} / \mathrm{N}$ em cultivos submetidos à luz azul.

Figura 46 - Gráfico da interação entre a iluminância e a concentração de $\mathrm{NaNO}_{3}$, para a produção de biomassa, no que diz respeito à $\mathrm{S} / \mathrm{N}$ em cultivos submetidos à luz azul.

Figura 47 - Gráfico da interação entre a iluminância e o fotoperíodo, para a produção de biomassa, no que diz respeito à $\mathrm{S} / \mathrm{N}$ em cultivos submetidos à luz azul.

Figura 48 - Gráficos dos efeitos dos fatores no que diz respeito à média do teor lipídico em cultivos submetidos à luz azul. 
Figura 49 - Gráficos dos efeitos dos fatores no que diz respeito à $\mathrm{S} / \mathrm{N}$ do teor lipídico, em cultivos submetidos à luz azul.

Figura 50 - Gráfico da interação entre a iluminância e a concentração de $\mathrm{NaH}_{2} \mathrm{PO}_{4} \cdot \mathrm{H}_{2} \mathrm{O}$, para o teor lipídico, no que diz respeito à média em cultivos submetidos à luz azul. 98

Figura 51 - Gráfico da interação entre a iluminância e a concentração de $\mathrm{NaNO}_{3}$, para o teor lipídico, no que diz respeito à média em cultivos submetidos à luz azul. 99

Figura 52 - Gráfico da interação entre a iluminância e o fotoperíodo, para o teor lipídico, no que diz respeito à média em cultivos submetidos à luz azul. 99

Figura 53 - Gráfico da interação entre a iluminância e a concentração de $\mathrm{NaH}_{2} \mathrm{PO}_{4} \cdot \mathrm{H}_{2} \mathrm{O}$, para o teor lipídico, no que diz respeito à $\mathrm{S} / \mathrm{N}$ em cultivos submetidos à luz azul. 100

Figura 54 - Gráfico da interação entre a iluminância e a concentração de $\mathrm{NaNO}_{3}$, para o teor lipídico, no que diz respeito à $\mathrm{S} / \mathrm{N}$ em cultivos submetidos à luz azul. 101

Figura 55 - Gráfico da interação entre a iluminância e o fotoperíodo, para o teor lipídico, no que diz respeito à $\mathrm{S} / \mathrm{N}$ em cultivos submetidos à luz azul. 101

Figura 56 - Gráfico de otimização simultânea das variáveis de resposta, em cultivos submetidos à luz azul. 103 


\section{LISTA DE TABELAS}

Tabela 1 - Taxas de ocorrência das palavras-chave envolvidas na pesquisa realizada na base de dados Scopus.

Tabela 2 - Composição de diferentes espécies de microalgas. 32

Tabela 3 - Comparação entre cultivos em rendimento em óleo (L/há) e área ocupada. 33

Tabela 4 - Teor percentual de lipídios, em relação à biomassa seca, para diferentes espécies de microalgas. 38

Tabela 5 - Características de diversos pigmentos em microalgas. 45

Tabela 6 - Composição do meio de cultivo.

Tabela 7 - Fatores considerados no planejamento de experimentos e seus respectivos níveis decodificados.

Tabela 8 - Matriz experimental $L_{8}$ de Taguchi com 4 fatores em dois níveis.... 68

Tabela 9 - Resultados de produção de biomassa referentes ao arranjo ortogonal L8 de Taguchi, obtidos em cultivos submetidos à luz branca. 73

Tabela 10 - Análise de variância, para a produção de biomassa, com respeito à média em cultivos submetidos à luz branca.

Tabela 11 - Análise de variância, para a produção de biomassa, com respeito à $\mathrm{S} / \mathrm{N}$ em cultivos submetidos à luz branca. 79

Tabela 12 - Resultados de teor lipídico referentes ao arranjo ortogonal L8 de Taguchi, obtidos em cultivos submetidos à luz branca.

Tabela 13 - Análise de variância, para o teor lipídico, com respeito à média em cultivos submetidos à luz branca. 86

Tabela 14 - Análise de variância, para o teor lipídico, com respeito à $\mathrm{S} / \mathrm{N}$ em cultivos submetidos à luz branca.. 86

Tabela 15 - Resultados de produção de biomassa referentes ao arranjo ortogonal $\mathrm{L}_{8}$ de Taguchi, obtidos em cultivos submetidos à luz azul.

Tabela 16 - Análise de variância, para a produção de biomassa, com respeito à média em cultivos submetidos à luz azul. 95

Tabela 17 - Análise de variância, para a produção de biomassa, com respeito à $\mathrm{S} / \mathrm{N}$ em cultivos submetidos à luz azul.. 95 
Tabela 18 - Resultados de teor lipídico referentes ao arranjo ortogonal L8 de Taguchi, obtidos em cultivos submetidos à luz azul........................................ 96

Tabela 19 - Análise de variância, para o teor lipídico, com respeito à média em cultivos submetidos à luz azul.

Tabela 20 - Análise de variância, para o teor lipídico, com respeito à S/N em cultivos submetidos à luz azul..... 


\section{SUMÁRIO}

1. INTRODUÇÃO

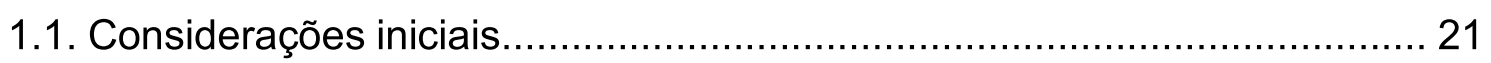

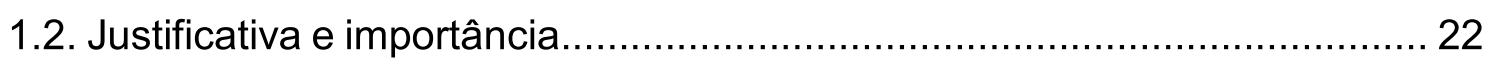

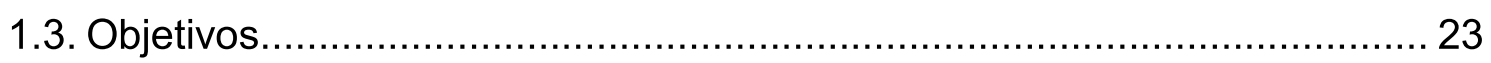

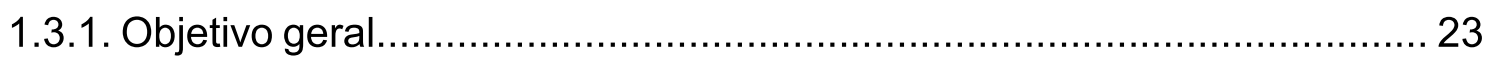

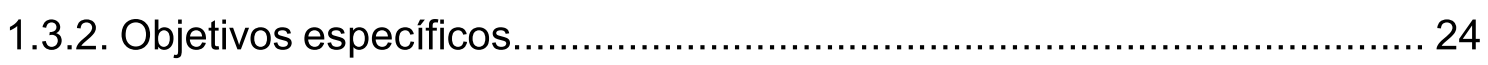

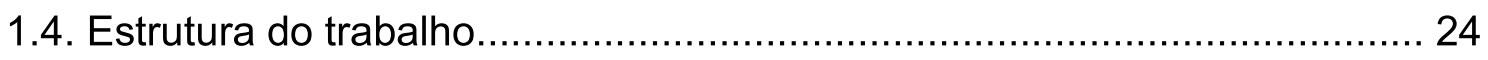

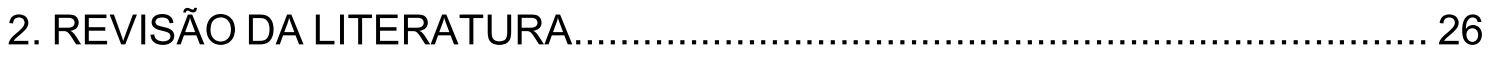

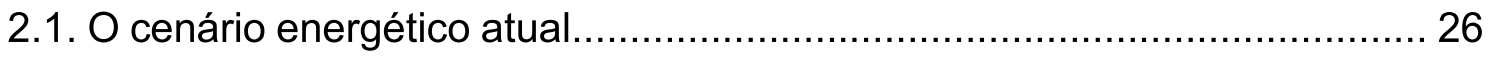

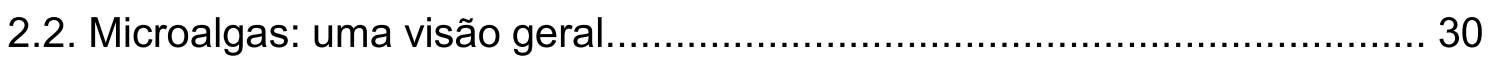

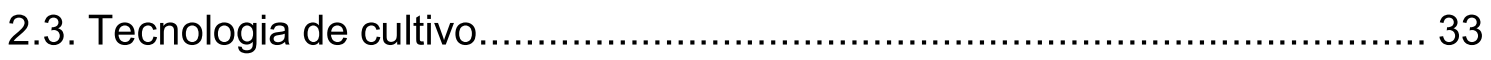

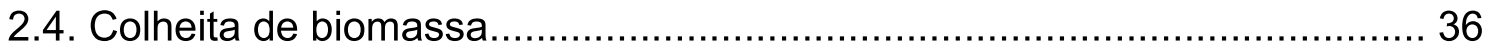

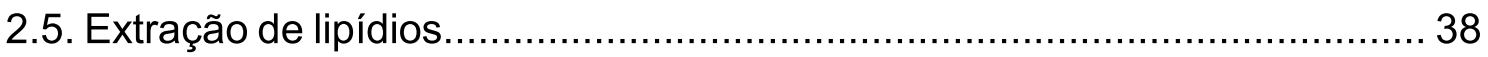

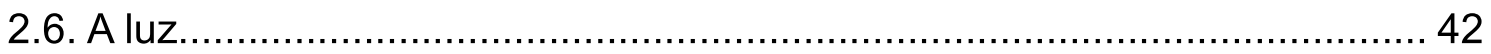

2.6.1. Aspectos físicos sobre a natureza da luz............................................ 42

2.6.2. Aspectos da luz relacionados ao cultivo e à fotossíntese ........................ 44

2.7. Fotossíntese

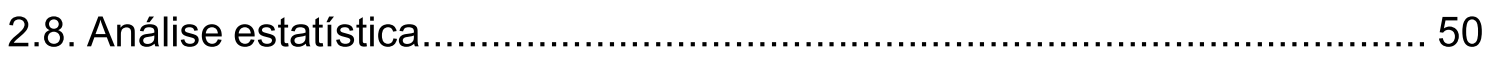

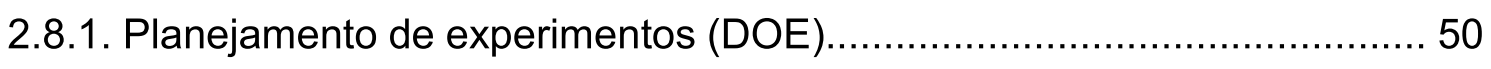

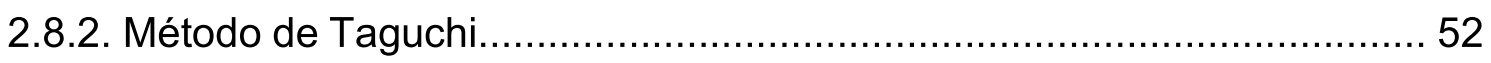

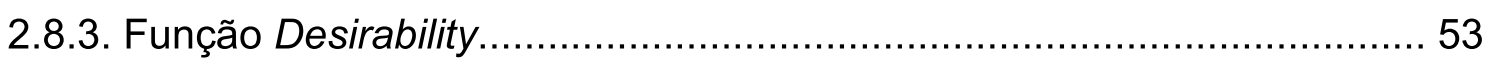

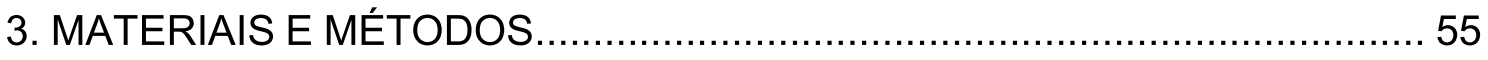

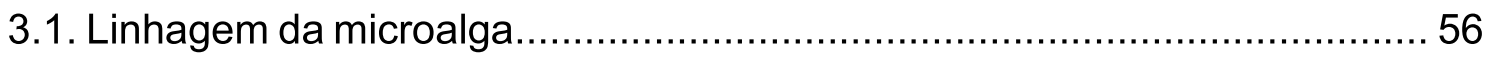

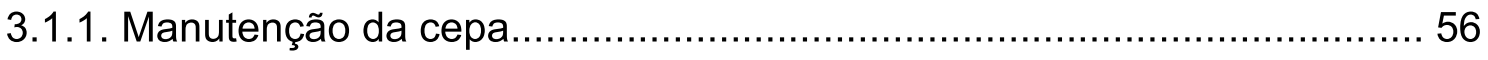

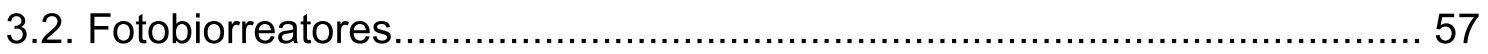


3.2.1. Método de desinfecção dos fotobiorreatores.................................. 59

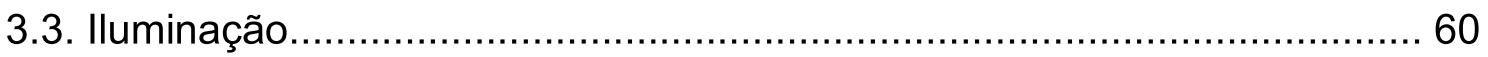

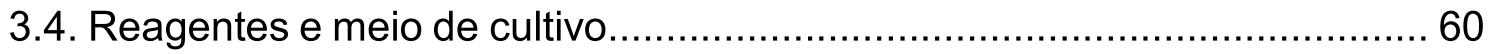

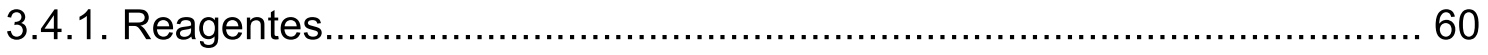

3.4.2. Preparo do meio de cultura e início do cultivo ................................... 61

3.5. Acompanhamento do crescimento celular................................... 62

3.6. Colheita e secagem da biomassa............................................ 63

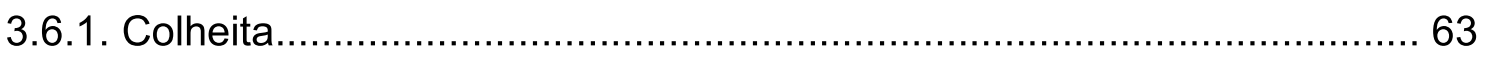

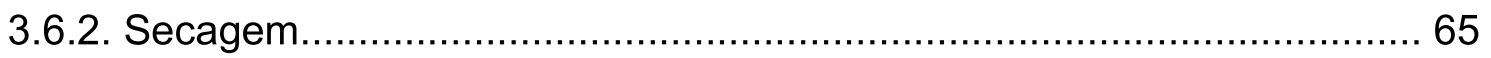

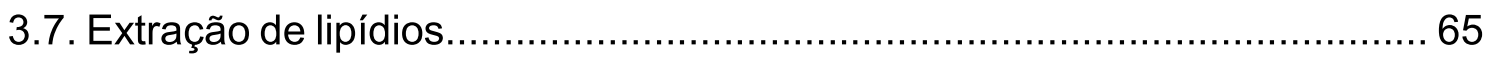

3.8. Determinação da massa seca.................................................... 66

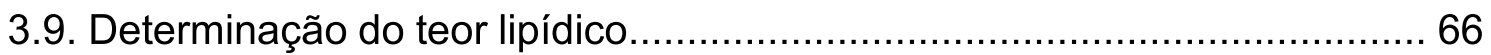

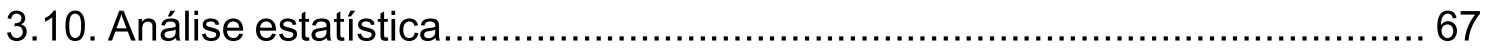

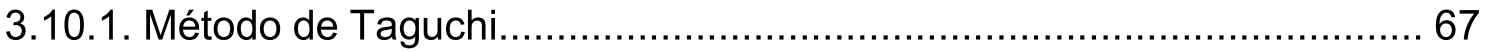

3.10.1.1. Escolha dos níveis para os fatores de entrada...............................69

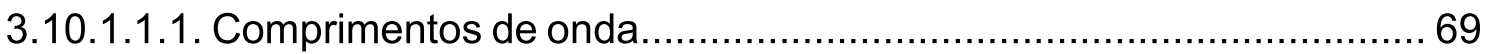

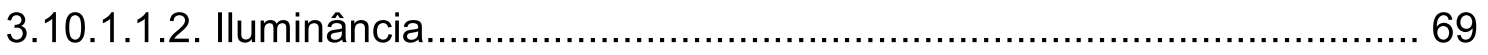

3.10.1.1.3. Concentração de dihidrogenofosfato de sódio hidratado.................69

3.10.1.1.4. Concentração de nitrato de sódio.........................................69 69

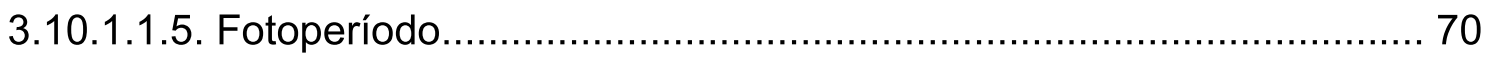

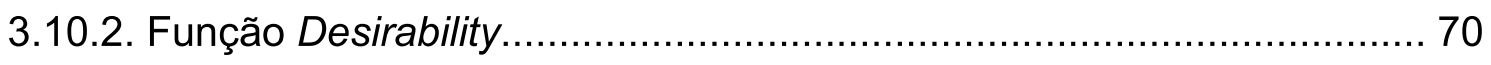

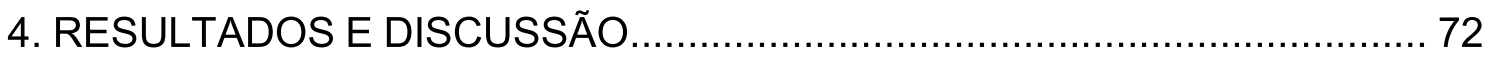

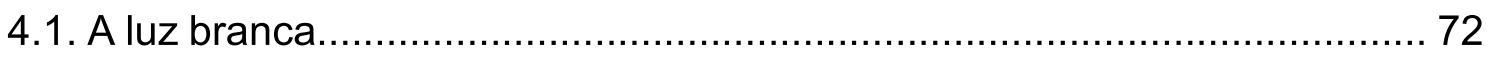

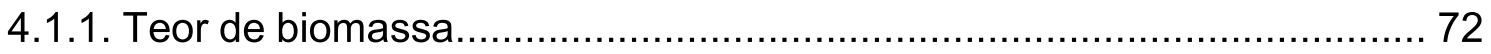

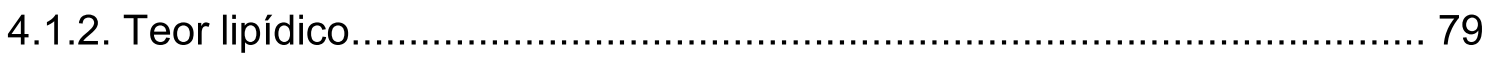

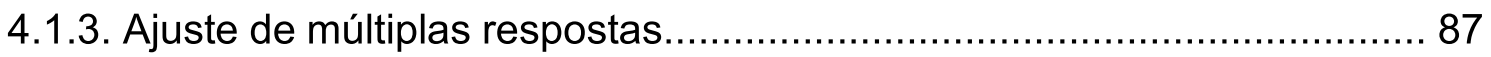

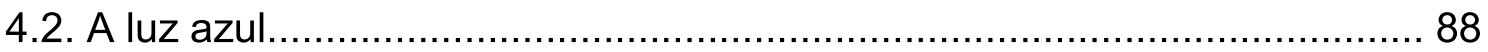




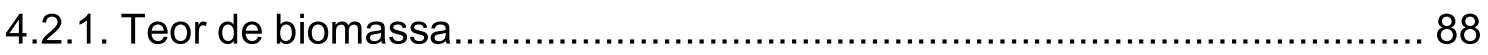

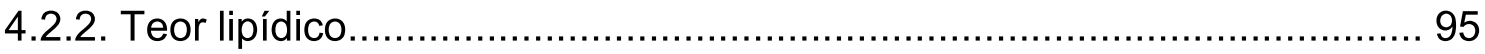

4.2.3. Ajuste de múltiplas respostas................................................... 102

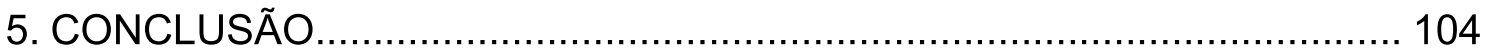

6. SUGESTÕES DE PRÓXIMAS ETAPAS DE PESQUISA ........................ 106

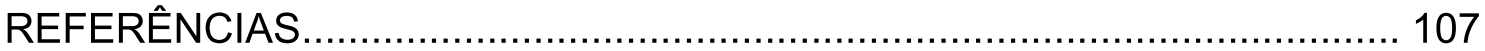




\section{INTRODUÇÃO}

\subsection{Considerações iniciais}

A queima de combustíveis fósseis e a consequente liberação de gases do efeito estufa vem se intensificando à medida que a sociedade se torna mais dependente dos derivados de petróleo.

Este combustível, por sua vez, além de provocar inúmeros e conhecidos problemas ambientais, é também um recurso natural finito, cujo processo de extração vem se tornando progressivamente mais complexo.

A evolução de tecnologias multidisciplinares relacionadas à exploração, termo referente à fase de prospecção e pesquisa, de petróleo tem identificado regiões com potencial de explotação que são um desafio para a engenharia. Alguns destes desafios, atualmente, já colocam em dúvida a viabilidade técnica e financeira da extração, aliados a pressões sociais e ambientais cada vez mais urgentes pelo desenvolvimento de vias energéticas alternativas ao petróleo.

Neste contexto, o estudo e desenvolvimento da tecnologia de microalgas se faz fundamental, não apenas por se tratar de uma possível fonte de combustíveis de origem biológica, limpa e renovável, mas também pela elevada produtividade por área e por motivar a interligação e a produção de conhecimento, de elevada confiabilidade científica e nível técnico, em conjunto com diversas áreas do conhecimento.

As microalgas Chlorella minutissima são seres fotossintetizantes e microscópicos (cujo diâmetro celular é da ordem de 1,2 $\mu \mathrm{m}$ ), capazes de se desenvolver nas mais variadas condições e localidades. Essas características já seriam suficientes para reduzir a área necessária ao cultivo, elevar a produtividade e eliminar a concorrência que outras fontes de biocombustíveis enfrentam com o setor alimentício.

Entretanto, o processo em questão precisa operar sob parâmetros precisos e bem estudados para todas as suas etapas. Alguns desses parâmetros, certamente, estão relacionados à fotossíntese e à luz, da qual ela é dependente.

Quando se fala em luz é necessário que tenhamos em mente que se refere à fonte primária de energia para as microalgas. Apesar disso, a luz, fisicamente, 
tem duas interpretações distintas, tanto pode ser interpretada como uma onda eletromagnética, como por um conjunto de partículas elementares chamadas fótons.

Trata-se da conhecida dualidade partícula-onda, descoberta científica de Albert Einstein, em 1905, e objeto de estudo da física quântica, cujas suas implicações iniciais precisam ser debatidas.

Max Planck, através do exposto na equação (1) postulou que a energia mínima que uma onda pode conter é proporcional a sua frequência (v). A constante de proporcionalidade, chamada de constante de Planck e simbolizada por $\hbar$, tem o valor $6,62607004 \times 10^{-34} \mathrm{~m}^{2} \mathrm{~kg} / \mathrm{s}$.

$E=\hbar \nu$

A equação fundamental da ondulatória, aplicada à luz, é exposta na equação (2).

$v=c / \lambda$

Pelo princípio da refração da luz, o valor da constante c $=299.792 .458 \mathrm{~m} / \mathrm{s}$, ao penetrar o ar e o meio onde as células de microalgas são cultivadas, se altera. Entretanto, a variação simultânea no comprimento de onda $(\lambda)$ mantém inalterado o valor da frequência $(v)$, para um dado valor do par $(\lambda, v)$.

Dada uma potência útil (W) de uma fonte luminosa (em Joules), então, a cada intervalo de tempo $\Delta \mathrm{t}$, medido em segundos, o número $\mathrm{n}$ de fótons que incide sobre uma área $A$, em metros quadrados, é dado pela equação (3).

$n=W /[(\hbar v) \times \Delta t \times A]$

Para que tal formulação matemática pudesse ser estabelecida, foi necessária a premissa da descontinuidade do espectro de energia da radiação eletromagnética, o que constitui a base teórica da física quântica.

\subsection{Justificativa e importância}

A motivação deste trabalho se dá por preencher uma lacuna presente na literatura, por meio da integração de conceitos de múltiplas áreas do conhecimento, aplicando técnicas estatísticas com vistas ao cultivo da microalga marinha Chlorella minutissima, em favor da sustentabilidade. 
A Tabela 1, obtida por meio da base de dados Scopus, relaciona palavras-chave na área de pesquisa que foi desenvolvida. Não foram encontradas publicações relacionando a microalga Chlorella minutissima e os seguintes temas: DOE e Biofotônica, tampouco foram encontradas publicações que relacionem o método de Taguchi à biofotônica. Este fato configura o ineditismo do presente estudo.

Tabela 1 - Taxas de ocorrência das palavras-chave envolvidas na pesquisa realizada na base de dados Scopus.

\begin{tabular}{cc}
\hline Palavras-chave & Ocorrência \\
\hline Micoalgae X Biodiesel & 2890 \\
Microalgae X DOE & 424 \\
Chlorella minutíssima X Biodiesel & 39 \\
Microalgae X Taguchi Method & 8 \\
Microalgae X Biophotonic & 7 \\
Chlorella minutíssima X Taguchi Method & 1 \\
Chlorella minutíssima X DOE & 0 \\
Chlorella minutíssima X Biophotonic & 0 \\
Taguchi Method X Biophotonic & 0 \\
Chlorella minutíssima X Biophotonic X Taguchi Method & 0 \\
\hline
\end{tabular}

Fonte: ELSEVIER, 2018

\subsection{Objetivos}

\subsubsection{Objetivo geral}

Analisar a influência de parâmetros luminosos, tais como iluminância, fotoperíodo e comprimento de onda no desenvolvimento de cultivos da microalga marinha Chlorella minutissima, empregando arranjos ortogonais de Taguchi para determinação do melhor ajuste desses parâmetros, conduzindo a uma maior produção de biomassa e lipídeos, com menor variabilidade. 


\subsubsection{Objetivos específicos}

- Desenvolver cultivos da microalga Chlorella minutissima aptos a se desenvolverem sob diferentes condições de luminosidade;

- Estudar os efeitos da iluminância, do fotoperíodo e do comprimento de onda, bem como da concentração de $\mathrm{NaNO}_{3}$ e $\mathrm{NaH}_{2} \mathrm{PO}_{4} \cdot \mathrm{H}_{2} \mathrm{O}$ na produção de biomassa seca;

- Estudar os efeitos da iluminância, do fotoperíodo e do comprimento de onda, bem como da concentração de $\mathrm{NaNO}_{3}$ e $\mathrm{NaH}_{2} \mathrm{PO}_{4} \cdot \mathrm{H}_{2} \mathrm{O}$ na acumulação de lipídeos pela microalga Chlorella minutissima;

- Investigar a existência de possíveis interações entre a iluminância e os demais parâmetros do processo;

- Determinar a melhor condição de ajuste dos parâmetros por meio de duas matrizes ortogonais $\mathrm{L}_{8}$ de Taguchi, cada uma direcionada aos experimentos submetidos à luz branca, e com comprimento de onda equivalente a $470 \mathrm{~nm}$, com a execução dos experimentos em duplicata.

\subsection{Estrutura do trabalho}

O presente trabalho, intitulado "Investigação da influência de parâmetros luminosos no desenvolvimento de cultivos da microalga marinha Chlorella minutissima", visa o desenvolvimento de melhorias de processo no que tange ao aumento da concentração celular e da razão dos teores lipídicos por biomassa seca. Para tanto, o método de Taguchi foi selecionado como o método experimental adequado e a função Desirability como ferramenta de ajuste simultâneo das melhores condições para ambas as variáveis de resposta.

O trabalho foi dividido em cinco capítulos. O capítulo 1 aborda a introdução ao tema, com considerações teóricas iniciais, delimitação dos objetivos, bem como a definição da justificativa e importância do estudo, caracterizando o ineditismo atrelado a ele.

O capítulo 2 propõe uma revisão da literatura de tópicos relevantes ao desenvolvimento do trabalho, tais como o cenário energético atual, aspectos gerais relacionados a microalgas, tecnologia de cultivo, colheita de biomassa, extração de lipídios, aspectos relacionados à luz e à fotossíntese e análise estatística. 
O capítulo 3 expõe em detalhes os materiais utilizados bem como o método de trabalho para obtenção dos resultados com padrão de segurança e confiabilidade científica, imperativo a um trabalho deste destaque e importância.

O capítulo 4, por meio de rigorosa e consagrada técnica estatística, detalha, trata e discute os resultados obtidos ao longo de todo o processo experimental, permitindo o alinhamento do trabalho com os objetivos anteriormente traçados e a conclusão proposta no capítulo 5 , que encerra o presente trabalho. 


\section{REVISÃO DA LITERAURA}

\subsection{O cenário energético atual}

A demanda por energia deve crescer em $50 \%$ ou mais até 2030 , devido ao crescimento da população humana. Por outro lado, o consumo do petróleo é relatado como sendo 105 vezes mais rápido do que sua taxa de reposição (SHUBA; KIFLE, 2018).

A emissão de dióxido de carbono $\left(\mathrm{CO}_{2}\right)$ na atmosfera, que representa $63 \%$ dos gases de efeito estufa, foi intensificada pela dependência mundial dos combustíveis fósseis no último século (HATTAB; GHALY, 2015). Em contraponto a este cenário é esperado, até 2040, um crescimento no consumo de energia derivada de fontes renováveis e gás natural, como mostra a figura 1. Destacase também um crescimento de 3,1\% ao ano no uso de biomassa para produção de energia (“US Energy Information Administration (EIA)”, 2015).

Figura 1 - Consumo de energia por combustível previsto até 2040

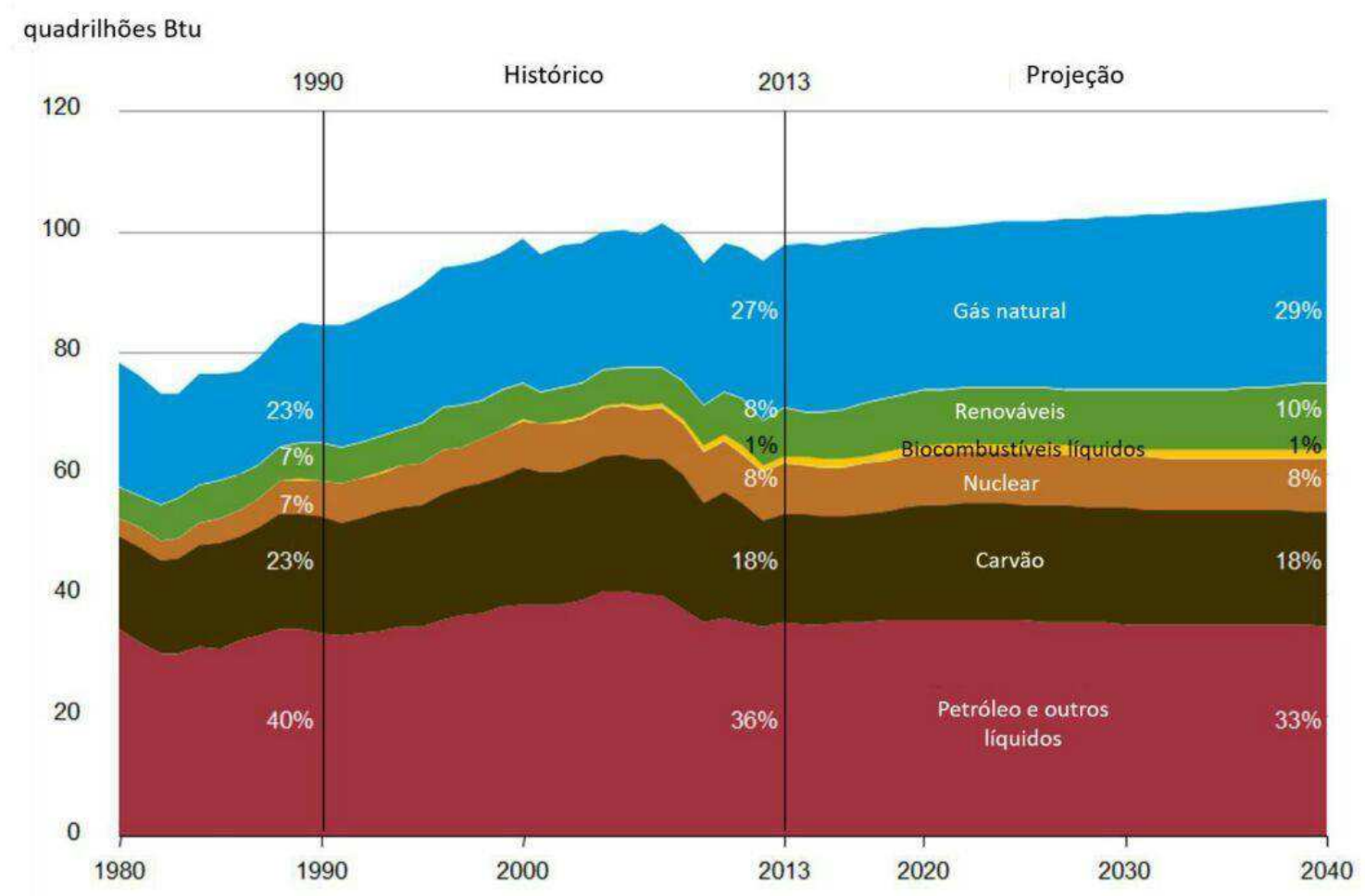

Fonte: US ENERGY INFORMATION ADMINISTRATION (EIA), 2015.

A Agência Internacional de Energia (2014) informou que $63,7 \%$ do petróleo produzido é consumido pelo setor de transporte, o que significa que cerca de 
$22 \%$ das emissões mundiais de $\mathrm{CO}_{2}$ são por este setor (INTERNATIONAL ENERGY AGENCY, 2014).

O Departamento de Energia dos EUA quantificou o nível de interesse e necessidade em combustíveis renováveis por meio do estabelecimento de um objetivo para o ano 2030 de que $30 \%$ do combustível de transporte dos EUA, ou 60 bilhões de galões por ano serão derivados de fontes renováveis (DEPARTMENT OF ENERGY, 2007).

Além das preocupações ambientais, as flutuações do preço do petróleo e a dependência deste, estão por trás dos maiores interesses científicos, públicos e políticos nos biocombustíveis em todo o mundo (PENG et al., 2016).

Para que os biocombustíveis se tornem fontes de energia alternativas econômicas e atrativas é necessário enfatizar as seguintes preocupações:

- Ampliação da produção de biocombustíveis;

- Disponibilidade e custo de materiais e recursos;

- Consumo de energia e emissão de carbono durante o processamento;

- Impactos a curto e longo prazo sobre o meio ambiente e a sociedade (PENG et al., 2016).

Durante décadas de pesquisa no segmento de biocombustíveis ao redor do mundo, foram desenvolvidas muitas técnicas que podem ser distribuídas dentro de três categorias:

- Geração I: bioetanol produzido a partir de culturas comuns como cana-de açúcar (no Brasil) e milho (na América do Norte); e biodiesel obtido de óleos vegetais

- Geração II: bioetanol produzido a partir de plantas terrestres menos exigentes em recursos, como sorgo e espécies da grama;

- Geração III: bio-óleo e biodiesel de plantas marinhas, como algas e microalgas (PENG et al., 2016).

Nota-se que os biocombustíveis de primeira geração são derivados de fontes comestíveis, por sua vez, os biocombustíveis de segunda geração provém de fontes que não se relacionam com o setor alimentício, porém agrícolas. 
As matérias-primas de óleo vegetal são altamente demandadas como fontes de alimentos que aumentam o preço e desafiam seu potencial como recursos de combustível em grande escala (ISLAM et al., 2017).

O biodiesel obtido a partir de óleos vegetais e gorduras animais apenas representa cerca de $0,3 \%$ da demanda atual de combustíveis para transporte (DEMIRBAS et al., 2010).

O biodiesel de fontes não comestíveis e não agrícolas compõe os biocombustíveis de terceira geração com microalgas consideradas como uma das melhores opções para a produção de biodiesel porque muitas delas mostram potencial de rendimentos altos de óleo e capacidade de cultivo em terras não cultiváveis (DEMIRBAS, 2009; BOROWITZKA et al., 2013). As microalgas também podem ser a única fonte renovável com a capacidade de satisfazer as necessidades mundiais de combustível de transporte (CHISTI, 2007).

O cultivo de microalgas se apresenta com destaque no cenário dos biocombustíveis em função do menor espaço físico exigido por ele e da eficiência fotossintética superior, quando comparado a processos que se utilizam de vegetais superiores como matéria-prima (KOLLER et al., 2014).

É altamente improvável que o biocombustível obtido por meio de microalgas como fonte de lipídios seja capaz de satisfazer todas as demandas de energia química, no entanto, poderia fornecer uma fonte de energia potencial e ser usado para substituir uma parte das necessidades de energia do transporte (ISHIKA et al., 2017).

A matéria-prima de microalgas é reconhecida como um dos recursos mais promissores para a produção de triglicerídeos, que posteriormente são convertidos em biodiesel. No entanto, a tecnologia em larga escala necessária para gerar biodiesel a partir de microalgas ainda está em seus estágios iniciais de desenvolvimento (ISLAM et al., 2017).

Os principais problemas que a humanidade enfrenta no século 21 são questões de qualidade da água e fornecimento de energia (SALAMA et al., 2017). 
Nas últimas décadas, a escassez de água doce aumentou de $69 \%$ para $77 \%$. Ao longo dos últimos 50 anos, as retiradas de água triplicaram (CONNOR et al., 2009).

Vários pesquisadores relatam que a geração de combustíveis de microalgas em larga escala ainda não é promissora sem o tratamento das águas residuais como principal objetivo (SALAMA et al., 2017).

Os custos finais do biodiesel obtido por meio de algas são estimados na faixa de US\$ 0,42-0,97/L (NAGARAJAN et al., 2013). Por esta razão, Richardson et al. (2010) ressaltam que a produção de óleo de microalgas é economicamente viável apenas se os resultados obtidos em escala laboratorial puderem ser transferidos para a escala comercial.

Para competir no mercado de biocombustíveis, o cultivo de microalgas precisaria ser economicamente sustentável e o co-cultivo de microalgas salinas usando apenas água salina e nutrientes reciclados pode ser a melhor solução para reduzir o uso excessivo e a rápida redução de recursos naturais (ISHIKA et al., 2017).

Shurtz et al. (2017) destacam a necessidade de modelos de sistemas de engenharia para quantificar os requisitos de nutrientes no processo de produção, em larga escala, de biocombustíveis por meio de microalgas, bem como a necessidade de avaliar o potencial de várias fontes de nutrientes, como fertilizantes e águas residuais, que possam atender a essa demanda por nutrientes.

As unidades industriais de microalgas requerem grandes quantidades de matéria-prima para a produção e processamento de biomassa. Portanto, uma planta de microalgas robusta, economicamente viável e sustentável deve se beneficiar da integração com outras unidades industriais estabelecidas, o que simplificaria em grande parte a cadeia de fornecimento dos insumos necessários (KLEIN et al., 2018).

É necessária uma avaliação completa da demanda de nutrientes para a produção de biocombustíveis em larga escala a partir de microalgas. Os requisitos de nitrogênio e fósforo representam uma barreira potencial para o 
desenvolvimento em larga escala de biocombustíveis à base de microalgas (SHURTZ et al., 2017).

O gênero Chlorella foi considerado como um candidato promissor para a produção comercial de biodiesel, uma vez que a taxa de crescimento e o teor de lipídios de muitas cepas de Chlorella podem atingir altos níveis (KHALILI et al., 2015).

\subsection{Microalgas: uma visão geral}

O número total de espécies de algas e microalgas, bem como a fração deste já conhecida e estudada sofre com alguma imprecisão na literatura. O número total de espécies de microalgas é tratado entre 200 mil e um milhão, ao passo que o número de espécies conhecidas varia de 35 mil a 44 mil.

Mais de 40 mil espécies de microalgas já foram identificadas, com base em métodos microscópicos e moleculares. A maioria dessas espécies têm alto teor de lipídios (entre 20 e 50\% de sua biomassa total dependendo da condição de cultivo empregada) (BHOLA et al., 2011).

Conforme Neofotis et al. (2016), o número de espécies de microalgas já conhecidas é de cerca de 44 mil, enquanto o número total pode chegar até um milhão de espécies.

As microalgas são um dos organismos mais antigos da Terra. $O$ número de espécies de algas é estimado entre 1 e 10 milhões, dos quais cerca de 200.000 a 800.000 são espécies de microalgas, e cerca de 35.000 foram estudados. (RATHA et al., 2012).

As microalgas têm uma importância excepcional devido à sua primitividade de estrutura e variação de atividades metabólicas. Elas atraíram uma atenção substancial devido à sua capacidade de absorver nutrientes orgânicos e inorgânicos da água e produzir biomassa que pode ser utilizada para geração de biocombustíveis (ABOROHRA et al., 2016; ABDO et al., 2016). A Figura 2 ilustra células da espécie de microalga marinha Chlorella minutissima vista através de microscópio. 
Figura 2 - Células de Chlorella minutissima vistas através de microscópio.

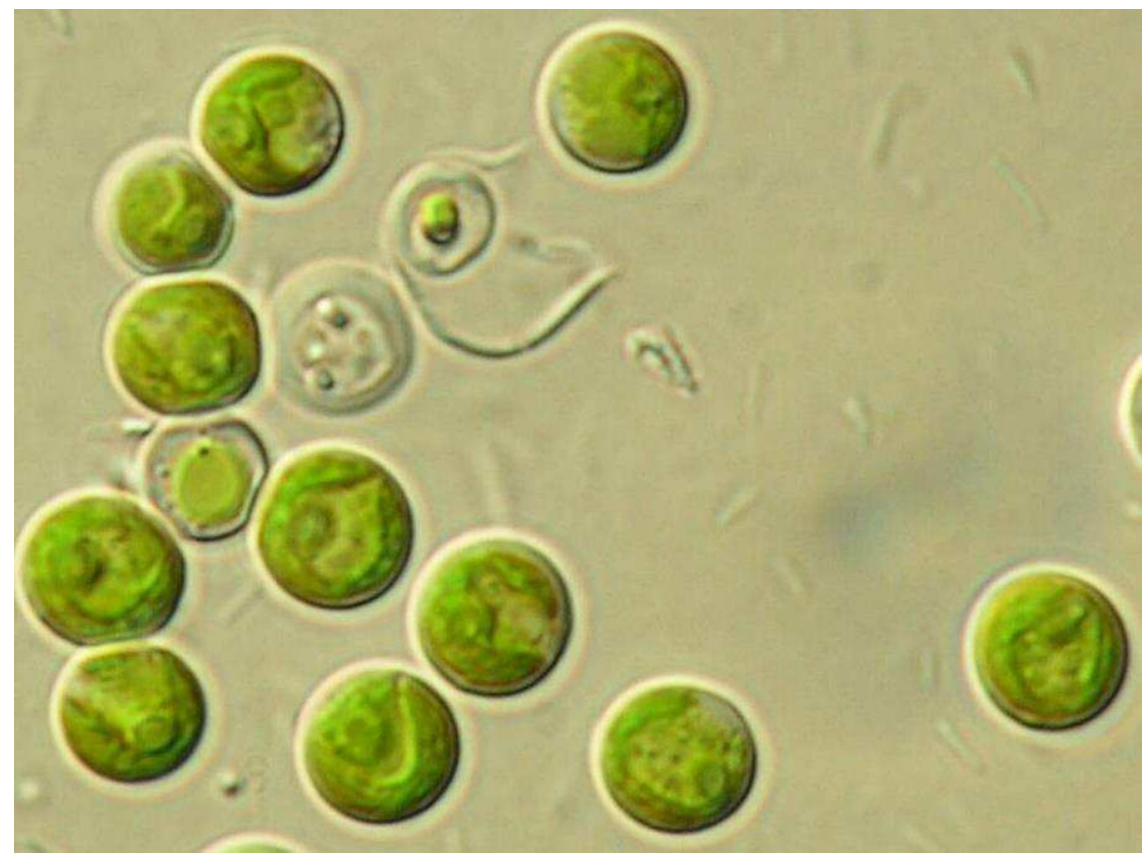

Fonte: MATA et al., 2006

A composição das microalgas são fundamentalmente carboidratos, lipídeos, proteínas e ácidos nucleicos, sendo que as proporções variam amplamente entre as espécies e de acordo com as condições de cultivo. A proporção de lipídeos presente nesses microrganismos varia normalmente de $5 \%$ a $75 \%$ em relação à biomassa seca, dependendo da microalga em questão, sendo que as espécies estudadas em sua maioria apresentam em torno de $20 \%$ a $50 \%$ de lipídeos (LOURES, 2016). A Tabela 2 quantifica, em termos percentuais, a composição de diferentes espécies de microalgas. 
Tabela 2 - Composição de diferentes espécies de microalgas.

\begin{tabular}{lllll}
\hline Espécies & Proteínas & Carboidratos & Lipídeos & $\begin{array}{l}\text { Ácidos } \\
\text { nucleicos }\end{array}$ \\
\hline Scenedesmus obliquus & $50-56$ & $10-17$ & $12-14$ & $3-6$ \\
Scenedesmus quadricauda & 47 & - & 1.9 & - \\
Scenedesmus dimorphus & $8-18$ & $21-52$ & $16-40$ & - \\
Chlamydomonas rheinhardii & 48 & 17 & 21 & - \\
Chlorella vulgaris & $51-58$ & $12-17$ & $14-22$ & $4-5$ \\
Chlorella pyrenoidosa & 57 & 26 & 2 & - \\
Spirogyra sp. & $6-20$ & $33-64$ & $11-21$ & - \\
Dunaliella bioculata & 49 & 4 & 8 & - \\
Dunaliella salina & 57 & 32 & 6 & - \\
Euglena gracilis & $39-61$ & $14-18$ & $14-20$ & - \\
Prymnesium parvum & $28-45$ & $25-33$ & $22-38$ & $1-2$ \\
Tetraselmis maculata & 52 & 15 & 3 & - \\
Porphyridium cruentum & $28-39$ & $40-57$ & $9-14$ & - \\
Spirulina platensis & $46-63$ & $8-14$ & $4-9$ & $2-5$ \\
Spirulina maxima & $60-71$ & $13-16$ & $6-7$ & $3-4,5$ \\
Synechoccus sp. & 63 & 15 & 11 & 5 \\
Anabaena cylindrica & $43-56$ & $25-30$ & $4-7$ & - \\
\hline
\end{tabular}

Fonte: SUGANYA et al., 2016

São microorganismos autotróficos com alta eficiência fotossintética, constituem também uma importante fonte de lipídios, hidrocarbonetos e outros óleos complexos (VIDYASHANKAR et al., 2015; DU et al., 2013; SANTILLANJIMENEZ et al., 2016). Além disso, podem produzir matérias-primas para obtenção de outros combustíveis valiosos como bioetanol, biometano e biohidrogênio (JUANTORENA et al., 2012; DE FARIAS SILVA et al., 2016; ZHEN et al., 2016).

Microalgas com alto teor de óleo possuem o potencial de produção de óleo até 25 vezes maior do que as oleaginosas tradicionais usadas para biodiesel, como 
o óleo de palma (ARENAS et al., 2017). A Tabela 3 estabelece comparações de rendimento por área cultivada para diversos cultivos.

Tabela 3 - Comparação entre cultivos em rendimento em óleo (L/ha) e área ocupada.

\begin{tabular}{|c|c|c|c|}
\hline Cultivos & $\begin{array}{c}\text { Rendimento em } \\
\text { óleo (L/ha) }\end{array}$ & $\begin{array}{c}\text { Área de terra } \\
\text { necessária }\left(\mathrm{M} \text { ha) }^{\text {a }}\right.\end{array}$ & $\begin{array}{c}\text { Porcentagem área de } \\
\text { cultivo }^{\text {a }}\end{array}$ \\
\hline Milho & 172 & 1540 & 846 \\
\hline Soja & 446 & 594 & 326 \\
\hline Canola & 1190 & 223 & 122 \\
\hline Jatropha & 1892 & 140 & 77 \\
\hline Côco & 2689 & 99 & 54 \\
\hline Óleo de palma & 5950 & 45 & 24 \\
\hline Microalga $^{b}$ & 136.900 & 2 & 1,1 \\
\hline Microalga $^{c}$ & 58.700 & 4,5 & 2,5 \\
\hline $\begin{array}{l}\text { a Para atender a } 50 \% \\
\text { b } 70 \% \text { óleo (em pes } \\
\text { c } 30 \% \text { óleo (em pes }\end{array}$ & $\begin{array}{l}\text { das as necessidade } \\
\text { iomassa. } \\
\text { iomassa. }\end{array}$ & ombustível de transpor & dos Estados Unidos. \\
\hline
\end{tabular}

Fonte: CHISTI, 2007

\subsection{Tecnologia de cultivo}

As microalgas têm alta taxa de crescimento e podem duplicar suas células várias vezes em um único dia. Durante a fase de crescimento exponencial, um cultivo pode ser duplicado em cerca de 3,5 horas (METTING, 1996; SPOLAORE et al., 2006).

Microalgas são vistas como uma fonte potencial de matéria-prima de biomassa sustentável para geração de biocombustíveis, podendo proliferar sob condições ambientais versáteis. O cultivo em massa de microalgas é o passo mais tecnicamente desafiador na geração de biocombustíveis microalgais (SALAMA et al., 2017).

O primeiro cultivo comercial de Chlorella foi iniciado no Japão no início de 1960. No início de 1980, 46 instalações de produção em grande escala de Spirulina e Chlorella estavam em operação na Ásia (BOROWITZKA, 1999). 
Uma suspensão de microalgas Chlorella contendo $2 \times 10^{10}$ células $/ L$ de água, normalmente fornece menos de $0,5 \%$ de biomassa úmida (aproximadamente $0,1 \%$ seca) (BURLEW, 1953). Assim, produzir um grama de biomassa seca de microalgas requer mais de um litro de cultivo (SHEN, 2014).

A seleção apropriada das espécies é o primeiro passo para a conversão bem sucedida de microalgas a biodiesel porque depende da quantidade de lipídios dentro da célula, em particular, o conteúdo de triacilglicerídeos (ARENAS et al., 2017).

O uso de água salgada para cultivar microalgas forneceria uma solução ideal para a produção de biocombustíveis, pois permitiria reduzir a pressão sobre o consumo de água doce (ISHIKA et al., 2017).

Porém, Ishika et al. (2017) advertem que a salinidade é um fator que limita o crescimento, afetando diretamente a produtividade de biomassa das microalgas.

As respostas fisiológicas e bioquímicas das microalgas demonstraram que a tolerância à salinidade das microalgas difere em diferentes espécies com base na distribuição ecológica e na fisiologia das microalgas (LIONARD et al., 2005).

Ainda não foi encontrada nenhuma espécie que seja capaz de crescer através de todo o intervalo de salinidade com produtividade suficiente de biomassa (ISHIKA et al., 2017).

Se uma microalga marinha com uma gama restrita de tolerância à salinidade fosse cultivada apenas com água salgada, não conseguiria crescer além de um certo intervalo de salinidade, uma vez que a salinidade aumentaria ao longo do tempo (SIGAUD et al., 1993; GU et al., 2012).

A observação microscópica mostrou que o tamanho da maioria das células de microalgas diminui em resposta ao aumento da salinidade (TAKAGI et al., 2006).

O cultivo fototrófico é a condição de cultura mais geralmente aplicada para o crescimento de microalgas. Vários pesquisadores observaram uma grande dissimilaridade no teor de lipídios / ácidos graxos sob cultivo fototrófico, variando de $7 \%$ a $58 \%$ dependendo da espécie de alga (SALAMA et al., 2017). 
As microalgas utilizam dióxido de carbono e água para sintetizar uma variedade de produtos, incluindo carboidratos, proteínas, vitaminas, lipídios, bem como outros bioativos (WANG et al., 2014). Atualmente, a produção autotrófica é o único método tecnicamente e economicamente viável para a produção em larga escala de biomassa de microalgas (SALAMA et al., 2017).

É importante trazer novas técnicas desenvolvidas em outros campos para impulsionar a pesquisa e o desenvolvimento dos biocombustíveis de microalgas e ajudar a resolver alguns desafios (PENG et al., 2016).

Conforme as pesquisas de Bajhaiya et al. (2017), a biossíntese de diversos produtos de alto valor metabólico pode ser alcançada pela engenharia de transcrição, que pretende modificar vários componentes de uma via metabólica simultaneamente, por meio de fatores de transcrição.

Bajhaiya et al. (2017) destacam que os fatores de transcrição regulam a expressão de genes alvo específicos para ativar ou reprimir a transcrição. $O$ processo de controle da transcrição pode ser manipulado para alterar perfis de expressão gênica, ou ainda para modificar componentes de uma via metabólica.

A edição genética em microalgas foi primeiramente demonstrada com microalgas verdes de água doce Chlamydomonas reinhardtii. As microalgas marinhas também já foram submetidas a técnicas de edição genética (MAEDA et al., 2018).

O crescimento e a bioquímica de rotina das espécies fotossintéticas envolvem a acessibilidade de 15-20 componentes vitais (SALAMA et al., 2017).

Khalili et al. (2015) demonstraram que em cultivos de microalgas Chlorella vulgaris a luz branca $(6000 \mathrm{~K})$ é ideal para a produção de biomassa. Além disso, o crescimento de microalgas com ureia como fonte de nitrogênio foi maior que com outras fontes como nitrato de sódio.

A uréia é a fonte de nitrogênio mais adequada visando a obtenção de altas densidades celulares, em função da queda no $\mathrm{pH}$, prejudicial ao crescimento celular, provocada pela adição de amônia e nitratos (KHALILI et al., 2015).

$\mathrm{O}$ pH desempenha um papel importante no crescimento de algas. Sob condições alcalinas, as microalgas capturarão facilmente o $\mathrm{CO}_{2}$ da atmosfera e produzirão 
biomassa adicional. $\mathrm{O} \mathrm{pH}$ gradualmente aumenta para o básico à medida que $\mathrm{O}$ crescimento de algas se inicia e um aumento instantâneo na fotossíntese e agregação de íons hidroxila ocorre (ENAMALA et al., 2018).

Sob condições ótimas de cultivo, as microalgas multiplicam-se rapidamente, porém não acumulam tanto substâncias de armazenamento, tais como carboidratos e lipídios. Por outro lado, sob condições ambientais desfavoráveis, ou seja, sob "stress", causado pela deficiência de nutrientes, principalmente nitrogênio e fósforo, ocorre o acúmulo de tais substâncias (KWIETNIEWSKA et al., 2012; MESKO; JACOB-LOPES, 2012).

Muitos pesquisadores têm relatado a eficácia em submeter os cultivos das mais variadas espécies de microalgas a duas fases de cultivo, na qual a primeira fase visa apenas a formação da biomassa, e a segunda, caracterizada por um período de estresse, como alteração de temperatura, regime de iluminação e principalmente a privação de nutrientes, proporciona significativo aumento no acúmulo de lipídios nas células das microalgas (AMARAL, 2018).

A concentração de fósforo no meio é diretamente proporcional à taxa de crescimento de algas, a menos que a mesma esteja acima do nível crítico (KHALILI et al., 2015).

\subsection{Colheita de biomassa}

A eficiência da produção de biomassa microalgal é altamente influenciada por condições ambientais, tais como luz, temperatura, concentração de $\mathrm{CO}_{2}$, composição de nutrientes, salinidades e condições de agitação (MILANO et al., 2016).

No processo de produção de biocombustíveis de microalgas, a colheita desempenha um papel importante devido à sua capacidade de expansão para a produção industrial. Com a colheita pretende remover toda a biomassa de algas do meio aquoso; este processo é significativo porque representa 20 a $30 \%$ dos custos de produção totais (ARENAS et al., 2017).

As estratégias mais comuns atualmente empregadas na colheita são a centrifugação, filtração, sedimentação, coagulação química, eletroforese e triagem. Técnicas como ultrassom ainda estão em desenvolvimento. Algumas 
das técnicas mencionadas são precedidas por um processo de floculação (CARDOZO et al., 2007; SUALI et al., 2012; LEE et al., 2013; UDUMAN et al., 2010). A Figura 3 esquematiza diferentes técnicas de colheita de biomassa.

Figura 3 - Diferentes técnicas de colheita e recuperação de biomassa após o cultivo.

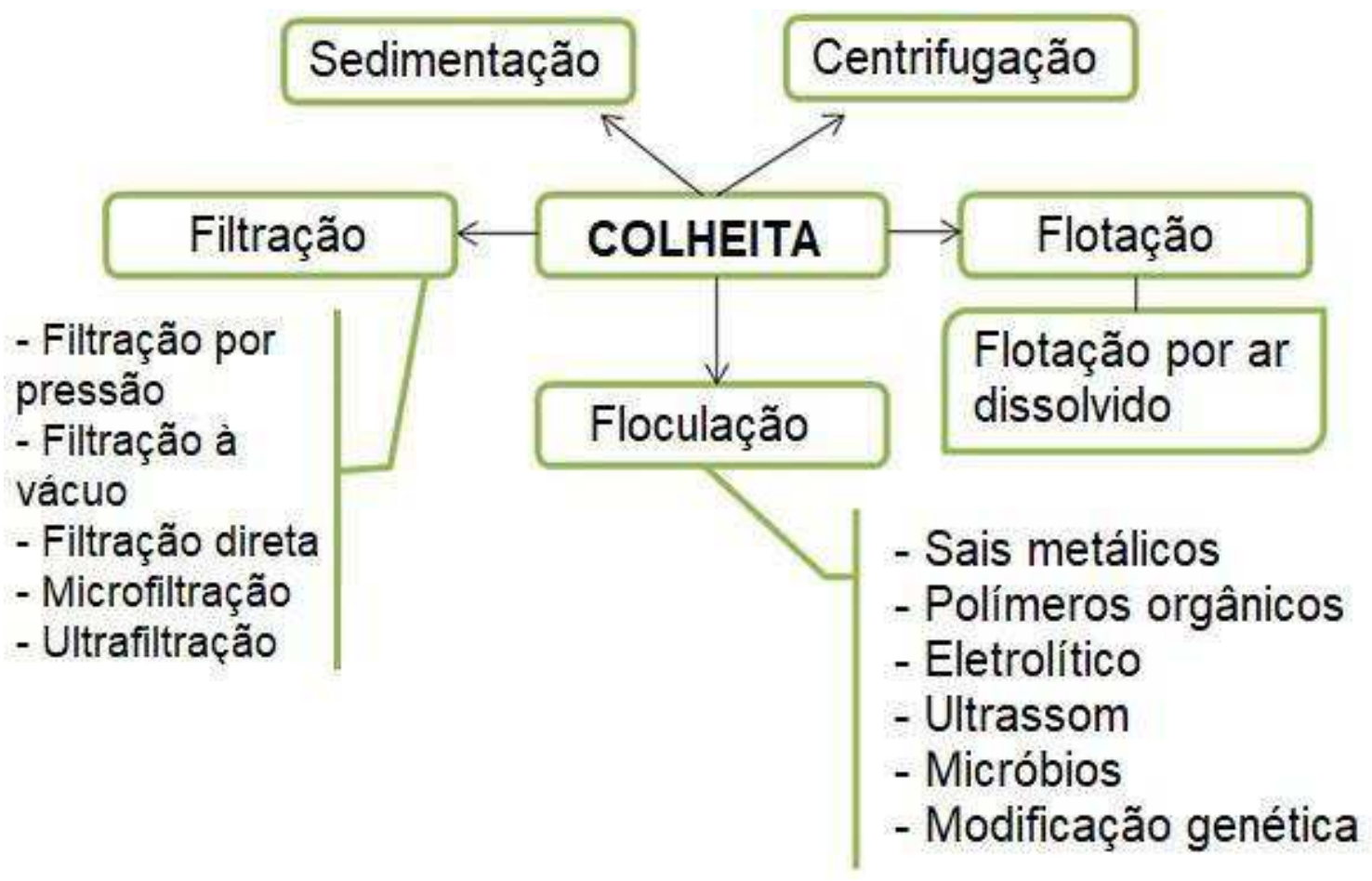

Fonte: Adaptado de ARENAS et al., 2017

A floculação visa aumentar a densidade das partículas de biomassa, que tem carga negativa aparente; esses agregados também aumentam o tamanho das partículas que facilita o assentamento (CHEN et al., 2011; GHERNAOUT et al., 2012). Os floculantes perturbam a estabilidade das partículas em suspensão e permitem a agregação, causando a separação das fases sólido-líquido de forma eficiente, melhorando os processos subsequentes, tais como centrifugação, sedimentação e filtração. Normalmente, floculantes são sais inorgânicos de metal multivalentes, polímeros orgânicos e micróbios (HANSEL et al., 2014; CHATSUNGNOEN et al., 2016; KAWAROE et al., 2016; LIU et al., 2014; VERMUË et al., 2014; GERDE et al., 2014). 


\subsection{Extração de Lipídios}

O teor de lipídios de microalgas varia consideravelmente para as diferentes espécies, conforme demonstro na Tabela 4. A composição e perfil dos ácidos graxos extraídos de uma espécie particular são influenciados pelo sistema de cultivo. Além disso, outras condições influenciam, tais como: composição do meio, temperatura, intensidade da iluminação, fotoperíodo e taxa de aeração (HALIM; DANQUAH; WEBLEY, 2012; D'ALESSANDRO; ANTONIOSI FILHO, 2016; SALAM; VELASQUEZ-ORTA; HARVEY, 2016).

Tabela 4 - Teor percentual de lipídios, em relação à biomassa seca, para diferentes espécies de microalgas.

Microalgas marinhas e de água doce

Conteúdo em Lipídios

(\% biomassa peso seco)

\begin{tabular}{cc}
\hline Botryococcus braunii & $25,0-75,0$ \\
Chlorella emersonii & $25,0-63,0$ \\
Chlorella protothecoides & $14,6-57,8$ \\
Chlorella vulgaris & $5,0-58,0$ \\
Chlorella minutissima & $10,0-57,0$ \\
Chlorococcum sp. & $19,3-53,7$ \\
Crypthecodinium cohnii & $20,0-51,1$ \\
Dunaliella salina & $6,0-25,0$ \\
Dunaliella tertiolecta & $16,7-71,0$ \\
Dunaliella sp. & $17,5-67,0$ \\
Euglena gracilis & $14,0-20,0$ \\
Isochrysis galbana & $7,0-40,0$ \\
Monallanthus salina & $20,0-22,0$ \\
Nannochloris sp & $20,0-56,0$ \\
Nannochloropsis oculata & $22,7-29,7$ \\
Nannochloropsis gaditana & $12,3-20,5$ \\
Neochloris oleoabundans & $29,0-65,0$ \\
Phaeodactylum tricornutum & $18,0-57,0$ \\
\hline & $1,9-18,4$ \\
\hline
\end{tabular}

Fonte: CHISTI, 2007; GOUVEIA; OLIVEIRA, 2009; KANEMOTO, 2012 
Zorn (2017) dividiu o processo de extração de lipídios de células de microalgas via solvente em cinco etapas.

Etapa 1: O solvente não polar, como clorofórmio ou hexano, em contato com uma célula microalgal, penetra através da parede celular para dentro de seu citoplasma;

Etapa 2: Após esta penetração, ocorre uma interação do solvente com os lipídios neutros por meio de forças de Van der Waals similares;

Etapa 3: Forma-se um complexo orgânico solvente-lipídios;

Etapa 4: O complexo solvente-lipídios formado, impulsionado por um gradiente de concentração, difunde-se através da membrana celular;

Etapa 5: Os lipídios extraídos, após difusão através da parede celular, permanecem dispersos no filme de solvente orgânico que envolve a célula.

$\mathrm{Na}$ Figura 4 encontra-se um esquema do processo de extração, numerando-se as etapas de acordo com o proposto por Zorn (2017). 
Figura 4 - Processo de extração lipídica via solventes em células de microalgas, dividido em etapas.

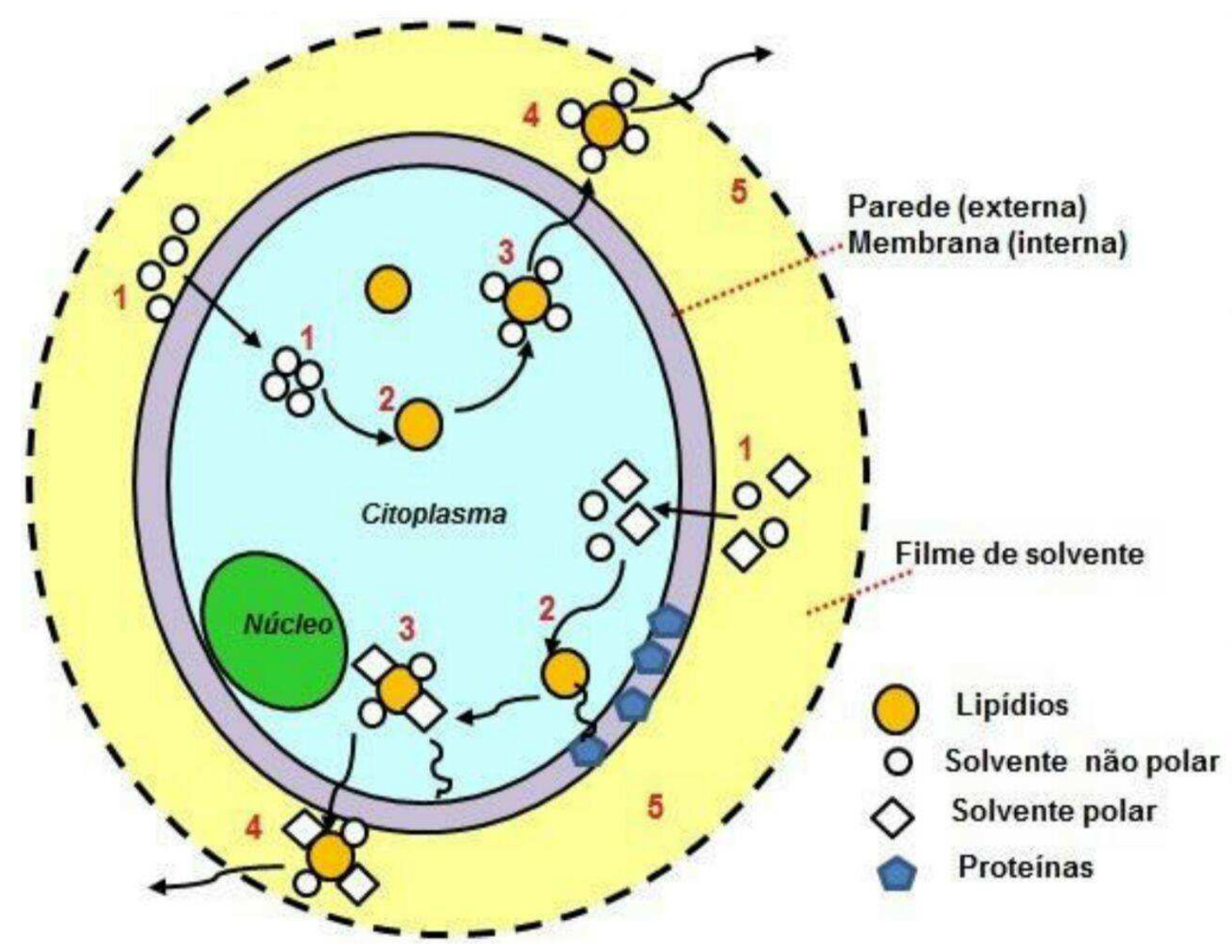

Fonte: HALIM; DANQUAH; WEBLEY, 2012

Dentro da matriz celular há lipídios neutros que se ligam fortemente, via pontes de hidrogênio, a proteínas localizadas na membrana celular, formando um complexo com lipídios polares. As interações de Van der Waals entre o solvente não polar e os lipídios não são capazes de romper esta membrana baseada nas associações lipídio-proteínas. Os solventes polares, tais como metanol ou isopropanol, são aptos a romper essas associações, formando ligações de hidrogênio com os lipídios polares no complexo. Portanto, a adição de um solvente polar a um solvente não polar facilita a extração do complexo de lipídios neutros associados à membrana, mas os lipídios polares também são extraídos (HALIM; DANQUAH; WEBLEY, 2012; SANTOS et al., 2015).

Lipídios neutros são usados principalmente nas células de microalgas para armazenamento de energia, ao passo que os lipídios polares se acumulam em 
paralelo para formar membranas celulares de duas camadas (SALAM; VELASQUEZ-ORTA; HARVEY, 2016).

A adição de um volume equivalente de solvente não polar reforça a captura do restante dos lipídios que não foram extraídos na primeira interação, bem como, juntamente com a pequena quantidade de água, induz à separação bifásica, pela composição de um sistema ternário (ZORN, 2017).

Alguns pesquisadores destacam a importância das microalgas como novas fontes de metabólitos para várias aplicações nos campos industrial, nutricional, farmacêutico e medicinal (vacinas). Algumas espécies produzem ácidos graxos poli-insaturados de cadeia longa de alto valor (PUFAs), tais como o ácido docosahexaenóico (DHA - C22:6) e o ácido eicosapentaenóico (EPA - C20:5), ambos pertencentes à família dos ácidos graxos ômega 3 ( $\omega-3)$ (ZORN, 2017).

Converti et al. (2009) extraíram 24,5\% de lipídios totais da biomassa da microalga Nannochloropsis oculata, utilizando a mistura de clorofórmio e metanol assistida por ultrassom e este foi o melhor resultado comparado aos demais realizados.

A extração assistida por ultrassom é reconhecida como uma técnica eficiente na redução do tempo de trabalho e aumento do rendimento em termos de lipídios totais extraídos. Neste processo ocorre a cavitação (funções mecânica e térmica juntas) que aumenta a eficiência da extração (SANTOS et al., 2015).

A técnica ultra-sônica utiliza o efeito de cavitação causado pelo ultrassom em um líquido para melhorar a ruptura celular de microrganismos. O ultrassom é irradiado para meios líquidos, formando pequenas regiões, conhecidas como microbolhas, que são formadas quando as moléculas líquidas estão sendo movidas pelas ondas acústicas. A cavitação aumenta os efeitos de microturbulência e ondas de choque, que aumentam a taxa de desintegração das microalgas para uma extração lipídica eficaz (ONUMAEGBU et al., 2018).

Quando microalgas salinas são expostas ao estresse salino, os ácidos graxos da membrana começam a sofrer desnaturação. Em resposta a condições desfavoráveis, as microalgas aumentam a síntese de lipídios (BARTLEY et al., 2013; HODGSON et al., 1991). 
A limitação de nitrogênio é frequentemente utilizada para aumentar o conteúdo de lipídios nas microalgas (SPOEHR et al., 1949), entretanto, o estresse por nitrogênio é geralmente associado ao crescimento lento da cultura, minimizando o rendimento global da biomassa (RATLEDGE, 2002; SCRAGG et al., 2002).

\subsection{A luz}

\subsubsection{Aspectos físicos sobre a natureza da luz}

Desde a antiguidade muitos cientistas se dedicaram à tarefa de explicar a natureza e o comportamento da luz.

InbAl-Haytham (965 - 1038) realizou os primeiros experimentos sobre dispersão da luz em seus constituintes. Expondo globos de vidro cheios de água à luz do Sol ele concluiu que o arco-íris era formado pela refração da luz.

No século XVII, Isaac Newton baseando-se na ideia grega do atomismo, descreve que a luz é composta por partículas denominadas corpúsculos, e que descrevem uma linha reta com velocidade limitada.

Newton conseguiu produzir várias e diferentes experiências sobre ótica, incluindo a com dois prismas, onde a luz branca incidia sobre o primeiro prisma e era decomposta e, ao passar pelo segundo prisma, retornava a cor branca. Assim, ele comprovou que a natureza da óptica geométrica de reflexão e refração da luz só poderia ocorrer se a luz fosse feita de partículas, já que as ondas não obedecem a uma trajetória em linha reta (SOUZA et al., 2017).

A decomposição da luz, ao passar pelo primeiro prisma, é demonstrada na Figura 5.

Figura 5 - Decomposição da luz por um prisma.

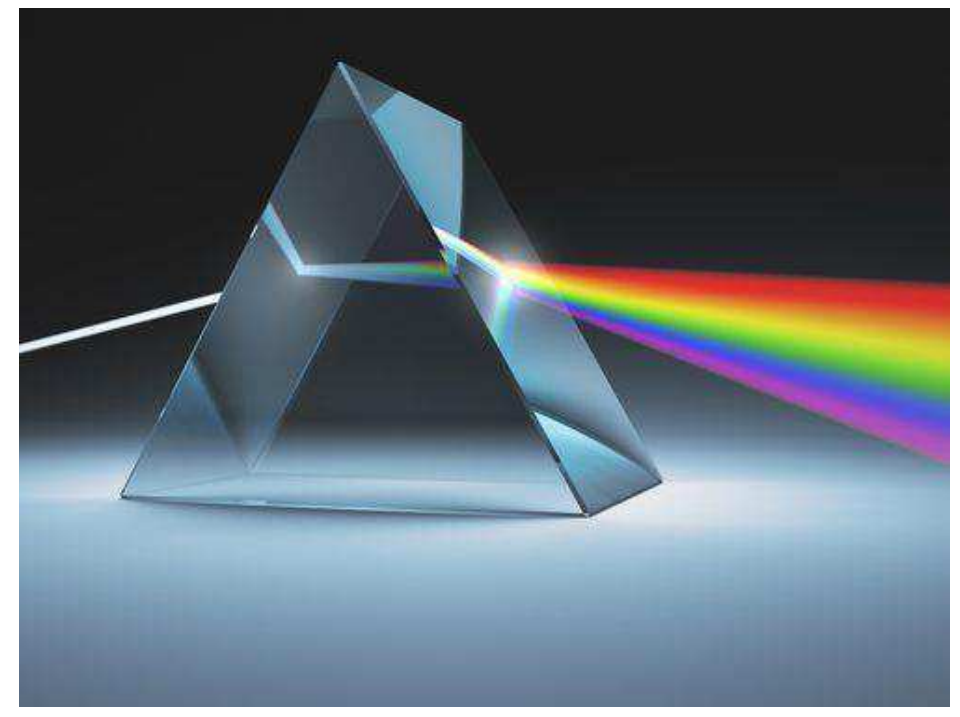

Fonte: UNIVERSIDADE ESTADUAL DE CAMPINAS, 2017 
Robert Hooke realizou, em 1665, experiências relacionadas com a luz e, em decorrência dessas experiências, afirmou que a luz era uma substância material, decorrente da vibração do éter, e que a emissão de luz por um corpo luminoso decorria de um movimento vibratório de pequena amplitude. Mais tarde, em 1672, Hooke afirmou que a luz era uma onda transversal.

Os trabalhos de Faraday e de Maxwell sobre o eletromagnetismo possibilitaram demonstrar a igualdade nas velocidades da luz e das ondas eletromagnéticas, tornando indiscutível o fato de que a luz é uma onda eletromagnética.

As ondas eletromagnéticas são perturbações compostas de campos elétricos e magnéticos, que se propagam com a velocidade da luz. $O$ que as difere é a sua frequência. Para o caso da luz visível, responsável por uma pequena fração do espectro eletromagnético, a frequência é da ordem de $1014 \mathrm{~Hz}$. Outra característica das ondas eletromagnéticas é que a sua energia é diretamente proporcional com o quadrado da amplitude (SOUZA et al., 2017).

Na Figura 6, ilustra-se o espectro eletromagnético da luz visível.

\section{Figura 6 - Espectro eletromagnético com ênfase na região do visível.}

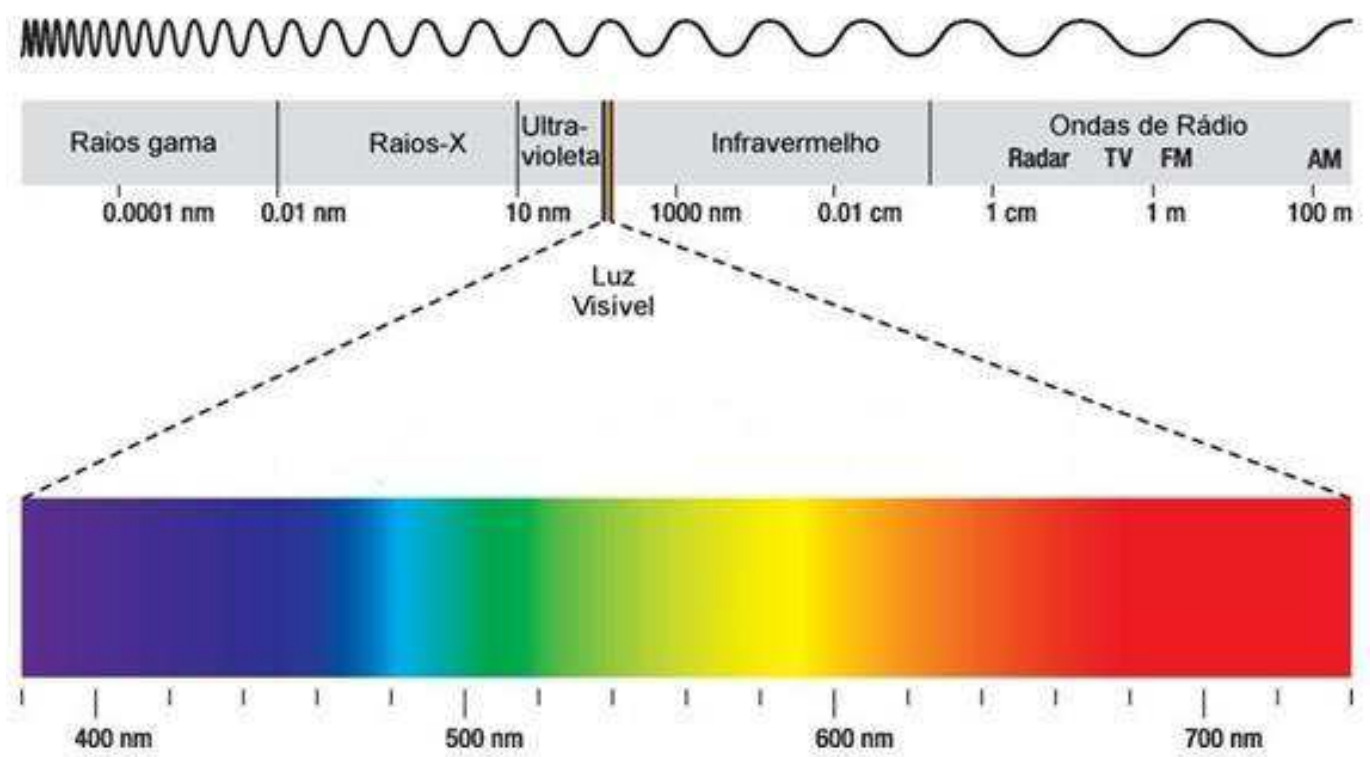

Fonte: FURIAN, 2017.

A Teoria da Relatividade Geral, elaborada em 1915, sugeriu que a gravidade pode desviar a trajetória da luz e alterar sua frequência.

Max Karl Ludwing Planck, em 1899, após estudar as radiações eletromagnéticas descobriu uma constante fundamental, que é usada para calcular a energia da partícula corpuscular mínima de luz, chamada de fóton. Em 1900, descobriu a lei da radiação Térmica ou Lei de Planck da Radiação que foi a base da teoria quântica (SOUZA et al., 2017). 
$\mathrm{Na}$ atualidade, a luz é considerada como tendo simultaneamente natureza corpuscular e ondulatória. Quando tratada como partícula, a energia da luz é proporcional ao número de fótons que, por sua vez, tem energia proporcional à frequência. A constante de proporcionalidade é chamada constante de Planck (SOUZA et al., 2017).

\subsubsection{Aspectos da luz relacionados ao cultivo e à fotossíntese}

A maioria dos materiais absorve preferencialmente certos comprimentos de onda de luz. Qualquer composto que absorva comprimentos de onda específicos exibe, consequentemente, uma cor distinta, e é designado pigmento (KHALILI et al., 2015).

Os principais grupos de pigmentos presentes em microalgas são clorofilas, ficobilinas e carotenóides (CARVALHO et al., 2011).

Como as algas contêm pigmentos de clorofila, a luz é essencial para a fotossíntese (KHALILI et al., 2015).

Visando o aumento do crescimento de microalgas em fotobiorreatores, a luz é um dos parâmetros mais importantes a ser avaliado, devendo ser fornecida com intensidade, tempo de exposição e comprimento de onda apropriados (CARVALHO et al., 2011).

A luz é a principal fonte de energia para os organismos fotossintéticos e também uma fonte chave de informação sobre o ambiente envolvente (JAUBERT et al., 2017).

Zhao et al. (2013) reforçam que as microalgas requerem condições ótimas de iluminação para atingirem taxas fotossintéticas máximas.

Para a fotossíntese ocorrer, a luz deve ser colhida por pigmentos de captura de luz em complexos de antenas de colheita de luz. Pigmentos diferentes absorvem luz de comprimentos de onda específicos do espectro solar e exibem uma cor distinta como mostrado na Tabela 5 (CARVALHO et al., 2011). 
Tabela 5 - Características de diversos pigmentos em microalgas.

\begin{tabular}{|c|c|c|c|}
\hline Grupo de Pigmentos & Cor & Faixas de Absorção (nm) & Pigmentos \\
\hline Clorofilas & Verde & $\begin{array}{l}450-475 \\
630-675\end{array}$ & $\begin{array}{c}\text { Clorofila } a \\
\text { Clorofila } b \\
\text { Clorofila } c 1, c 2, d\end{array}$ \\
\hline Carotenoides & Amarela, laranja & $400-550$ & $\begin{array}{c}\beta \text {-caroteno } \\
\alpha \text {-caroteno } \\
\text { Luteína } \\
\text { Violaxantina } \\
\text { Fucoxantina }\end{array}$ \\
\hline Ficobilinas & Azul, vermelha & $500-650$ & $\begin{array}{l}\text { Ficocianina } \\
\text { Ficoeritrina } \\
\text { Aloficocianina }\end{array}$ \\
\hline
\end{tabular}

Fonte: WANG et al., 2014

A cor da luz incidente idealmente deve combinar com a banda de absorção de pigmento que corresponde ao estado mais excitado. No caso da clorofila, as bandas de absorção estão presentes em regiões espectrais azuis e vermelhas (MATTHIJS et al., 1996).

O conhecimento sobre as capacidades de detecção de luz dos autótrofos unicelulares aquáticos, que constituem, de longe, o componente mais diversificado e maior dos produtores primários marinhos, ainda é pouco relatado na literatura (CARON et al., 2017).

No crescimento de microalgas, a intensidade da luz no comprimento de onda desejado é um parâmetro essencial a ser investigado. A luz incidente excessiva ou insuficiente restringe o desempenho ideal em termos de rendimentos de biomassa ou metabólitos (KHALILI et al., 2015).

Variações nas condições luminosas afetam significativamente o crescimento e a composição bioquímica de microalgas, tornando-se essencial a determinação das condições de iluminação adequadas a uma determinada espécie de microalga (SRIRAM; SEENIVASAN, 2015).

Por conta deste fato, Khalili et al. (2015) apontam que cultivar microalgas usando luz artificial pode ser a solução para estabilizar o fornecimento de energia, mantendo a variação sob controle. O uso de faixas de luz estreitas como o diodo emissor de luz (LED) é mais econômico que a lâmpada de tungstênio. 
A intensidade de luz acima do nível de saturação provoca inibição e dificulta o crescimento de microalgas. Devido à inibição da luz, a iluminação constante pode não ser a condição ideal para altos rendimentos na produção de microalgas (PENG et al., 2016).

A energia solar direta excede em muito a capacidade fotossintética das células em níveis de saturação de luz (RAHEEM et al., 2018). Em altas densidades de fótons, a taxa de absorção destes pela antena de clorofila excede em muito a taxa na qual os fótons podem ser utilizados para a fotossíntese. Assim, os cultivos de microalgas que crescem a pleno Sol têm uma baixa produtividade em clorofila, resultando excesso de fótons (até $80 \%$ ) dissipados como fluorescência ou calor (SHUBA; KIFLE, 2018).

Quando a intensidade da luz é insuficiente, as microalgas consomem carboidratos durante a fotorrespiração, ainda assim, é improvável que cause danos fatais. A intensidade da luz excessiva provoca a foto-oxidação, sobrecarga dos fotosistemas, branqueamento dos pigmentos e consequente interrupção no fotosistema II (JEONG et al., 2013). Na Figura 7 apresenta-se o efeito da intensidade luminosa na taxa de crescimento específica de microalgas, destacando o ponto de saturação luminosa

Figura 7 - Efeito da intensidade luminosa na taxa de crescimento específica de microalgas.

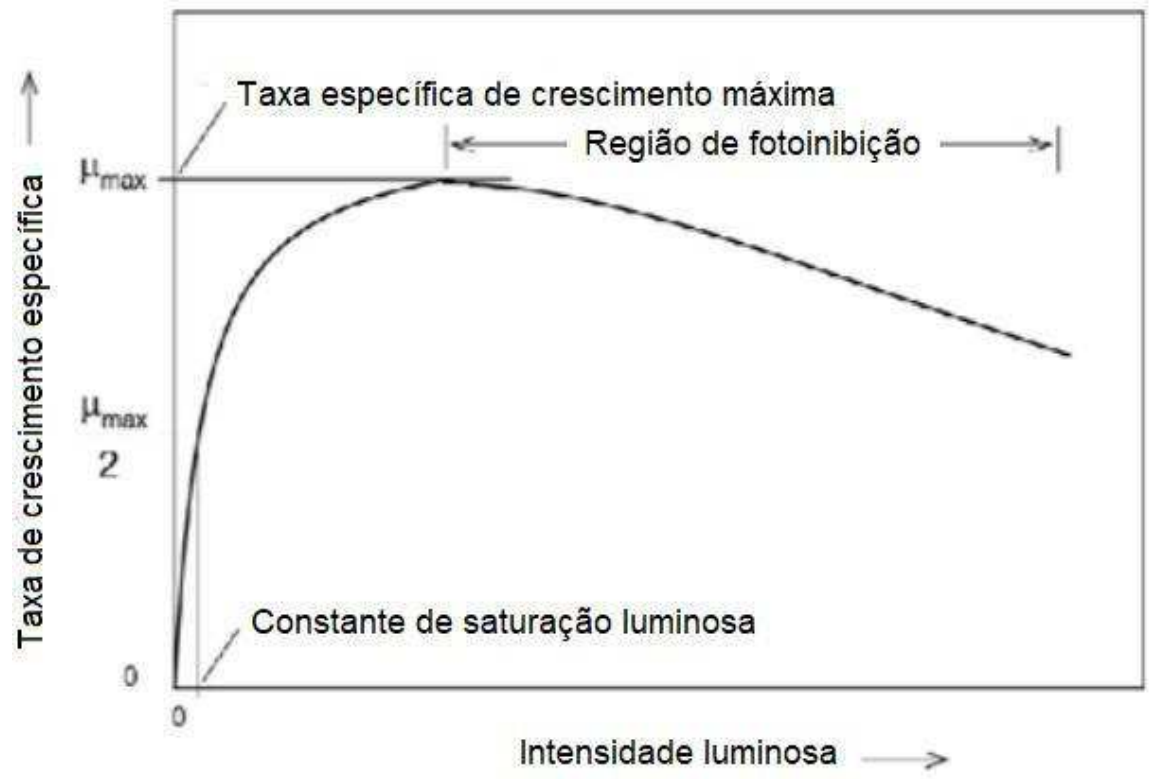


A limitação de iluminação é mais frequentemente encontrada em biorreatores fechados, o que torna o rendimento inferior ao potencial teórico (FERNÁNDEZ et al., 2005).

Na grande maioria dos casos, a foto-oxidação é um fenômeno secundário, ocorrendo após uma fase distinta lenta, durante a qual há um declínio da fotossíntese em decorrência da fotoinibição ocasionada pela intensidade da luz e do tempo de exposição, sem que ocorram mudanças na composição do reservatório dos pigmentos (DO CARMO ARAÚJO et al., 2009).

O ciclo claro-escuro é um método comum para a diluição da luz, que é consistente com o mecanismo de fotossíntese e os ciclos biológicos naturais (GRIMA et al., 1999). As eficiências fotossintéticas máximas podem ser alcançadas expondo as células da microalga a períodos cíclicos muito curtos de iluminação e escuridão, da ordem de 1 ms a 5 ms (RICHMOND et al., 2003).

Além da intensidade, os espectros de luz também afetam significativamente a fotossíntese em microalgas. Os comprimentos de onda de radiação fotossintética ativa situam-se na faixa de $400 \mathrm{~nm}$ a $700 \mathrm{~nm}$ (RICHMOND et al., 2003).

Um sistema com capacidade de mudança de comprimento de onda da luz fornece uma ferramenta interessante que pode ser incorporada ao cultivo de microalgas (PENG et al., 2016).

Peng et al. (2016) concluíram que a luz azul aumenta o crescimento celular e a produção de polissacarídeos pela microalga Phorphyridium cruentum.

Khalili et al. (2015) documentam que a luz azul, mais energética, faz com que os elétrons sejam elevados ao segundo estado excitado de clorofila. O excesso de energia presente nos fótons azuis é dissipado como calor.

As microalgas marinhas podem sofrer alterações distintas no campo de luz subaquática em diferentes profundidades, na mistura de água, em diferentes habitats ou na presença de outros organismos, como demonstrado na Figura 8 (JAUBERT et al., 2017). 
Figura 8 - Taxas de fluxo de fótons no espectro visível em diferentes profundidades de águas límpidas (linhas azuis) e na presença de fitoplânctons (linhas verdes).

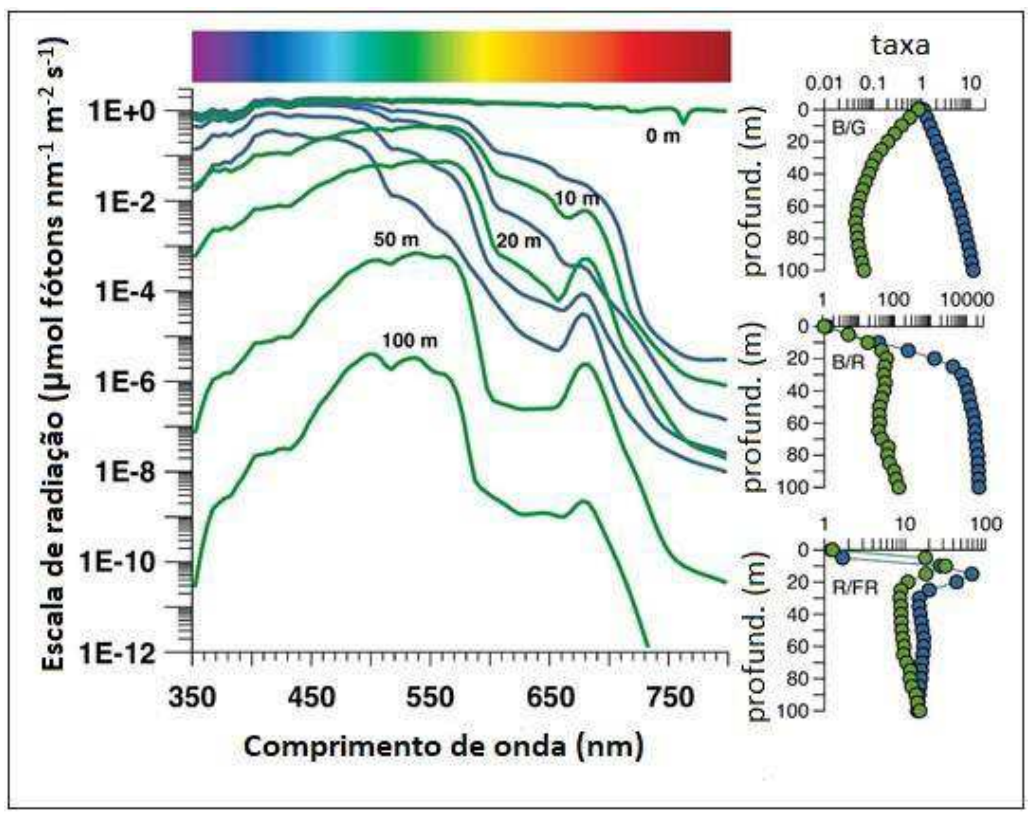

Fonte: JAUBERT et al., 2017

Ao penetrar os fotobioreatores a diminuição da intensidade luminosa é influenciada por muitos fatores, como a concentração de algas, o caminho da luz, o tamanho das células e os tipos de pigmentos intracelulares (WANG et al., 2014).

A intensidade da luz que atinge as células das microalgas é significativamente reduzida pelo auto-sombreamento durante o crescimento, especialmente em culturas de alta densidade. Ao se aprofundar no meio de cultura, o aumento da densidade de culturas diminui a disponibilidade de fótons para células individuais (PENG et al., 2016).

As zonas de assentamento e estagnação de biomassa (BECKER, 1994) geralmente resultam em déficit de nutrientes e luz e acumulação tóxica, prejudicando a produtividade (CARLSSON, 2007).

A luz requerida por cultivos de microalgas, em regime descontínuo, pode variar de acordo com a fase de crescimento (HAN et al., 2015). Em fase inicial (lag), as células requerem intensidade menor de luz, visando evitar a foto inibição. Por outro lado, quando o cultivo alcança a fase de crescimento exponencial, é 
necessária maior intensidade de luz, para evitar os efeitos do sombreamento de células e a foto limitação (LEE et al., 2006). Uma hipótese de ajuste apropriada, considerando os vários estágios de crescimento microalgal é a utilização de uma fonte luminosa de intensidade incremental (YAN et al., 2013).

Para mitigar as mudanças nos níveis de luz, as microalgas têm a capacidade de foto-aclimatação, que permite que as células microálgicas se adaptem às mudanças de condições de luz e otimizem o uso da luz disponível (DUBINSKY et al., 1995).

Os sinais de luz provocam mudanças maciças na expressão do gene microalgal (VALLE et al., 2014). As mudanças metabólicas em resposta a diferentes cores claras e fotoperíodos também são documentadas (JUNGANDREAS et al., 2014; SMITH et al., 2016).

\subsection{Fotossíntese}

Nas células de microalgas, a fotossíntese ocorre no tilacoide, a membrana fotossintética localizada dentro do cloroplasto (PILON et al., 2011). A absorção de energia por organismos fotossintéticos depende da natureza química de seus pigmentos constitutivos (KHALILI et al., 2015).

Embora a eficiência fotossintética das microalgas seja semelhante à de outras culturas, as microalgas têm maior produtividade de biocombustíveis porque não há necessidade de usar a energia colhida para construir bioestruturas complexas como o caule (PENG et al., 2016).

As clorofilas são os únicos elementos da antena central no aparelho fotossintético, e também são os pigmentos-chave da antena periférica acompanhados de carotenóides e ficobilinas. Os carotenóides podem proteger o aparelho fotossintético da foto-oxidação em condições de alta luz e expandem o espectro de absorção que melhora a eficiência da utilização da luz. As ficobilinas são hidrofílicas e funcionam na colheita e transferência de luz, e também desempenham um papel fundamental na sobrevivência das células em condições de pouca luz (MADIGAN et al., 2006; KE, 2001).

O processo fotossintético envolve duas etapas principais: a fase clara (foto dependente) e a fase escura. Durante as reações da fase clara, os elétrons 
doados pela água são transferidos para dois tipos de unidades fotossintéticas, fotosistema I e fotosistema II. Juntamente com o complexo do citocromo b6f, eles convertem a água e fótons em adenosina trifosfato (ATP) e o fosfato de dinucleótido de nicotinamida adenina (NADPH). Os produtos formados nas reações da fase clara são, então, utilizados para a fixação de $\mathrm{CO}_{2}$ no ciclo de Calvin nas reações seguintes da fase escura (WANG et al., 2014).

Cinco micronutrientes $(\mathrm{Mn}, \mathrm{Zn}, \mathrm{Cu}, \mathrm{Ca}$ e $\mathrm{Fe})$ estão diretamente relacionados à fotossíntese em todas as plantas verdes, incluindo microalgas (SALAMA et al., 2017).

O enxofre (S), o ferro (Fe), o magnésio $(\mathrm{Mg})$, o cálcio $(\mathrm{Ca})$ e outros elementos são indispensáveis para o crescimento de microalgas. O enxofre é um componente essencial para a biossíntese de proteínas e para a fotossíntese (ZHANG et al., 2002). O magnésio é necessário para a atividade enzimática no metabolismo celular. O ferro e o cálcio estão envolvidos nas reações de oxirredução da fotossíntese (RODEN et al., 1996).

Os níveis baixos de fósforo no meio estão associados à atividade fotossintética diminuída e à diminuição das concentrações de proteínas (THEODOROU et al., 1991).

\subsection{Análise Estatística}

\subsubsection{Planejamento de Experimentos (DOE)}

O modo tradicional de realização de experimentos para otimizar um processo de produção por meio de planejamento experimental, que consiste em identificar vários fatores e níveis independentes para, posteriormente, conduzir os experimentos variando um único fator, enquanto mantém todos os outros em um nível predeterminado é muito ineficiente em muitos casos, uma vez que envolve a realização de muitos experimentos, o que é demorado e laborioso. Além disso, esses planejamentos geralmente ignoram a possível existência de interações entre as variáveis (RAO et al., 2008).

Um método de Planejamento de Experimentos é um teste ou uma série de testes, onde são feitas alterações determinadas nas variáveis de entrada de um 
processo ou sistema que permitem observar e identificar as razões para as alterações nas variáveis de saída ou respostas (MONTGOMERY, 2001).

O Planejamento de Experimentos consiste em três fases importantes: planejamento pré-experimental; execução dos experimentos; e análise estatística dos dados coletados, conforme demonstrado na Figura 9. 0 planejamento pré-experimental é uma fase-chave para a implementação bemsucedida dos experimentos porque as conclusões finais dependem, em grande parte, da maneira como os experimentos são planejados. No final da fase de planejamento pré-experimental, espera-se que os objetivos do experimento, a seleção de variáveis de resposta, os fatores e seus níveis sejam claramente definidos (FAROOQ et al., 2016).

Figura 9 - Fases do Planejamento de Experimentos.
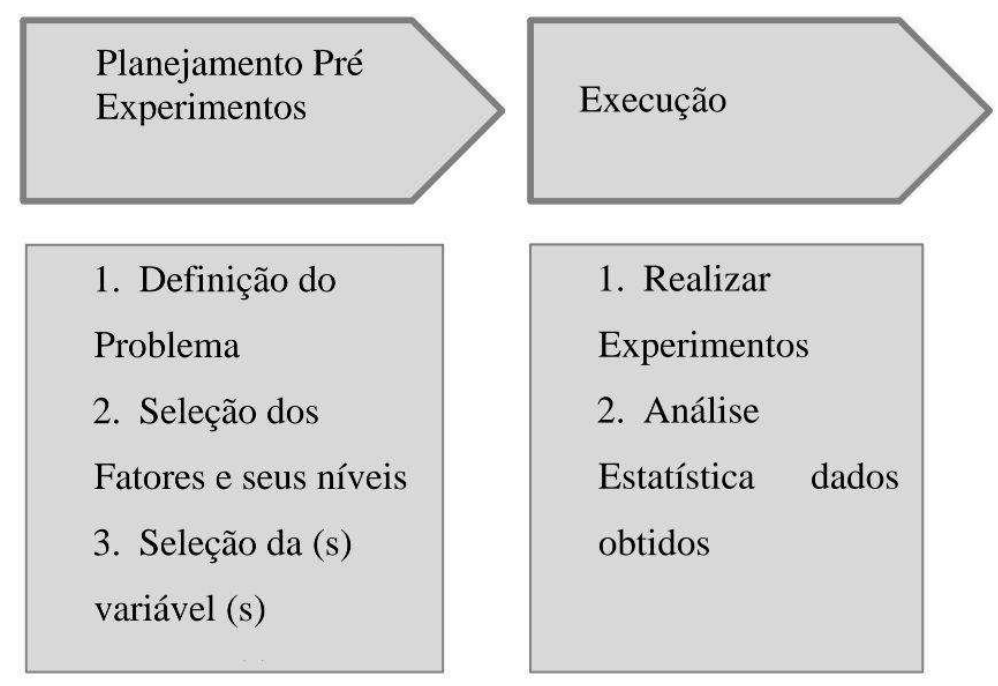

Análise Estatística e

Recomendações

1. Realizar
Experimentos
2. Análise
Estatística dados
obtidos

1. Validar

os resultados usando experimento confirmatório

2. Conclusões

Fonte: FAROOQ et al., 2016

Uma situação experimental geralmente complexa e dispendiosa é facilmente resolvida com Planejamento de Experimentos. Todos os fatores são considerados em um número mínimo de experimentos, e os resultados são verificados com métodos estatísticos reconhecidos (ERIKSSON et al., 2000).

A Metodologia de Planejamento e Análise de Experimentos, ou simplesmente Planejamento de Experimentos, é uma ferramenta poderosa para a melhoria da qualidade e produtividade (DA SILVA et al., 2016). 
Da Silva et al. (2016) ressaltam que técnicas de planejamento de experimentos vêm sendo utilizadas como uma ferramenta para verificar o funcionamento de sistemas ou processos produtivos, permitindo a melhorias destes, como a redução na variabilidade e conformidade próximas do resultado desejado, além de diminuição no tempo de processo e, consequentemente, nos custos operacionais.

\subsubsection{Método de Taguchi}

Genichi Taguchi introduziu o importante conceito na literatura em experimentos chamado de fatores de ruído, incontroláveis, a percepção de Taguchi foi notar que esses fatores podem, em muitos casos, ter seus efeitos minimizados (LOURES, 2016). Na Figura 10, as variáveis controláveis são os parâmetros de entrada do processo representado, ao passo que os ruídos interferem na variabilidade das variáveis resposta (YANG; HWANG; LEE, 2002).

Figura 10 - Representação esquemática de um processo.

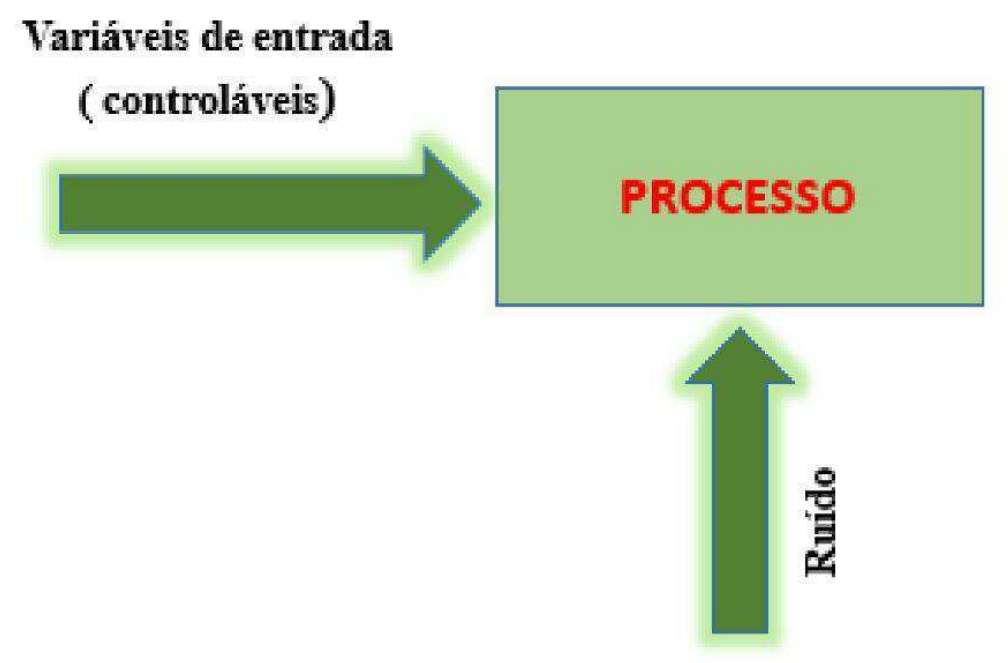

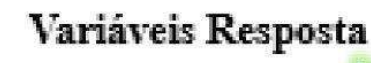

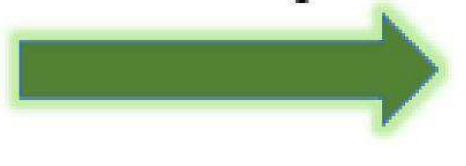

Fonte: YANG; HWANG; LEE, 2002

No método de Taguchi, variáveis ou fatores são dispostos em um arranjo ortogonal. As propriedades do arranjo ortogonal são tais que, entre cada par de colunas, cada combinação de níveis aparece um número igual de vezes (RAO et al., 2008). 
O método de Taguchi pode adquirir informações técnicas rápidas e precisas para projetar e produzir produtos e processos de baixo custo e alta confiabilidade (ROY, 2001).

Experimentos estatisticamente planejados podem ser usados para identificar os ajustes das variáveis de entrada de um processo, que reduzem a variabilidade das variáveis de saída (SWAN; SAVAGE, 1998).

O objetivo do método de Taguchi é minimizar a variabilidade do processo, identificando os meios de dar-Ihe robustez durante o processo. Ao reduzir a variabilidade, por meio do ajuste ideal das variáveis de entrada, visando um determinado comportamento da variável de saída, o método também permite reduzir o impacto das fontes de ruído, reduzir custos, reduzir o tempo de desenvolvimento do produto e alcançar a robustez (CARBAS et al., 2012).

O princípio fundamental é que, para garantir uma qualidade consistente, devese olhar para os processos que são insensíveis a defeitos de flutuações, ou seja, o processo deve ser projetado de modo que seu desempenho é o menos sensível a todos os tipos de ruído (CASTRO, 2001).

A análise de variância (ANOVA) é uma técnica estatística padrão comumente utilizada para determinar a significância das variáveis de entrada sob as variáveis de saída (BOUZID et al., 2014). Não analisa diretamente os dados, mas determina a porcentagem da contribuição de cada fator na determinação da variabilidade (variância) dos dados (CHABBI et al., 2017).

\subsubsection{Função Desirability}

A função Desirability é um algoritmo criado originalmente por Harrington (1965) que posteriormente foi aprimorado por Derringer e Suich (1980), para tratar da otimização simultânea de modelos de múltiplas respostas. Este método é capaz de avaliar um conjunto de respostas simultaneamente, permitindo determinar o conjunto de condições mais desejáveis para as propriedades estudadas (VAN GYSEGHEM et al., 2004).

Ao utilizar a formulação unilateral ou bilateral de Harrington (1965) e Derringer e Suich (1980) apresentada pela equação (4) é possível encontrar o índice global $D$, que deve se encontrar entre o intervalo $[0,1]$. Este índice é determinado a 
partir da combinação de cada uma das respostas transformadas $\left(d_{i}\right)$ através de uma média geométrica e será maximizado quando todas as respostas se aproximarem o máximo possível de suas especificações. Quanto mais próximo de 1 estiver $D$, mais próximas as respostas originais estarão de seus respectivos limites de especificação (ROSSI, 2001).

$D=\{[d 1(Y 1)] \times[d 2(Y 2)] \times[d 3(Y 3)] \ldots[d u(Y u)]\}^{1 / u}$

Cada uma das respostas do conjunto original é transformada de modo que $\mathrm{d}_{\mathrm{i}}$ pertença ao intervalo $0 \leq d_{i} \leq 1$. O valor de $d_{i}$ aumenta quando a i-ésima resposta se aproxima dos limites impostos. O ponto de ótimo geral do sistema é o ponto de ótimo alcançado pela maximização da desejabilidade global (D), calculada a partir das funções desejabilidade individuais $\left(d_{i}\right)$. A utilização da média geométrica tem a vantagem de fazer com que a solução global seja alcançada de maneira balanceada, permitindo que todas as respostas atinjam os valores esperados e forçando o algoritmo a se aproximar das especificações impostas (WU, 2005). 


\section{MATERIAIS E MÉTODOS}

A etapa experimental do presente trabalho foi antecedida de uma fase de planejamento, na qual houve a contextualização do problema, bem como a definição das variáveis de entrada, com seus respectivos níveis, e de saída do processo, além do método a ser utilizado.

Após os processos da etapa experimental, o estudo foi finalizado com a análise estatística dos resultados, confirmação destes e recomendações. Um esquema das principais etapas de pesquisa é demonstrado na Figura 11.

\section{Figura 11 - Fluxograma das principais etapas da pesquisa.}

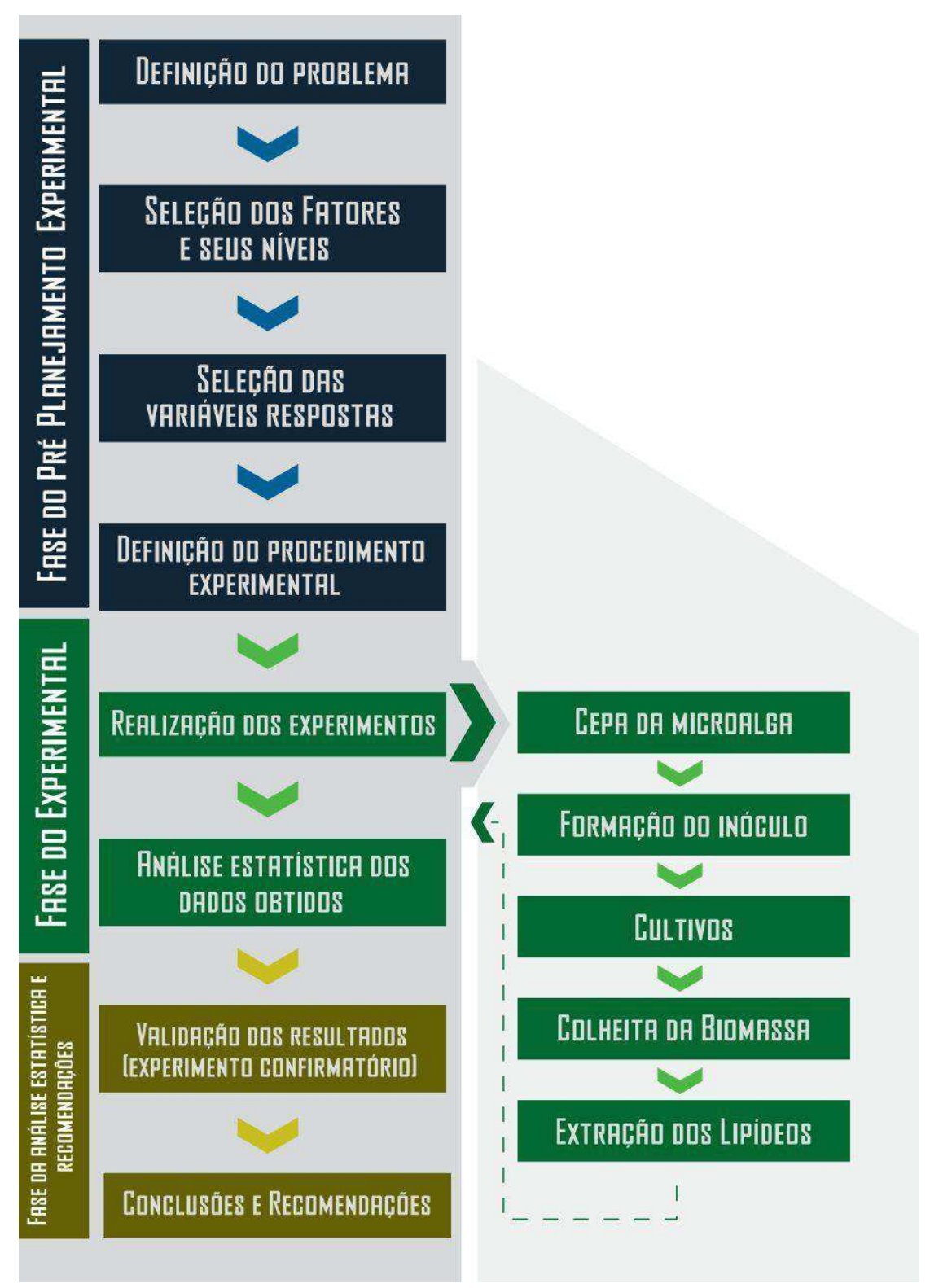

Fonte: Próprio Autor 


\subsection{Linhagem da microalga}

Todos os experimentos foram realizados com cepa de microalga marinha Chlorella minutissima, isolada em Cabo Frio (Rio de Janeiro, Brasil) que integra a coleção de culturas de algas do Instituto Oceanográfico da Universidade de São Paulo (São Paulo - SP, Brasil), cultivadas no Laboratório de Engenharia de Microalgas da Escola de Engenharia de Lorena.

\subsubsection{Manutenção da cepa}

A cepa da espécie em estudo, bem como de outras linhagens no laboratório de engenharia de microalgas da Escola de Engenharia de Lorena (EEL-USP) são mantidas em reservatório de madeira iluminado por lâmpada fluorescente com potência de $15 \mathrm{~W}$, conectada a um temporizador que controla o fotoperíodo em 12 horas claro: 12 horas escuro, no qual 100 mililitros da cepa são cultivados em meio f/2 sem sílica, garantindo o fornecimento de células durante todo o período da pesquisa. Um esquema demonstrativo da estrutura para manutenção das cepas é demonstrado na Figura 12.

Figura 12 - Esquema da estrutura de manutenção de cepas de microalgas.

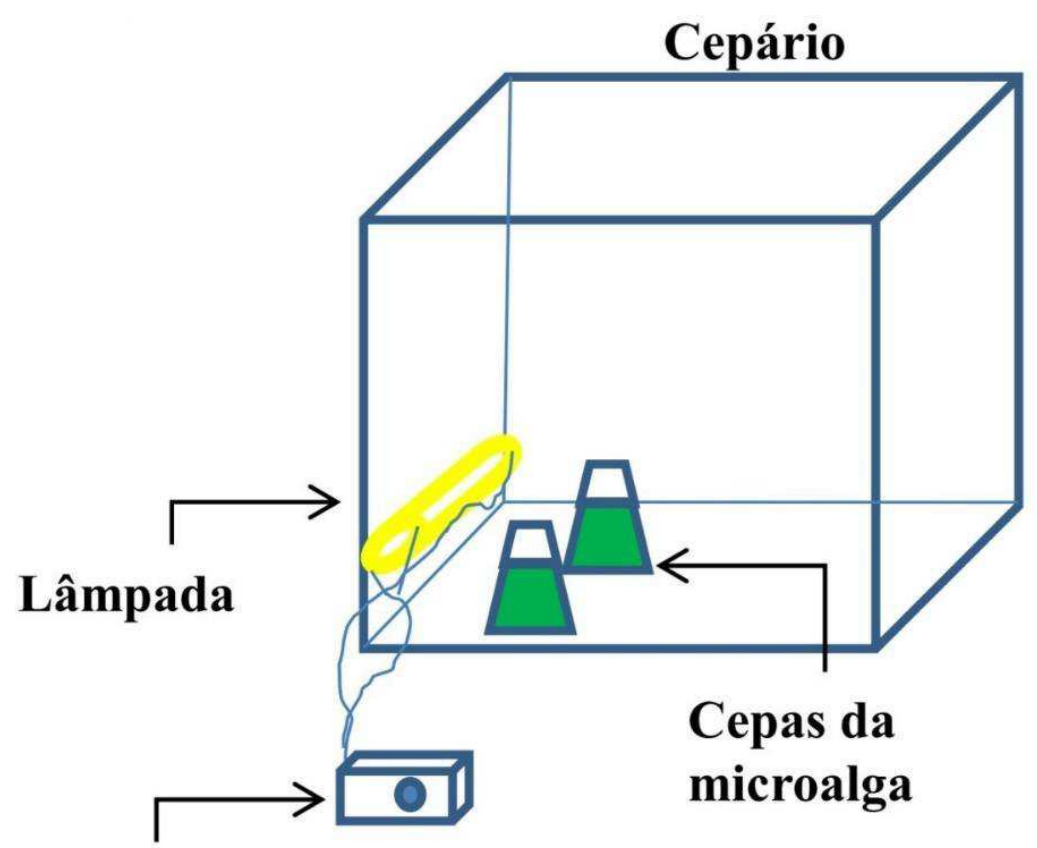

Temporizador 


\subsection{Fotobiorreatores}

Os fotobiorreatores utilizados neste trabalho foram constituídos por um par de prismas de base retangular, sem base superior, cujas arestas têm 5 milímetros

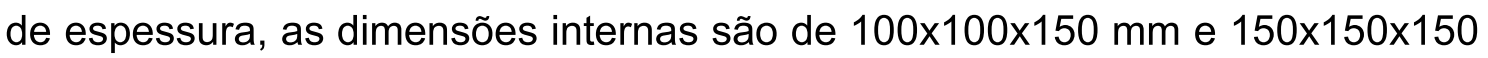
$\mathrm{mm}$, com volume útil de 1,1 L.

Em cada fotobiorreator, os prismas de dimensões inferiores são posicionados internamente ao centro dos prismas de dimensões superiores, estes têm suas arestas externas isoladas da luz exterior, ao passo que nas arestas internas são instaladas fitas de LED nas especificações do estudo. As Figuras 13 a 16 representam os fotobiorreatores citados.

Figura 13 - Esquema dos fotobiorreatores empregados para o cultivo da microalga Chlorella minutíssima.

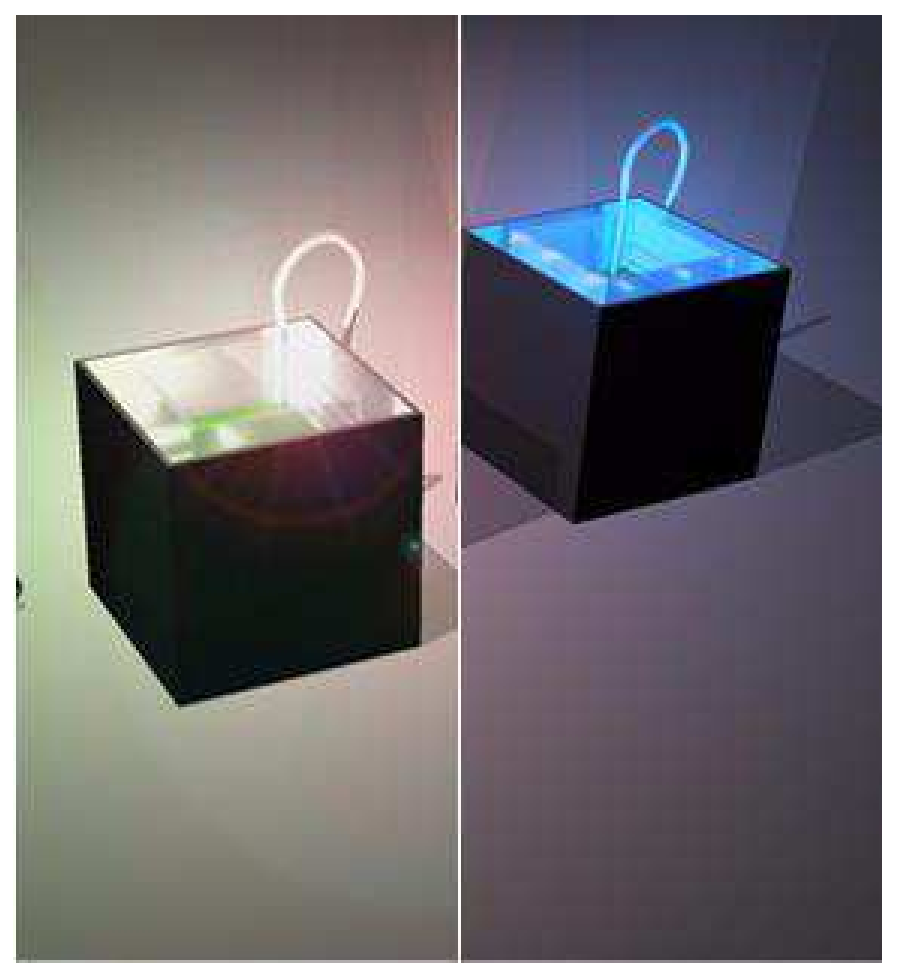

Fonte: Próprio Autor 
Figura 14 - Vista lateral aberta dos fotobiorreatores usados no trabalho.

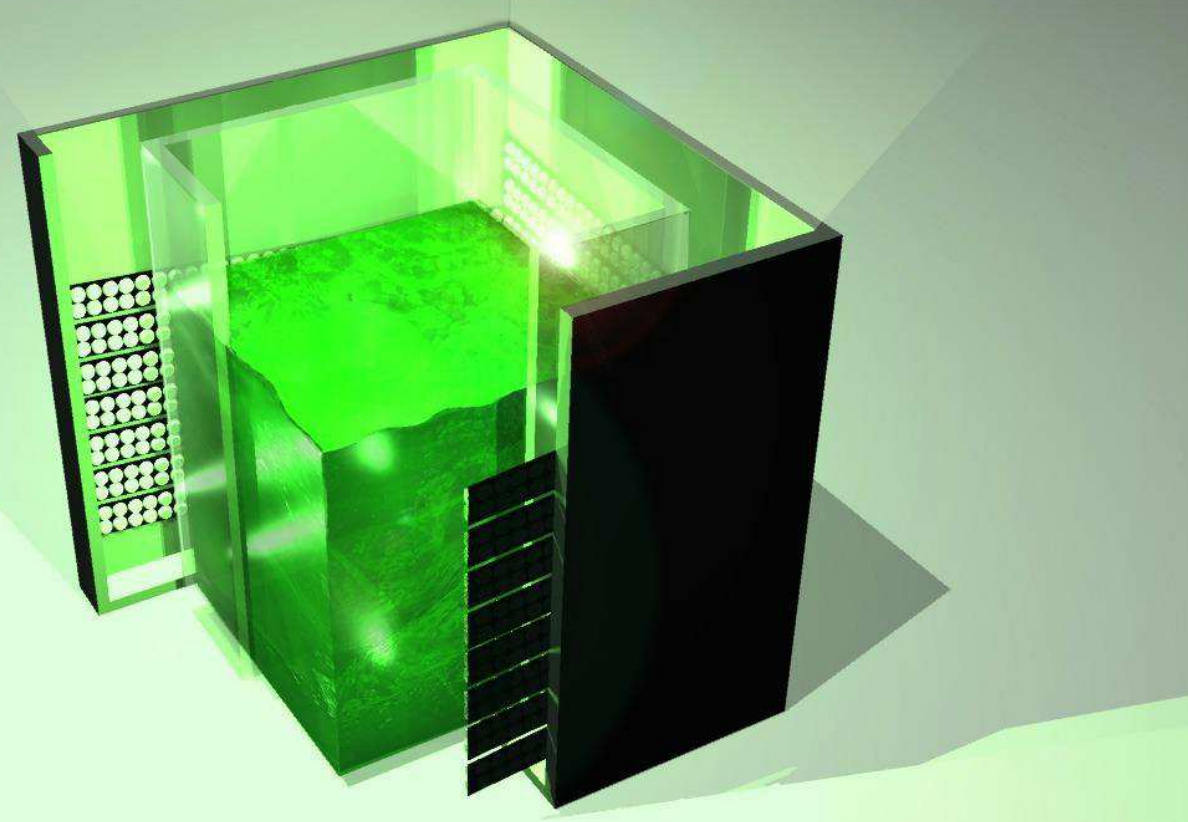

Fonte: Próprio Autor

Figura 15 - Vista superior segmentada dos fotobiorreatores.

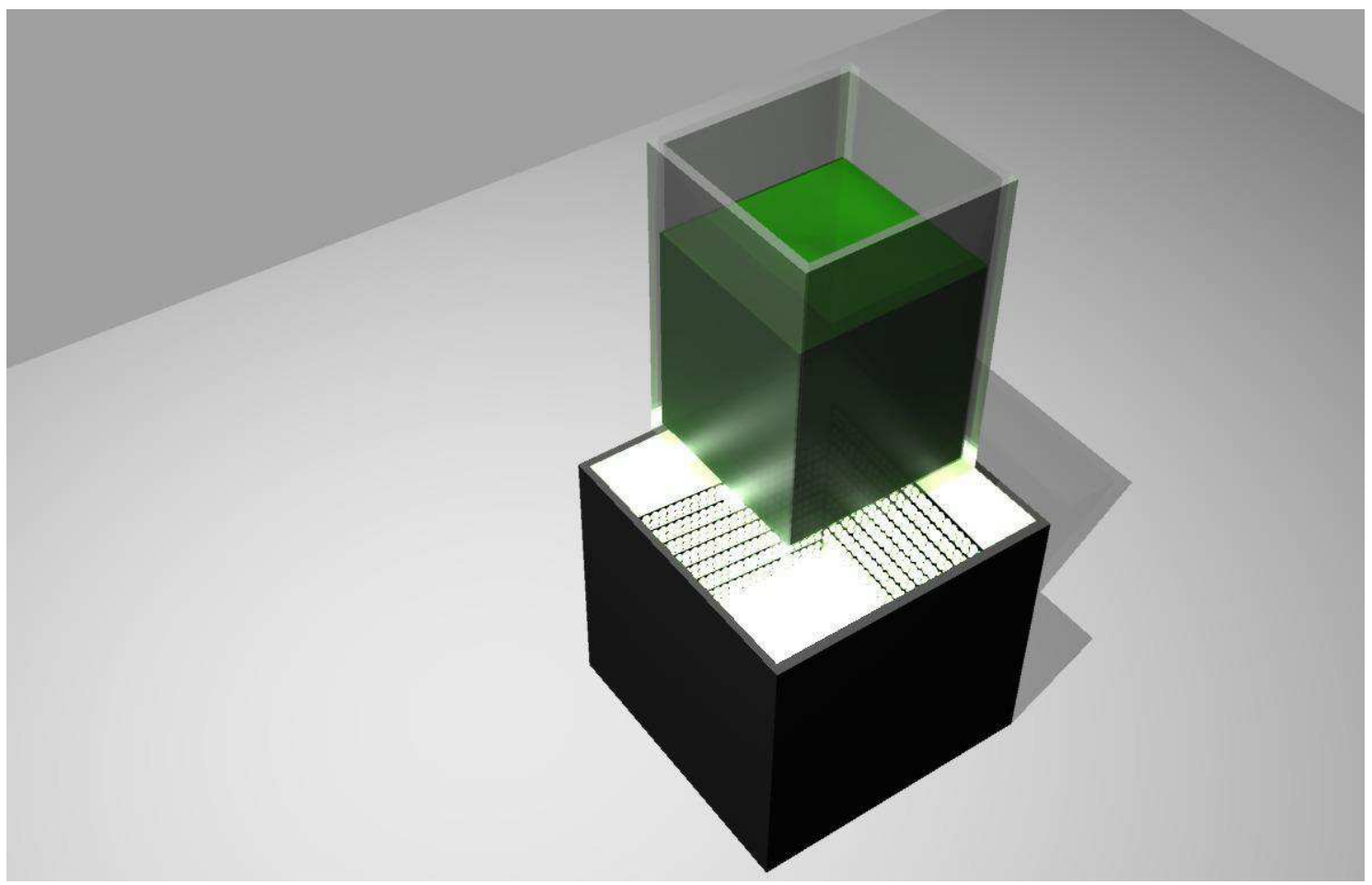

Fonte: Próprio Autor 
Figura 16 - Desenho técnico mecânico da estrutura dos fotobiorreatores empregados no trabalho.
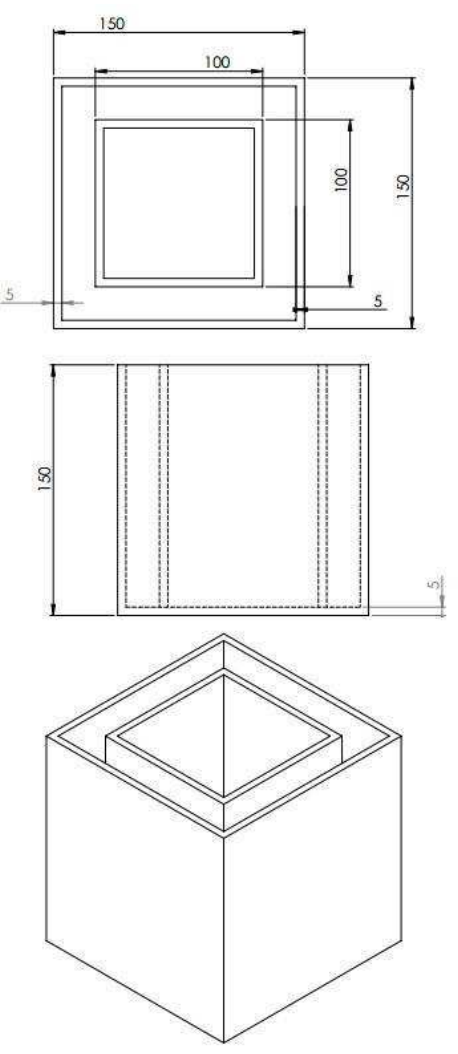

Fonte: Próprio Autor

\subsubsection{Método de desinfecção dos fotobiorreatores}

Antes de carregados os fotobiorreatores foram desinfetados pela adição de solução de hipoclorito de sódio comercial ( 2 a $3 \%$ de cloro ativo) na proporção de $1 \mathrm{ml}$ para cada litro de água destilada.

Após transcorridas 24 horas de repouso da adição da solução de hipoclorito de sódio comercial, foi procedida reação de neutralização com a adição de $100 \mathrm{mg}$ de tiossulfato de sódio, sob aeração durante 2 horas.

Concluída a neutralização, o gotejamento de solução de dicloridrato de ortotolidina a concentração de $0,05 \%$ em parte do conteúdo dos fotobiorreatores, garantiu a isenção de cloro livre na solução. Neste ponto então, a parte interna dos fotobiorreatores foi lavada com água destilada para remoção de eventuais resíduos de cloro de suas arestas. 


\subsection{Iluminação}

A iluminação utilizada consiste em fitas de LED da fabricante AIHA, identificadas pela fabricante pelo código AH-3528-IP65-60-12, na cor branca e que emite fótons de luz de energia equivalente a 2,64 eV, correspondente ao comprimento de onda de $470 \mathrm{~nm}$, na cor azul.

As fitas utilizadas, munidas de certificação RoHS e CE, apresentam 2,2 mm de espessura, $8 \mathrm{~mm}$ de largura, fluxo luminoso de $210 \mathrm{Im} / \mathrm{m}$, potência de 4,8 W/m e ângulo de abertura de $120^{\circ}$.

\subsection{Reagentes e meio de cultivo}

\subsubsection{Reagentes}

Todos os reagentes utilizados, tanto na fase experimental como na preparação dos meios de cultivo foram de grau padrão analítico para microbiologia, permitindo assim, menor variabilidade e maior precisão no meio de cultivo. $\mathrm{Na}$ Tabela 6 demonstra-se a composição do meio de cultivo sem sílica e sem $\mathrm{NaNO}_{3}$ e $\mathrm{NaH}_{2} \mathrm{PO}_{4} \cdot \mathrm{H}_{2} \mathrm{O}$, que foram adicionados de acordo com a condição experimental em andamento, previamente planejada. 
Tabela 6 - Composição do meio de cultivo

\begin{tabular}{|c|c|}
\hline Componente & Concentração \\
\hline Sal Marinho & $30 \mathrm{~g} / \mathrm{l}$ \\
\hline $\mathrm{NeCl}_{3} .6 \mathrm{H}_{2} \mathrm{O}$ & $3,15 \mathrm{~g} / \mathrm{l}$ \\
\hline $\mathrm{ZnSO}{ }_{4} .7 \mathrm{H}_{2} \mathrm{O}$ & $22,2 \mathrm{mg} / \mathrm{l}$ \\
\hline $\mathrm{MnCl}_{2} .4 \mathrm{H}_{2} \mathrm{O}$ & $180 \mathrm{mg} / \mathrm{l}$ \\
\hline $\mathrm{Na}_{2} \mathrm{MoO}_{4} .2 \mathrm{H}_{2} \mathrm{O}$ & $6,3 \mathrm{mg} / \mathrm{l}$ \\
\hline $\mathrm{CoCl}_{2} .6 \mathrm{H}_{2} \mathrm{O}$ & $10 \mathrm{mg} / \mathrm{l}$ \\
\hline $\mathrm{CuSO}_{4} .5 \mathrm{H}_{2} \mathrm{O}$ & $9,8 \mathrm{mg} / \mathrm{l}$ \\
\hline $\mathrm{Tiamina}_{2}$ & $100 \mathrm{mg} / \mathrm{l}$ \\
\hline Cianocobalamina & $0,5 \mathrm{mg} / \mathrm{l}$ \\
\hline Biotina & $0,5 \mathrm{mg} / \mathrm{l}$ \\
\hline
\end{tabular}

Fonte Adaptado de GUILLARD, 1975

\subsubsection{Preparo do meio de cultura e início do cultivo}

Para a preparação dos meios de cultivo, foi utilizada água destilada para a obtenção de uma solução cuja concentração dos solutos obedecesse ao exposto na tabela 6. $\mathrm{O} \mathrm{NaNO}_{3}$ e o $\mathrm{NaH}_{2} \mathrm{PO}_{4} \cdot \mathrm{H}_{2} \mathrm{O}$ foram adicionados à solução de acordo com o estabelecido no planejamento experimental.

Antes da adição dos compostos vitamínicos (tiamina, cianocobalamina e biotina), o meio foi autoclavado, mantido a temperatura de $121^{\circ} \mathrm{C}$ durante 20 minutos, promovendo a esterilização do meio e evitando a perda de atividade das vitaminas.

Depois de preparado, o inóculo concentrado de células ativas de Chlorella minutissima foi adicionado ao meio de cultivo na proporção de $10 \%$ do volume final levado aos fotobiorreatores, previamente desinfetados. A Figura 17 demonstra um meio de cultivo recém inoculado. 
Figura 17 - Meio de cultivo recém inoculado.

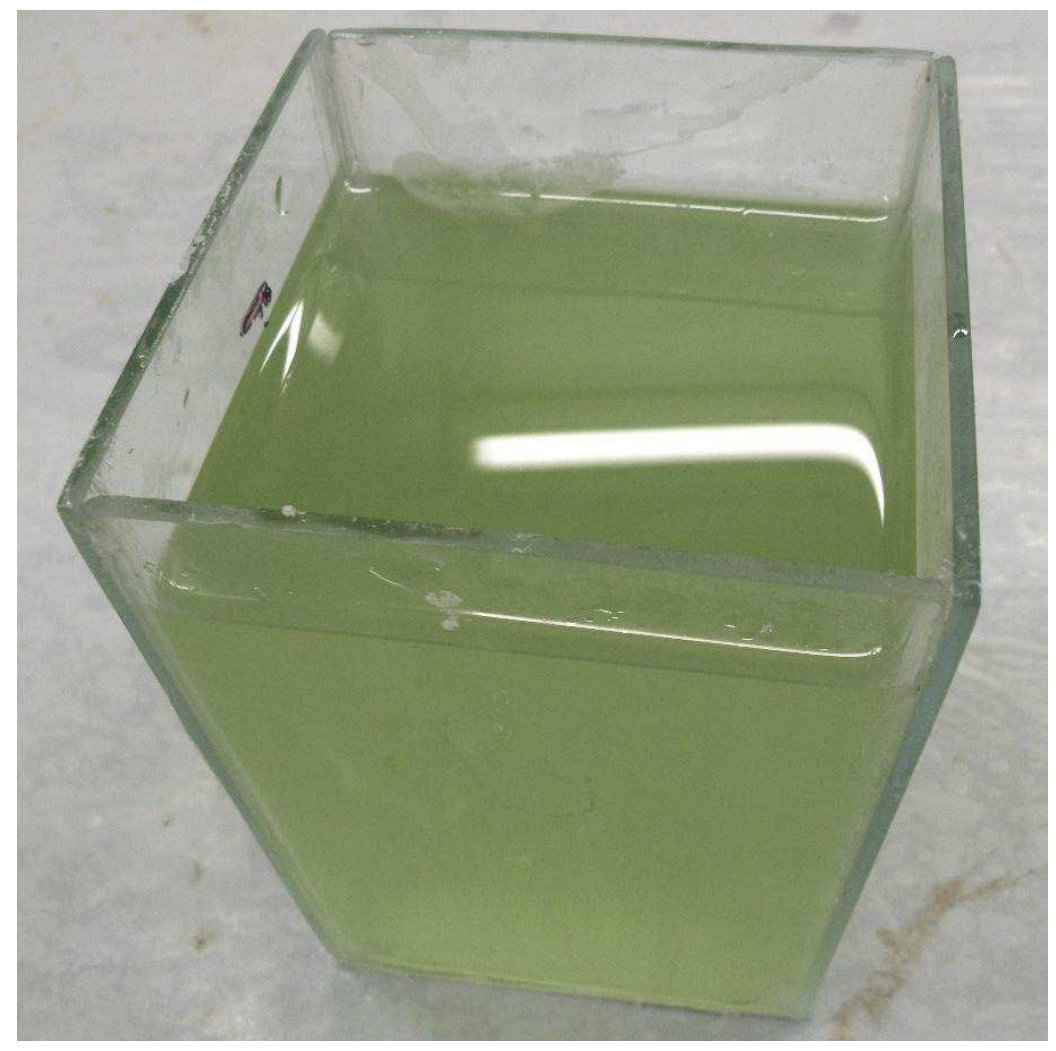

Fonte: Próprio Autor

\subsection{Acompanhamento do crescimento celular}

Diariamente, sob condições assépticas, foram coletadas pequenas alíquotas dos meios de cultivo para a determinação da biomassa por turbidimetria e contagem celular.

A densidade óptica foi medida para o comprimento de onda de $540 \mathrm{~nm}$ com o auxílio de um espectrofotômetro UV-Visível da marca Quimis, modelo Q898DPT. A escolha do comprimento de onda deve-se ao espectro de absorção dos pigmentos de clorofila (Figura 18) que poderiam interferir nos valores de absorbância. 
Figura 18 - Espectro de absorção da clorofila a e da clorofila b.

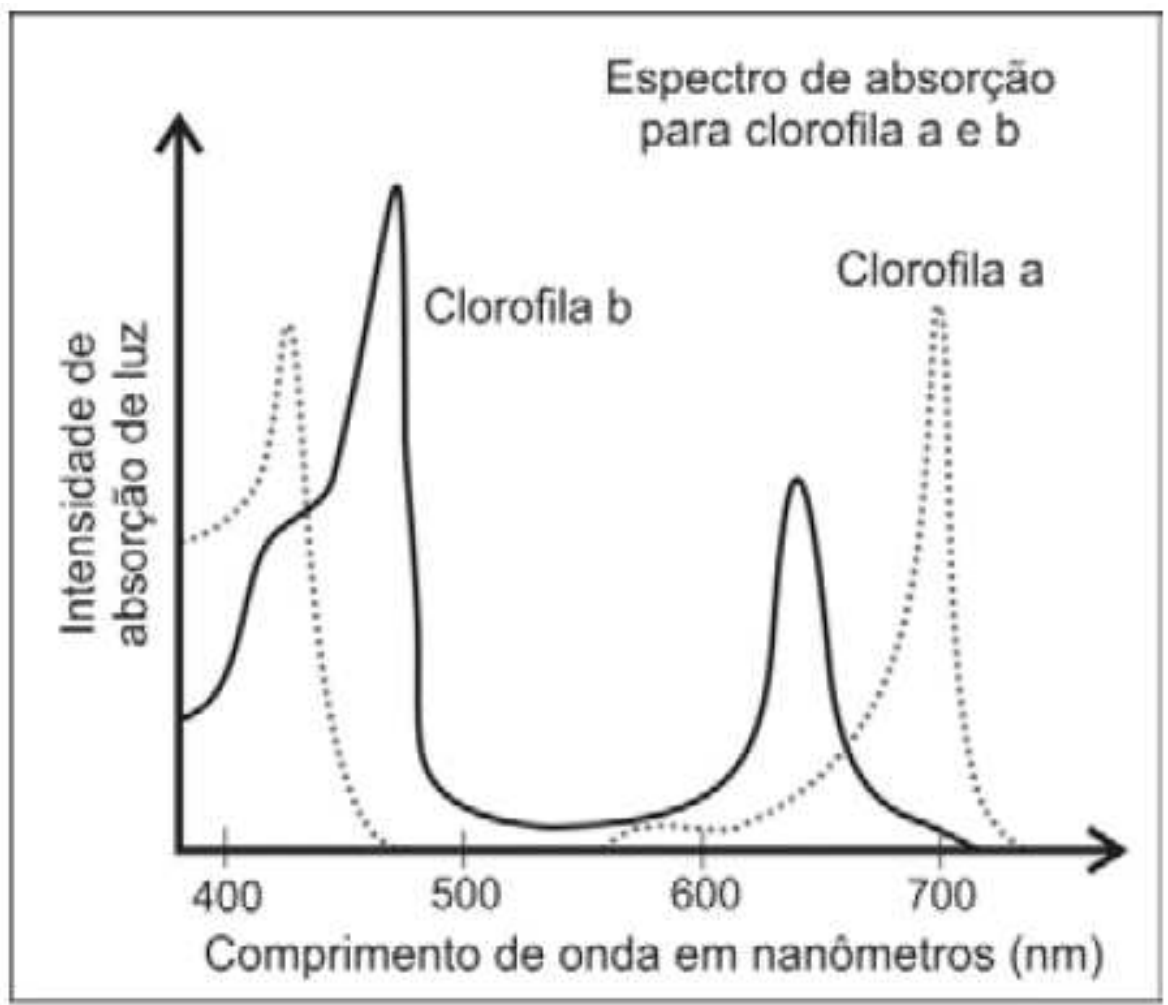

Fonte: FUNDAÇÃO UNIVERSITÁRIA PARA O VESTIBULAR, 2017

A contagem celular foi realizada com o auxílio de um microscópio da marca Bioval, modelo L-1000T-AC e de um hemacitômetro tipo câmara de Neubauer de $0,1 \mathrm{~mm}$ de profundidade. Uma curva de correlação entre número de células por $\mathrm{mL}$ e densidade óptica foi obtida para todos os comprimentos de onda em estudo.

\subsection{Colheita e secagem}

\subsubsection{Colheita}

No instante em que os dados provenientes da contagem celular apresentaram queda, e os valores de absorbância acompanhavam queda superior ao dobro da incerteza de medição do espectrofotômetro $(0,0005)$, a biomassa resultante de uma porção de $100 \mathrm{~mL}$ do volume útil de cada cultivo foi colhida por meio de operação de floculação, induzida pela adição de $2 \mathrm{~mL}$ de solução $1 \mathrm{~N}$ de sulfato de alumínio e $1 \mathrm{~mL}$ de solução $1 \mathrm{~N}$ de hidróxido de sódio por litro de meio de cultivo. A Figura 19 ilustra a biomassa floculada em porções do meio de cultivo. 
Figura 19 - Biomassa após operação de floculação.

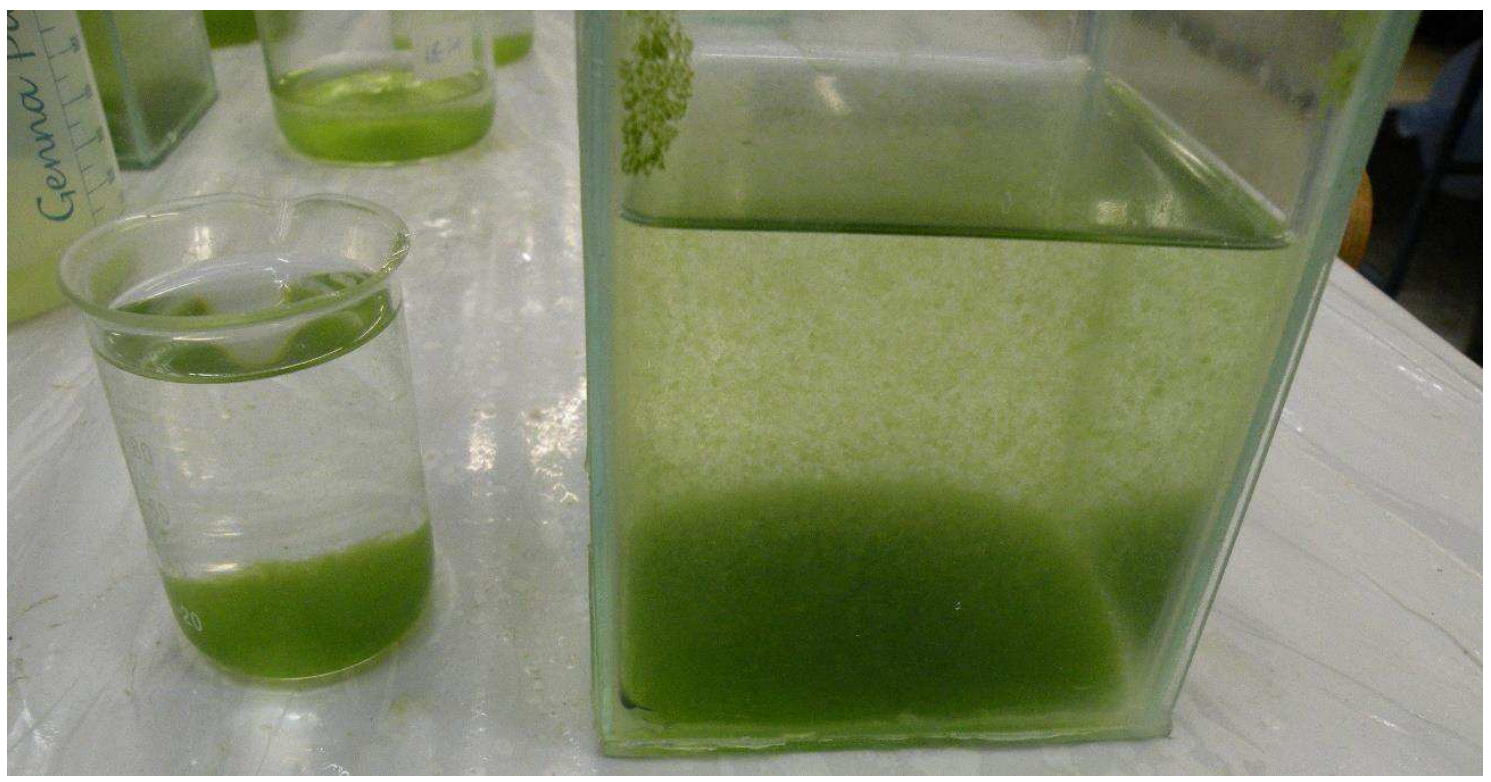

Fonte: Próprio Autor

Após floculada, a biomassa foi submetida à filtração a vácuo, por meio de papel de filtro quantitativo (de massa previamente conhecida) com diâmetro médio de poro de $7 \mu \mathrm{m}$. A Figura 20 ilustra a biomassa após o processo de filtração à vácuo. Após filtrada, a biomassa foi lavada com água destilada para remover eventuais resíduos solúveis em água.

Figura 20 - Biomassa filtrada à vácuo.

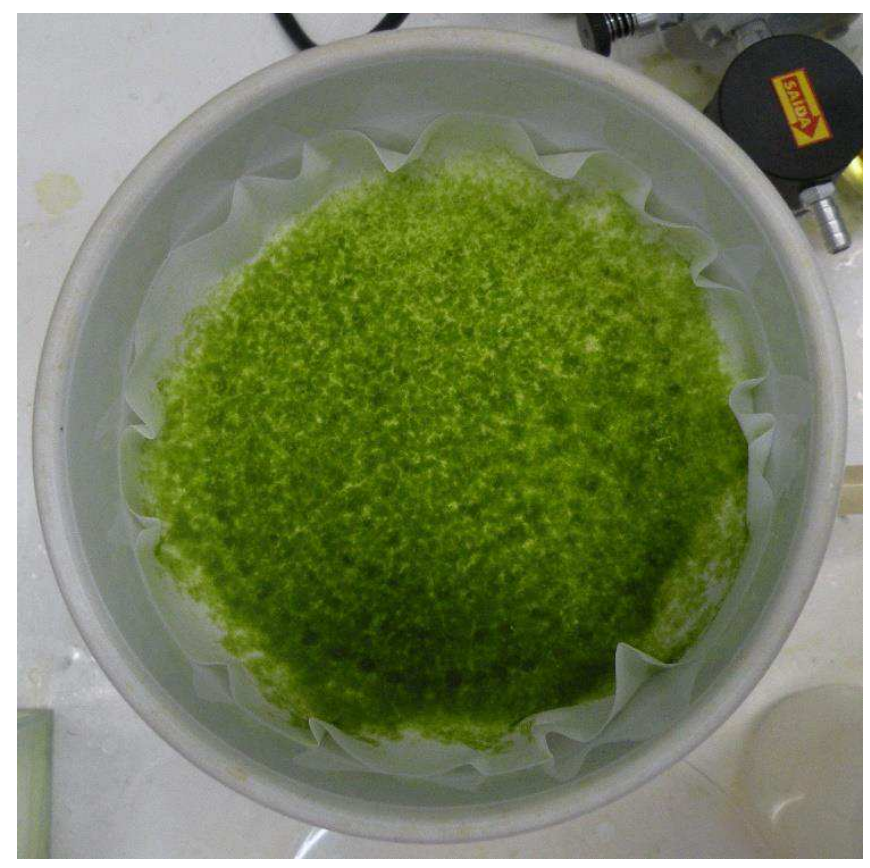

Fonte: Próprio Autor 


\subsubsection{Secagem}

A operação de secagem foi realizada em estufa a $60^{\circ} \mathrm{C}$. Após períodos de 24 horas em estufa, a biomassa retida no papel de filtro foi pesada até atingir massa constante.

\subsection{Extração de lipídios}

Os teores de lipídios totais foram quantificados de acordo com a metodologia proposta por Bligh \& Dyer modificada (BLIGH and DYER, 1959). A biomassa resultante de uma porção de $850 \mathrm{~mL}$ do volume útil de cada cultivo foi submetida aos procedimentos de floculação, filtração a vácuo e lavagem, seguindo a mesma rota experimental da operação de colheita.

Após filtrada, uma pequena porção da biomassa úmida teve sua massa aferida para que o seu teor de umidade fosse quantificado, para tanto, essa porção foi colocada em estufa a $60^{\circ} \mathrm{C}$, na mesmo rota experimental da operação de secagem, até massa constante.

Ao restante da biomassa úmida obtida a partir de $850 \mathrm{~mL}$ de cada meio de cultivo, com massa previamente determinada, foram adicionados 3,6 $\mathrm{mL}$ de clorofórmio por grama de biomassa úmida. Após homogeneização, outros 3,6 $\mathrm{mL}$ de metanol por grama de biomassa úmida completaram a composição da solução extratora.

Após agitação até a homogeneização da biomassa na solução extratora, o resultado passou por um pré-tratamento com ultrassom, durante 50 minutos, visando facilitar a ruptura da parede celular, para ser filtrado por meio de papel de filtro quantitativo com diâmetro médio de poro de $7 \mu \mathrm{m}$. A Figura 21 ilustra o esquema utilizado para o rompimento da parede celular em banho de ultrassom. 
Figura 21 - Esquema para rompimento da parede celular em banho de ultrassom.

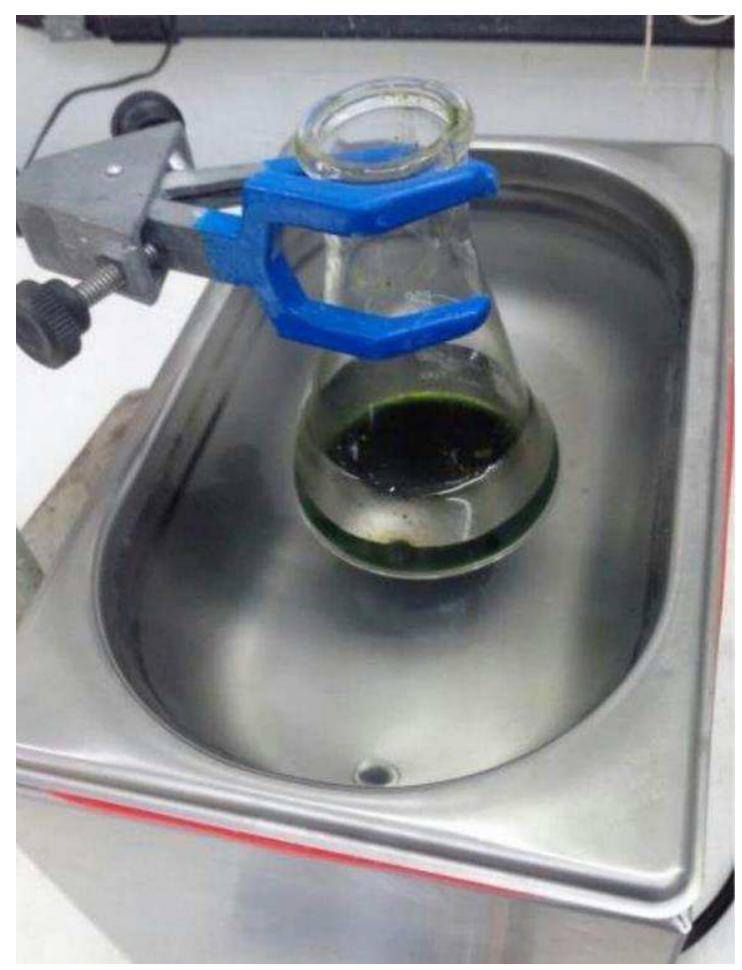

Fonte: LOURES, 2016

\subsection{Determinação da massa seca}

A biomassa seca obtida foi calculada por diferença de massa. Para tanto, os papeis de filtro utilizados na filtração de porção de $100 \mathrm{~mL}$ do volume útil total de cada experimento foram levados previamente à estufa. Após a aferição de massa constante, os filtros foram resfriados para atender à operação de filtração.

Após as etapas de colheita e secagem, a diferença entre a massa obtida nos papeis de filtro com biomassa retida e a massa previamente conhecida do papel de filtro foi multiplicada pelo fator 10 , para obtenção da biomassa seca na unidade grama por litro de cultivo.

\subsection{Determinação do teor lipídico}

O teor lipídico foi calculado por diferença de massa entre as massas dos frascos apropriados para esta operação e a massa destes após a completa evaporação dos solventes extratores. Para tanto, estes frascos foram levados à estufa a 60 ${ }^{\circ} \mathrm{C}$ por 24 horas antes de terem sua massa quantificada. Após resfriados, receberam o permeado da filtração, por meio de papel de filtro quantitativo com 
diâmetro médio de poro de $7 \mu \mathrm{m}$, da homogeneização da biomassa na solução extratora após o pré-tratamento em banho de ultrassom.

Finalizada a filtração, os frascos, com o permeado, foram levados à estufa a 60 ${ }^{\circ} \mathrm{C}$ e tiveram sua massa quantificada, até que atingissem massa constante. $\mathrm{O}$ teor lipídico foi obtido por meio da equação (5).

Teor lipídico $=\frac{\text { massa dos frascos após evaporação dos solventes-massa inicial dos frascos }}{(\text { biomassa úmida } \times(1-\text { teor de umidade }))}$

\subsection{Análise Estatística}

\subsubsection{Método de Taguchi}

O planejamento dos experimentos foi realizado usando 2 matrizes ortogonais de Taguchi $L_{8}$, cada uma direcionada aos experimentos submetidos à luz com um dos comprimentos de onda estudados (470 nm, além da luz branca), operando de acordo com os fatores e níveis apresentados na Tabela 7. A produção de biomassa e teor lipídico foram tomados como variáveis de resposta. 0 tratamento dos dados estatísticos foi realizado analisando gráficos de efeitos e interações, além de tabelas de análise de variância (ANOVA).

Tabela 7 - Fatores considerados no planejamento de experimentos e seus respectivos níveis decodificados.

\begin{tabular}{cccc}
\hline \multirow{2}{*}{ Código } & Fator & \multicolumn{2}{c}{ Nível } \\
\cline { 3 - 4 } & & $\mathbf{1}$ & $\mathbf{2}$ \\
\hline $\mathrm{A}$ & lluminância (klx) & 26 & 13 \\
B & $\mathrm{NaH}_{2} \mathrm{PO}_{4} \cdot \mathrm{H}_{2} \mathrm{O}\left(\mathrm{mgL}^{-1}\right)$ & 5 & 15 \\
C & $\mathrm{NaNO}_{3}\left(\mathrm{mgL}^{-1}\right)$ & 45 & 75 \\
& Fotoperíodo (claro: & & \\
D & escuro) & $12: 12 \mathrm{~h}$ & $16: 08 \mathrm{~h}$ \\
\hline
\end{tabular}

Fonte: Próprio Autor

De acordo com o método do número de graus de liberdade, utilizado para a escolha do arranjo ortogonal apropriado ao estudo, quando se objetiva verificar a influência de interações entre fatores nas variáveis de resposta, por meio do método de Taguchi, precisa-se analisar um dos gráficos lineares correspondentes ao arranjo escolhido. 
Os gráficos lineares, cujo adotado aparece na Figura 22, guiam a alocação dos fatores e interações nas colunas disponíveis em um determinado arranjo ortogonal de Taguchi. Nestes, os pontos representam as colunas onde se deve alocar os fatores, ao passo que os segmentos de reta representam as colunas onde se deve alocar as interações entre os fatores ligados por este segmento.

Figura 22 - Gráfico linear correspondente ao arranjo ortogonal $L_{8}$ de Taguchi.

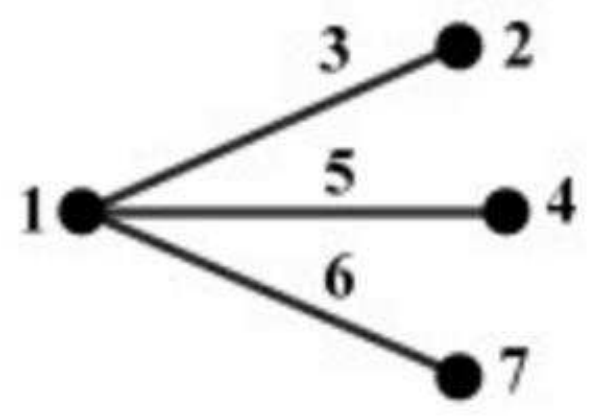

Fonte: Adaptado de ROSS, 1995

Diante do objetivo de se investigar possíveis interações entre a iluminância e os demais parâmetros do processo, faz-se a necessidade de alocar o referido fator na primeira coluna do arranjo ortogonal, apresentado na Tabela 8.

Tabela 8 - Matriz experimental $L_{8}$ de Taguchi com 4 fatores em dois níveis.

\begin{tabular}{cccccccc} 
& \multicolumn{7}{c}{ Fatores e Interações } \\
\hline Experimento & A & B & AB & C & AC & AD & D \\
\hline 1 & 1 & 1 & 1 & 1 & 1 & 1 & 1 \\
2 & 1 & 1 & 1 & 2 & 2 & 2 & 2 \\
3 & 1 & 2 & 2 & 1 & 1 & 2 & 2 \\
4 & 1 & 2 & 2 & 2 & 2 & 1 & 1 \\
5 & 2 & 1 & 2 & 1 & 2 & 1 & 2 \\
6 & 2 & 1 & 2 & 2 & 1 & 2 & 1 \\
7 & 2 & 2 & 1 & 1 & 2 & 2 & 1 \\
8 & 2 & 2 & 1 & 2 & 1 & 1 & 2 \\
\hline
\end{tabular}

Fonte: Próprio Autor 


\subsubsection{Escolha dos níveis para os fatores de entrada}

\subsection{Comprimentos de onda}

Tendo em vista o espectro de absorção das clorofilas a e b, bem como que a luz incidente sobre um cultivo de microalgas deve combinar com a banda de absorção que corresponde ao seu estado mais excitado, faz-se relevante a condução do estudo no comprimento de onda de $470 \mathrm{~nm}$. O estímulo para a inclusão da luz branca no estudo, deve-se às menções de alta produtividade, constantes na literatura, com o uso dessa luz, o que pode ser justificado com um possível stress energético provocado pela alta energia dos fótons de luz azul.

\subsection{Iluminância}

Com a finalidade de contornar o efeito de auto-sombreamento além da limitação luminosa tida como frequente em fotobiorreatores fechados foram empregados níveis de iluminância de $13 \mathrm{klx}$ e $26 \mathrm{klx}$. Outro fator motivador para a escolha destes níveis de estudo foi a observação da elevada taxa de variação da taxa de crescimento específico de células em relação a intensidade luminosa antes de atingido o limite de saturação.

\subsection{Concentração de dihidrogenofosfato de sódio hidratado}

A atividade fotossintética diminuída motivada por níveis de fósforo insuficientes, bem como a utilização do dihidrogenofosfato de sódio hidratado como fonte de fósforo, motivaram a inclusão de um nível de estudo significativamente superior àquele determinado no meio de cultivo f/2 sem sílica para o reagente.

\subsection{Concentração de nitrato de sódio}

Considerada a evidência, relatada na literatura, de que a ureia seria idealmente a fonte de nitrogênio por conta de eventuais alterações de $\mathrm{pH}$ provocadas pela adição de nitratos, o que poderia provocar a morte da célula, além da evidência de que limitações de nitrogênio poderiam induzir maior acumulação lipídica, torna-se justificável a adoção de um nível de estudo inferior àquele determinado pelo meio de cultivo f/2 sem sílica. 


\subsection{Fotoperíodo}

Para promover a diluição da luz, uma vez que a iluminação constante não é tida como ideal ao crescimento celular, o uso de ciclos de claro e escuro é determinante. Em função do curto espaço de tempo necessário para absorção de fótons por parte das clorofilas a e b, o emprego de ciclos curtos parece ser 0 ideal, razão pela qual repetidos ciclos diários de 2 horas de iluminação e 1 hora de restrição luminosa, totalizando 16 horas diárias de iluminação, foi adicionado ao estudo juntamente com o nível em que as microalgas eram mantidas no cepário.

\subsubsection{Função Desirability}

Após a identificação das variáveis de entrada (fatores) com maior influência sobre o comportamento das variáveis de resposta concentração celular e teor lipídico, para cada comprimento de onda de luz, por meio do arranjo ortogonal L8 de Taguchi, foi utilizada a função Desirability para determinação das melhores condições de ajuste das variáveis de entrada com o objetivo de maximizar, simultaneamente, ambas as variáveis de resposta.

Com o uso da técnica é possível a obtenção, simultaneamente, das melhores condições das respostas, adaptadas à conveniência de cada processo, isso é, quer as intenções para uma variável de entrada sejam de maximização ou minimização de seus valores, ou ainda no caso de se desejar atingir um patamar o mais próximo possível do nominal.

Ao utilizar a formulação unilateral ou bilateral de Harrington (1965) e Derringer e Suich (1980) apresentada pela equação $D=(d 1(Y 1)$. $\mathrm{d} 2(\mathrm{Y} 2)$. $\mathrm{K} . \mathrm{du}(\mathrm{Yu})$ )1/u é possível encontrar o índice global $\mathrm{D}$, que deve se encontrar entre o intervalo $[0,1]$. Este índice é determinado a partir da combinação de cada uma das respostas transformadas (di) através de uma média geométrica e será maximizado quando todas as respostas se aproximarem no máximo possível de suas especificações. Quanto mais próximo de 1 estiver $D$, mais próximas as respostas originais estarão de seus respectivos limites de especificação (ROSSI, 2001). 
Para a realização das análises estatísticas foram utilizados os softwares Statistica 11.0 e Minitab® 18. Para a otimização de múltiplas respostas, utilizando a função Desirability, foi utilizado o software Minitab® 18. 


\section{RESULTADOS E DISCUSSÃO}

Este capítulo analisará os resultados obtidos ao longo da prática experimental por meio do método de Taguchi, conforme apresentado no capítulo anterior. Por se tratar de dois arranjos ortogonais distintos, um para cada comprimento de onda de operação, faz-se conveniente a divisão do capítulo em dois tópicos distintos, em cada um dos quais se discutirá, separadamente, ambas as variáveis de resposta, antes de tentar unifica-las por meio da função Desirability. A razão sinal-ruído $(\mathrm{S} / \mathrm{N})$, cuja expressão matemática, para o objetivo de maximizar o valor da variável resposta, é exposta na equação (6), é um parâmetro com o potencial de mensurar a variabilidade das respostas, de modo que para fins do presente trabalho, busca-se uma resposta com o maior valor físico possível, com a menor variabilidade, representada pela maximização da razão sinal-ruído.

$S / N=-10 \times \log \left[\sum\left(1 / Y^{2}\right) / n\right]$

\subsection{A luz branca}

A luz branca é resultado da união de todos os componentes do espectro eletromagnético visível, conforme demonstrado na Figura 5 , no ítem 2.6.1. As equações (1) e (2) provam, então, que esse padrão de iluminação é constituído de fótons com energias variáveis, desde os menos energéticos, até os mais energéticos, ainda dentro do espectro eletromagnético visível.

\subsubsection{Teor de biomassa}

No que tange à variável de resposta "Produção de biomassa", em cultivos submetidos à luz branca, a média dos resultados, considerando todas as oito condições experimentais, realizadas em duplicatas, foi de 1001,25 mg/L, o que representa um ganho de $0,125 \%$ em relação ao proposto por Shen (2014). A Tabela 9 mostra os resultados, bem como a média e a razão sinal-ruído para cada condição experimental. 
Tabela 9 - Resultados de produção de biomassa referentes ao arranjo ortogonal $L_{8}$ de Taguchi, obtidos em cultivos submetidos à luz branca.

\begin{tabular}{|c|c|c|c|c|}
\hline Experimento & \multicolumn{2}{|c|}{ Produção de Biomassa (mg/L) } & Média & S/N \\
\hline 1 & 970 & 1340 & 1155 & 58,725 \\
\hline 2 & 1120 & 1210 & 1165 & 59,436 \\
\hline 3 & 1170 & 1430 & 1300 & 60,11 \\
\hline 4 & 770 & 750 & 760 & 55,891 \\
\hline 5 & 730 & 1020 & 875 & 56,276 \\
\hline 6 & 1010 & 990 & 1000 & 58,267 \\
\hline 7 & 870 & 960 & 915 & 57,296 \\
\hline 8 & 930 & 750 & 840 & 56,893 \\
\hline
\end{tabular}

Fonte: Próprio Autor

A Tabela 9 permite supor que a condição experimental condizente com 0 praticado no experimento 3 , isto é, iluminância de $26 \mathrm{klx}$, concentração de $\mathrm{NaH}_{2} \mathrm{PO}_{4} . \mathrm{H}_{2} \mathrm{O}$ de $15 \mathrm{mg} / \mathrm{L}$, concentração de $\mathrm{NaNO}_{3}$ de $45 \mathrm{mg} / \mathrm{L}$ e fotoperíodo de 8 ciclos diários de 2: 1 horas claro: escuro, conduz à maior produção de biomassa com menor variabilidade.

Entretanto, faz-se necessária a análise estatística completa para avaliação da significância dos fatores e das interações entre estes que se pretende estudar. As Figuras 23 e 24 ilustram os gráficos dos efeitos dos fatores no que diz respeito à média e a razão sinal-ruído, respectivamente. 
Figura 23 - Gráficos dos efeitos dos fatores no que diz respeito à média de biomassa, em cultivos submetidos à luz branca.

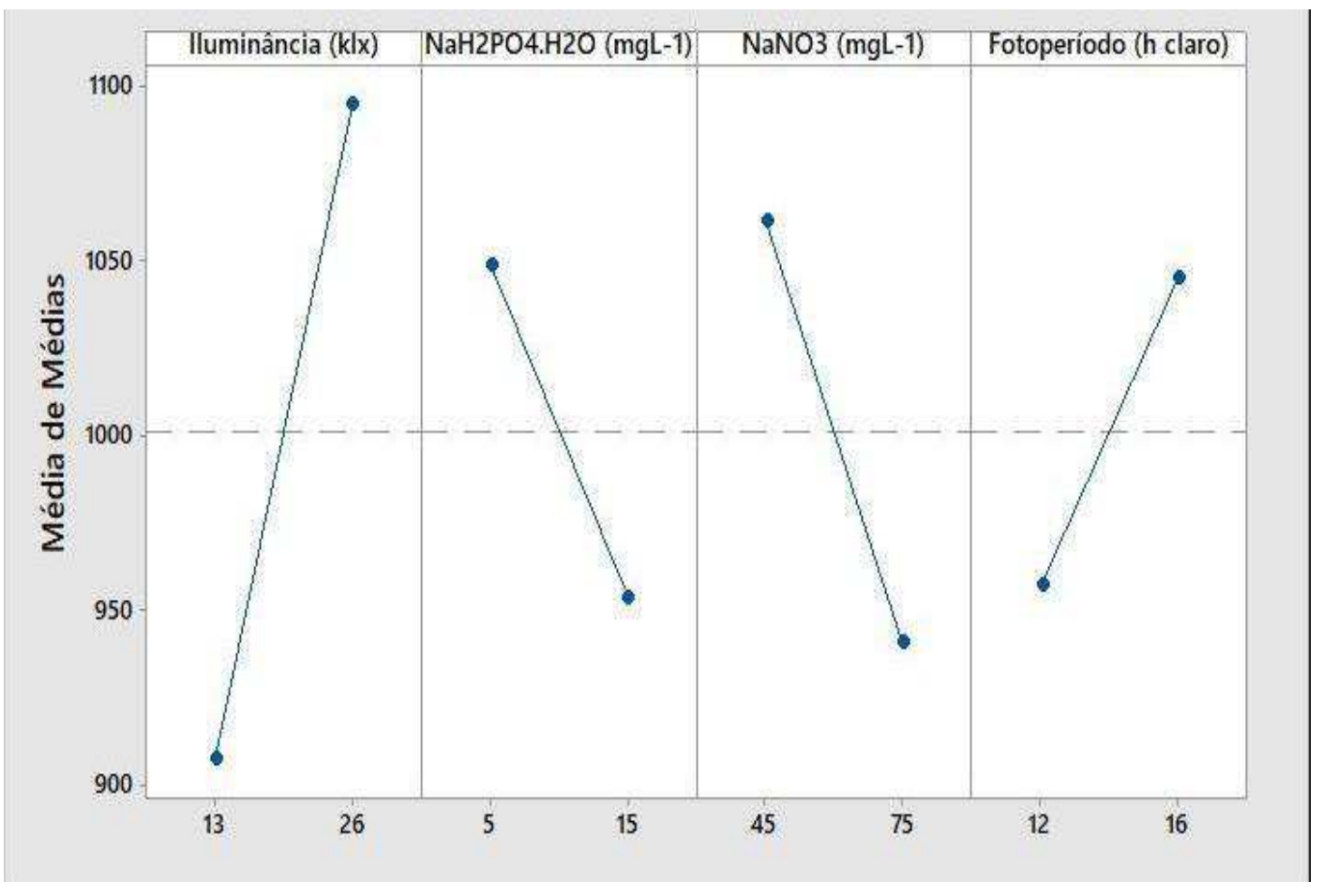

Fonte: Próprio Autor

Figura 24 - Gráficos dos efeitos dos fatores no que diz respeito à $S / N$ da produção de biomassa, em cultivos submetidos à luz branca.

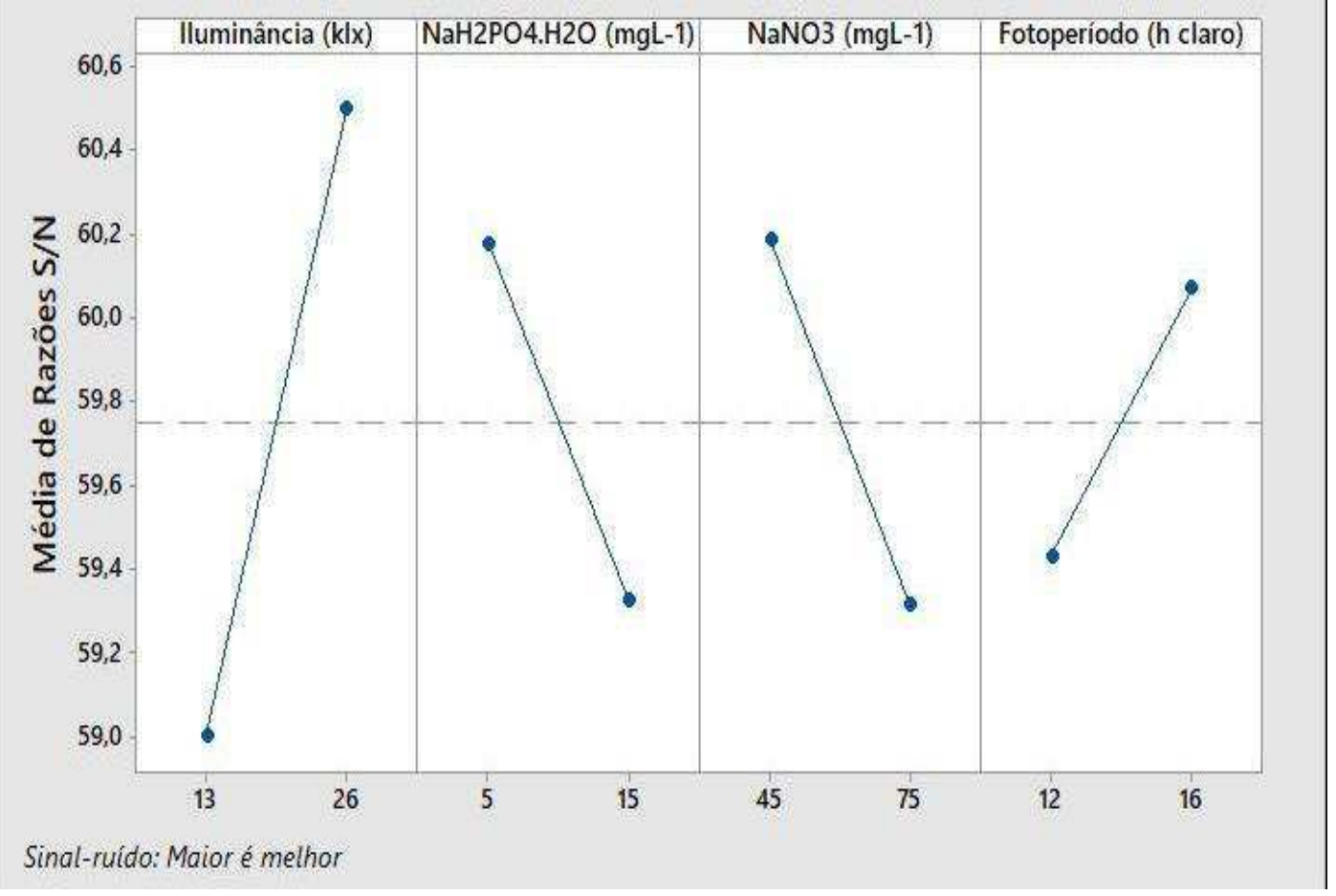

Fonte: Próprio Autor 
As Figuras 23 e 24 indicam que a iluminância deve ser o fator crítico do processo tanto para a produção de biomassa como para a variabilidade da resposta. As figuras também concordam que o ajuste dos fatores, conforme o realizado no experimento 3 , deve ser o melhor, exceto pela concentração de $\mathrm{NaH}_{2} \mathrm{PO}_{4} \cdot \mathrm{H}_{2} \mathrm{O}$ que deve ser de $5 \mathrm{mg} / \mathrm{L}$.

A análise, ainda pendente, das interações entre os fatores é crucial para a compreensão de um processo no qual os fatores operam em conjunto. As Figuras 25 a 27 apresentam o gráfico da interação entre a iluminância e os demais fatores no que diz respeito a média.

Figura 25 - Gráfico da interação entre a iluminância e a concentração de $\mathrm{NaH}_{2} \mathrm{PO}_{4} \cdot \mathrm{H}_{2} \mathrm{O}$, para a produção de biomassa, no que diz respeito à média em cultivos submetidos à luz branca.

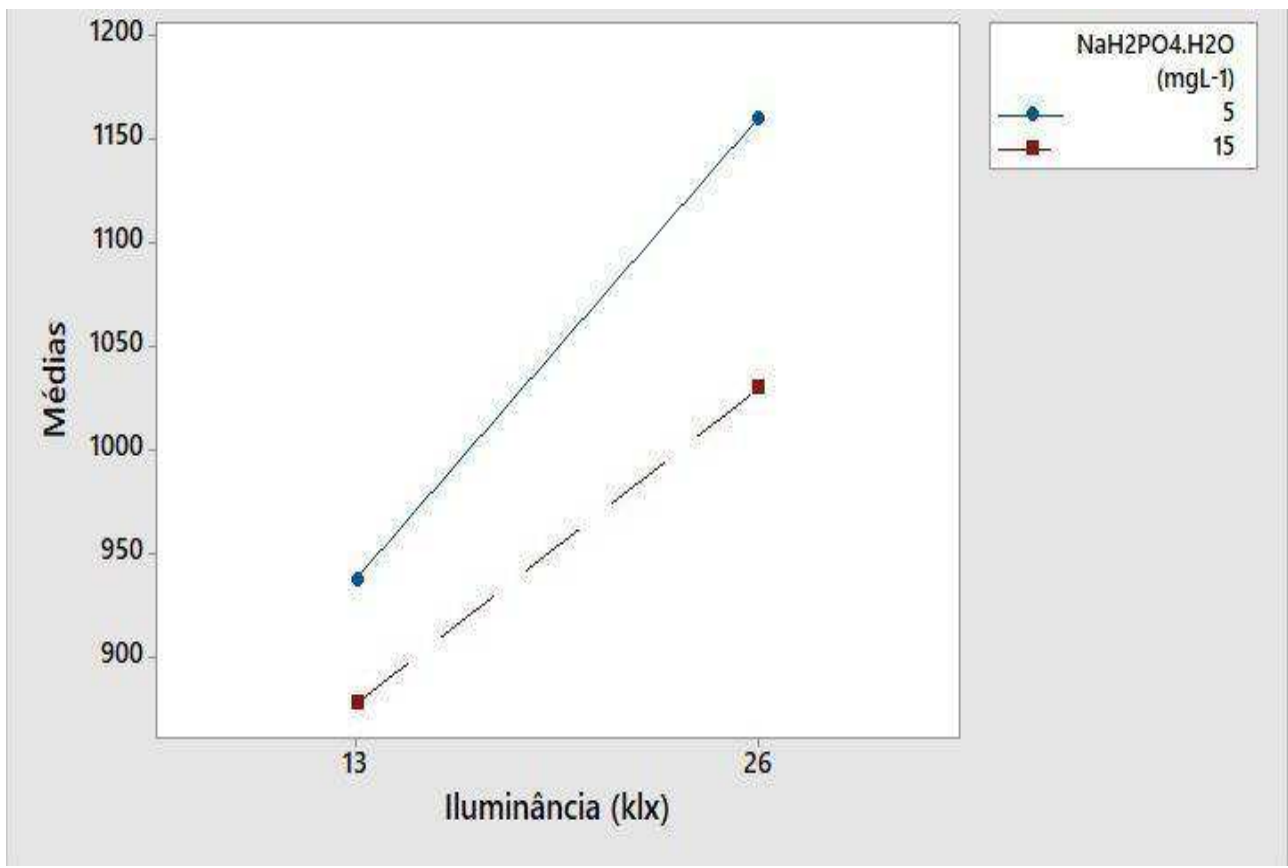

Fonte: Próprio Autor 
Figura 26 - Gráfico da interação entre a iluminância e a concentração de $\mathrm{NaNO}_{3}$, para a produção de biomassa no que diz respeito à média em cultivos submetidos à luz branca.

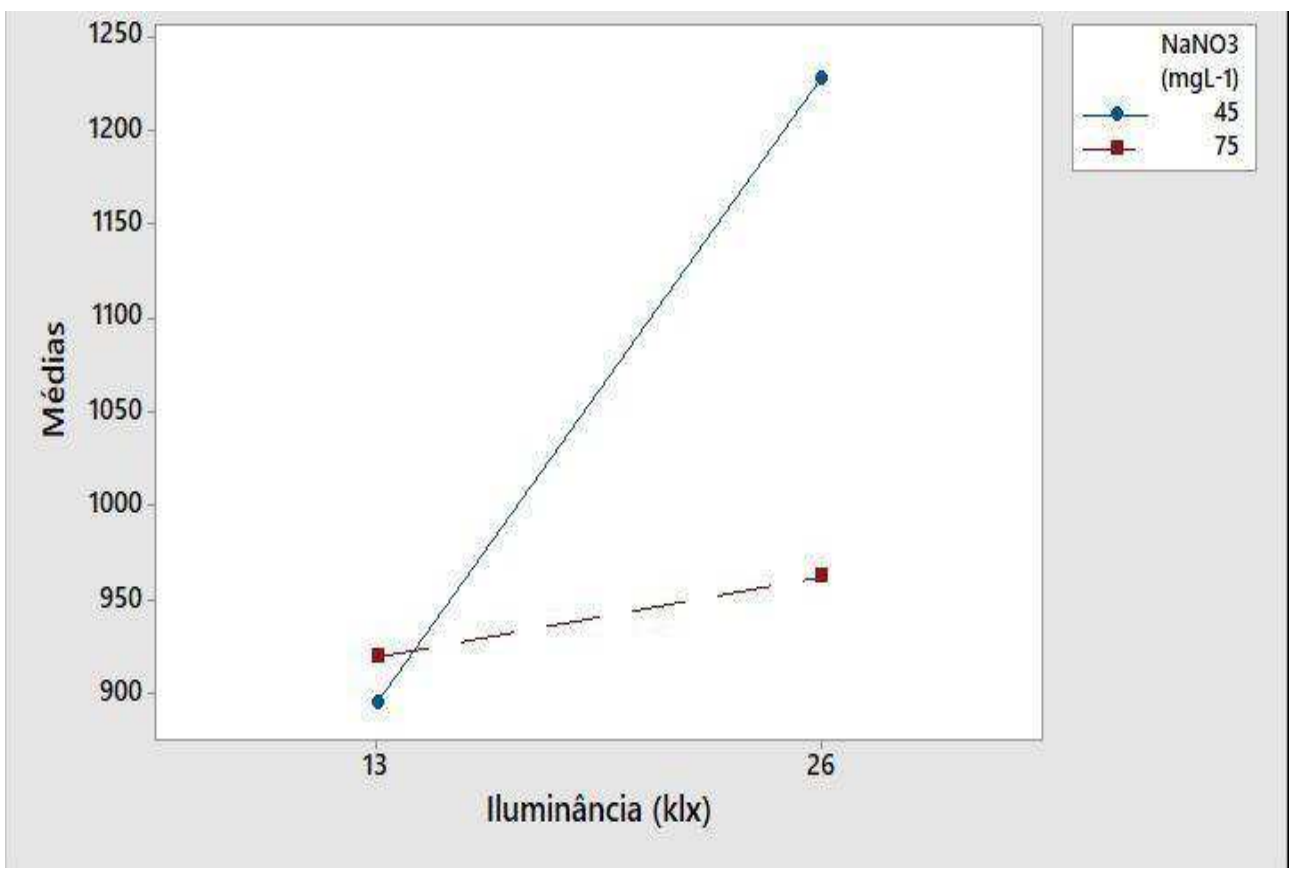

Fonte: Próprio Autor

Figura 27 - Gráfico da interação entre a iluminância e o fotoperíodo, para a produção de biomassa, no que diz respeito à média em cultivos submetidos à luz branca.

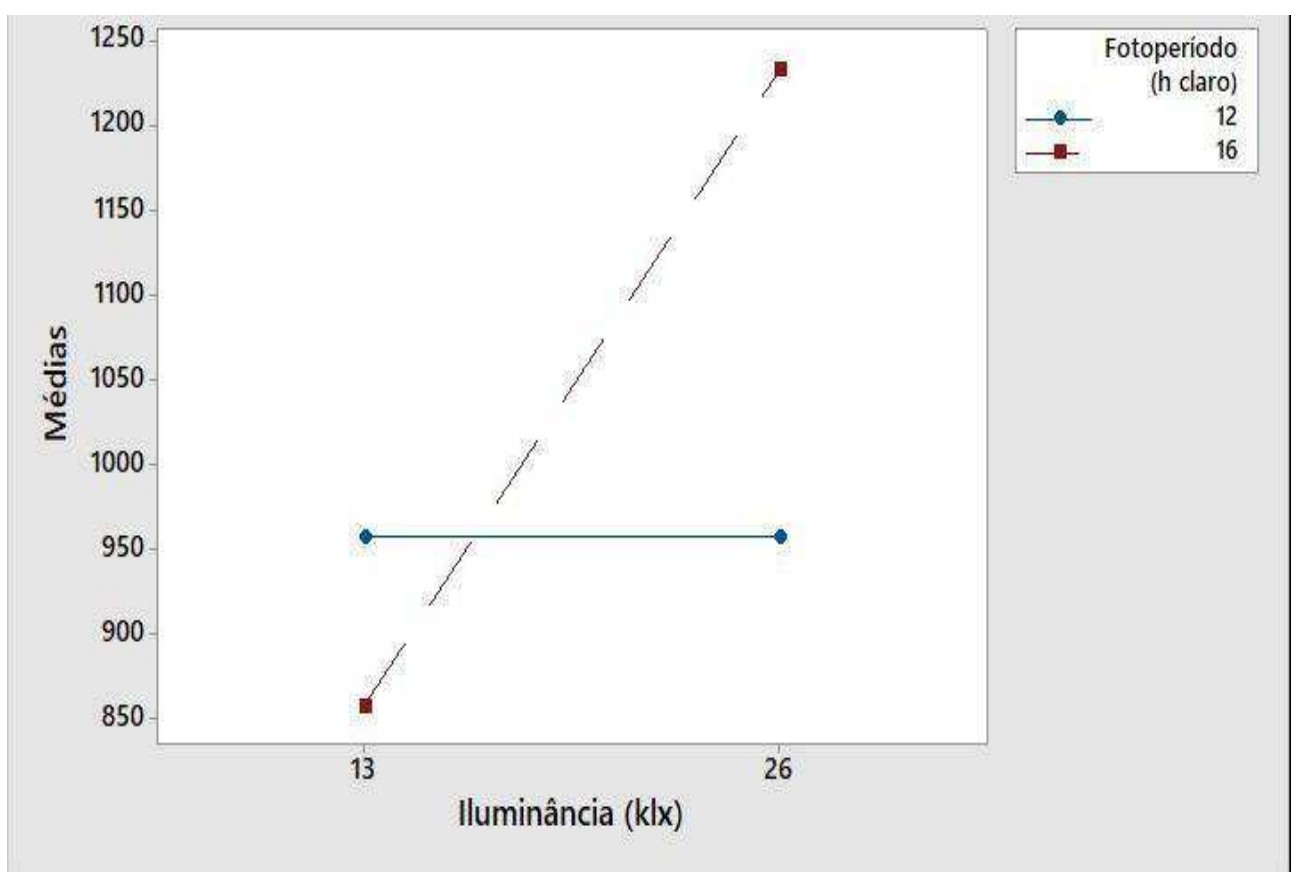

Fonte: Próprio Autor 
As Figuras 25, 26 e 27 demonstram que, para o intervalo de confiança de 95\%, não deve haver significância estatística para a interação entre a iluminância e a concentração de $\mathrm{NaH}_{2} \mathrm{PO}_{4} \cdot \mathrm{H}_{2} \mathrm{O}$.

Para as interações entre a iluminância e a concentração de $\mathrm{NaNO}_{3}$ e entre a iluminância e o fotoperíodo, apesar do indício de significância estatística, para o mesmo intervalo de confiança, não há dúvidas de que quando a iluminância é de $26 \mathrm{klx}$ a concentração de $\mathrm{NaNO}_{3}$ deve ser de $45 \mathrm{mg} / \mathrm{L}$ e o fotoperíodo de 8 ciclos diários de 2: 1 horas claro: escuro, visando a maior produção de biomassa, visto que a intersecção entre as retas nas Figuras 26 e 27, respectivamente, se dá no ponto em que a iluminância equivale a 14,12 klx e 16,41 klx.

As Figuras 28 a 30 permitem avaliar as interações entre os fatores no que diz respeito à razão sinal-ruído. A análise delas permite confirmar que as conclusões obtidas quanto ao ajuste ideal dos fatores, para a maior produção de biomassa, permanecem válidas para a redução da variabilidade.

Figura 28 - Gráfico da interação entre a iluminância e a concentração de $\mathrm{NaH}_{2} \mathrm{PO}_{4} \cdot \mathrm{H}_{2} \mathrm{O}$, para a produção de biomassa, no que diz respeito à $\mathrm{S} / \mathrm{N}$ em cultivos submetidos à luz branca.

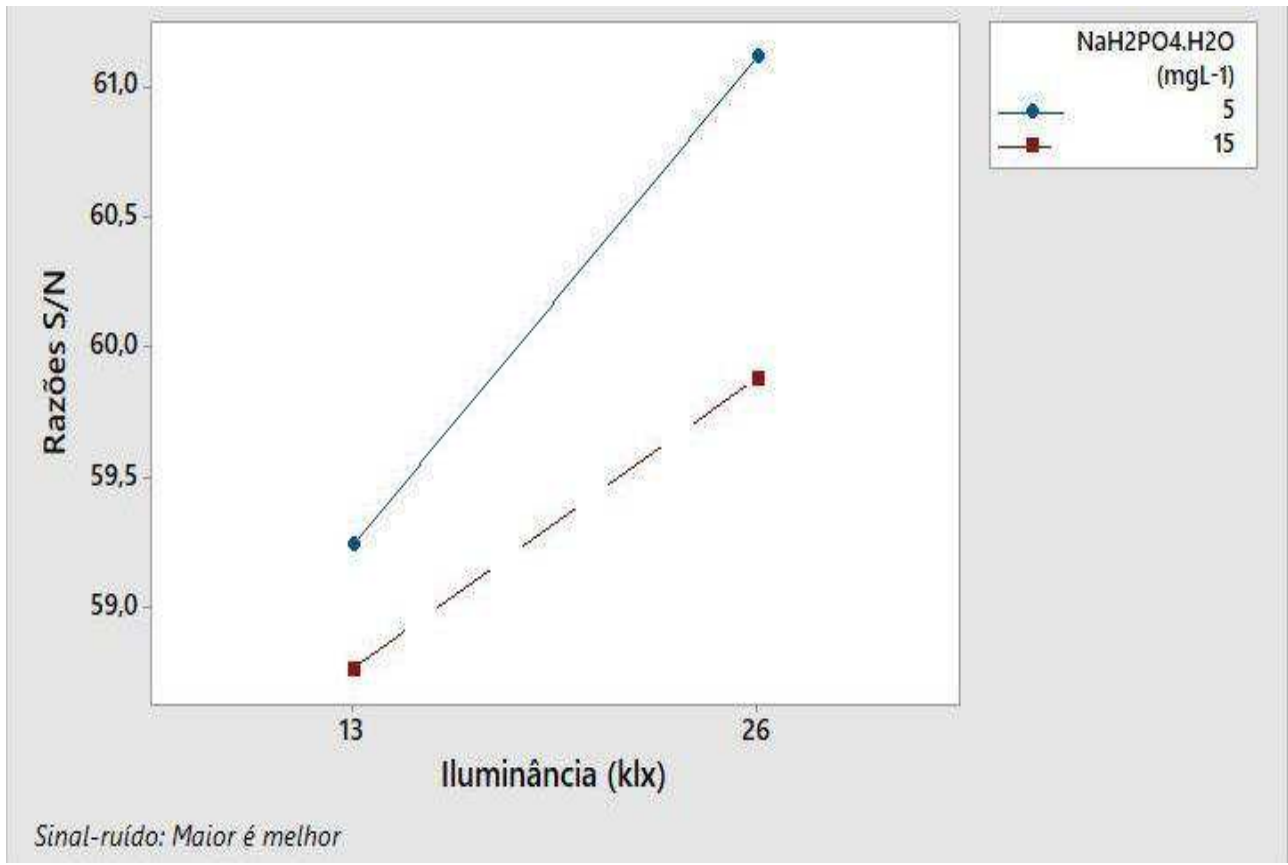

Fonte: Próprio Autor 
Figura 29 - Gráfico da interação entre a iluminância e a concentração de $\mathrm{NaNO}_{3}$, para a produção de biomassa, no que diz respeito à $\mathrm{S} / \mathrm{N}$ em cultivos submetidos à luz branca.

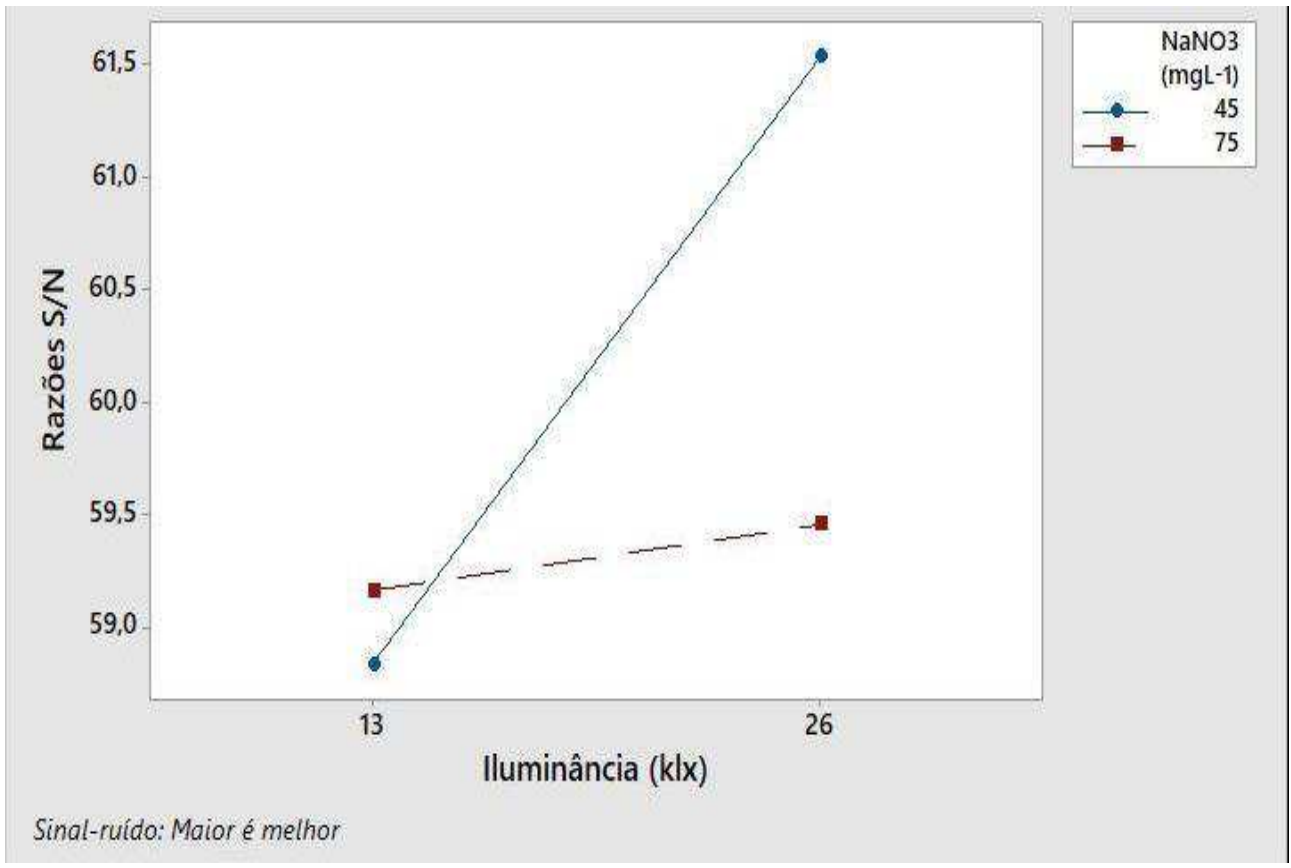

Fonte: Próprio Autor

Figura 30 - Gráfico da interação entre a iluminância e o fotoperíodo, para a produção de biomassa, no que diz respeito à $\mathrm{S} / \mathrm{N}$ em cultivos submetidos à luz branca.

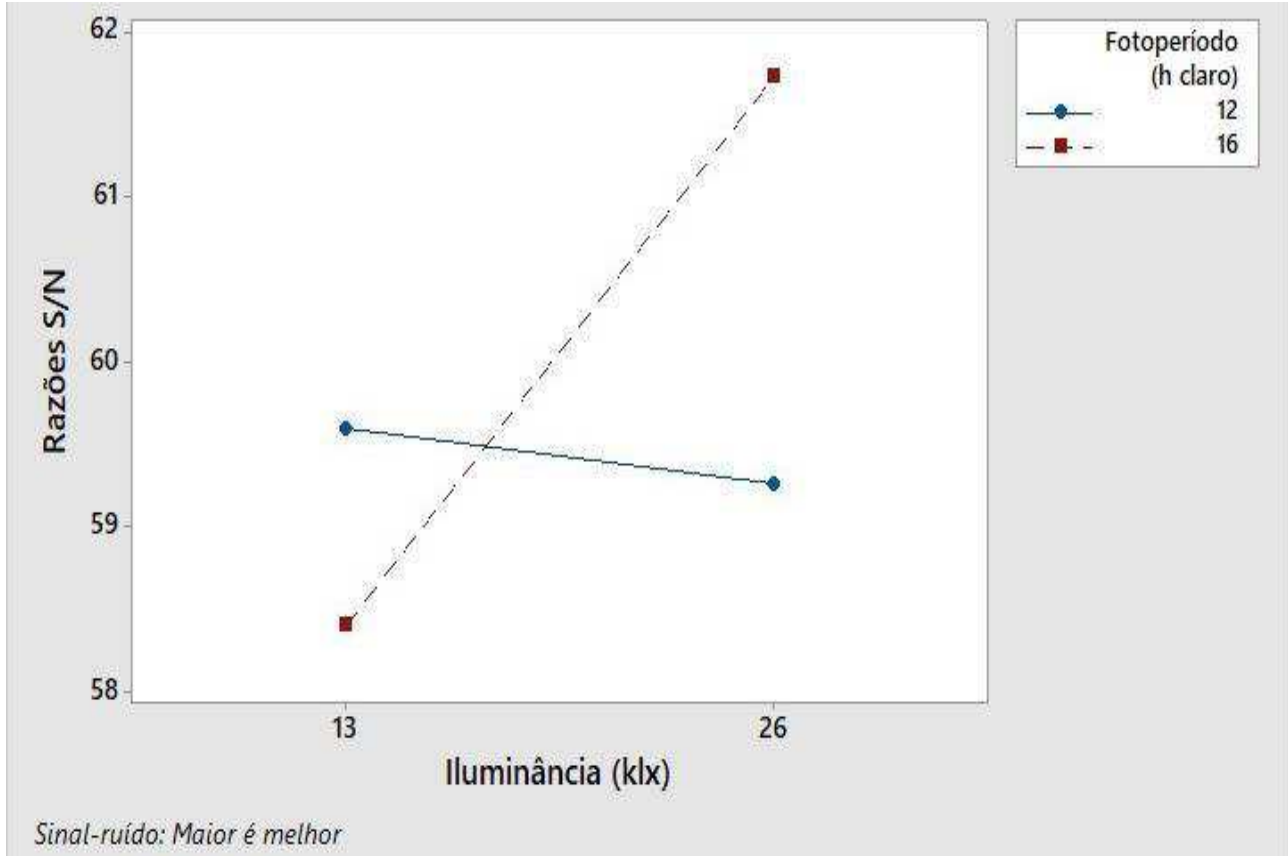

Fonte: Próprio Autor 
As Tabelas 10 e 11 apresentam a análise de variância (ANOVA) com respeito à média e à razão sinal-ruído, respectivamente. Ambas comprovam que a ilumiância e sua interação com o fotoperíodo são os únicos parâmetros que apresentam significância estatística, observado o intervalo de confiança de 95\%.

Tabela 10 - Análise de variância, para a produção de biomassa, com respeito à média em cultivos submetidos à luz branca.

\begin{tabular}{|c|c|c|c|c|c|}
\hline \multicolumn{7}{|c|}{ ANÁLISE DE VARIÂNCIA } \\
\hline Média $=\mathbf{1 0 0 1 , 2 5}$ & $\mathbf{S Q}$ & $\mathbf{g l}$ & $\mathbf{S Q M}$ & $\mathbf{F}$ & $\mathbf{p}$ \\
\hline Efeito & 140625,00000 & 1 & 140625,00000 & 6,656805 & 0,032612 \\
\hline Iluminância & 36100,00000 & 1 & 36100,00000 & 1,708876 & 0,227450 \\
\hline $\mathrm{NaH}_{2} \mathrm{PO}_{4} \cdot \mathrm{H}_{2} \mathrm{O}$ & 4900,00000 & 1 & 4900,00000 & 0,231953 & 0,642978 \\
\hline Iluminância - Fosfato & 57600,00000 & 1 & 57600,00000 & 2,726627 & 0,137293 \\
\hline $\mathrm{NaNO}_{3}$ & 84100,00000 & 1 & 84100,00000 & 3,981065 & 0,081110 \\
\hline Iluminância - Nitrato & 140625,00000 & 1 & 140625,00000 & 6,656805 & 0,032612 \\
\hline Iluminância - Fotoperíodo & 30625,00000 & 1 & 30625,00000 & 1,449704 & 0,262988 \\
\hline Fotoperíodo & 169000,00000 & 8 & 21125,00000 & & \\
\hline Resíduo & & & &
\end{tabular}

Fonte: Próprio Autor

Tabela 11 - Análise de variância, para a produção de biomassa, com respeito à $\mathrm{S} / \mathrm{N}$ em cultivos submetidos à luz branca.

\begin{tabular}{|c|c|c|c|c|c|}
\hline \multicolumn{7}{|c|}{ ANÁLISE DE VARIÂNCIA } \\
\hline Média $=\mathbf{5 9 , 8 3 5 2}$ & $\mathbf{S Q}$ & $\mathbf{g l}$ & $\mathbf{S Q M}$ & $\mathbf{F}$ & $\mathbf{p}$ \\
\hline Efeito & 8,81317 & 1 & 8,81317 & 5,847938 & 0,041964 \\
\hline \|luminância & 3,37367 & 1 & 3,37367 & 2,238583 & 0,172972 \\
\hline $\mathrm{NaH}_{2} \mathrm{PO}_{4} \cdot \mathrm{H}_{2} \mathrm{O}$ & 0,59491 & 1 & 0,59491 & 0,394752 & 0,547326 \\
\hline Iluminância - Fosfato & 3,88200 & 1 & 3,88200 & 2,575884 & 0,147171 \\
\hline $\mathrm{NaNO}_{3}$ & 6,09177 & 1 & 6,09177 & 4,042169 & 0,079215 \\
\hline Iluminância - Nitrato & 11,77782 & 1 & 11,77782 & 7,815122 & 0,023357 \\
\hline Iluminância - Fotoperíodo & 1,87439 & 1 & 1,87439 & 1,243745 & 0,297128 \\
\hline Fotoperíodo & 12,05644 & 8 & 1,50706 & & \\
\hline Resíduo & & & &
\end{tabular}

Fonte: Próprio Autor

\subsubsection{Teor lipídico}

No que diz respeito à variável de resposta "Teor lipídico", em cultivos submetidos à luz branca, a média dos resultados, considerando todas as oito condições experimentais, realizadas em duplicata, foi de $16,05 \%$, o que está de acordo com 
os dados da Tabela 4, apresentada no item 2.5. A Tabela 12 mostra os resultados, bem como a média e a razão sinal-ruído para cada condição experimental.

Tabela 12 - Resultados de teor lipídico referentes ao arranjo ortogonal $L_{8}$ de Taguchi, obtidos em cultivos submetidos à luz branca

\begin{tabular}{|c|c|c|c|c|}
\hline Experimento & \multicolumn{2}{|c|}{ Teor Lipídico } & Média & S/N \\
\hline 1 & 0,2397 & 0,2152 & 0,2275 & $-14,503$ \\
\hline 2 & 0,1695 & 0,1921 & 0,1808 & $-16,844$ \\
\hline 3 & 0,1801 & 0,1899 & 0,185 & $-16,503$ \\
\hline 4 & 0,1791 & 0,2056 & 0,1924 & $-16,335$ \\
\hline 5 & 0,1458 & 0,1639 & 0,1549 & $-18,173$ \\
\hline 6 & 0,0575 & 0,0807 & 0,0691 & $-25,789$ \\
\hline 7 & 0,1761 & 0,1348 & 0,1555 & $-17,764$ \\
\hline 8 & 0,1177 & 0,1198 & 0,1188 & $-20,295$ \\
\hline
\end{tabular}

Fonte: Próprio Autor

Pela Tabela 12 é possível supor que a condição experimental condizente com o praticado no experimento 1 , isto é, iluminância de $26 \mathrm{klx}$, concentração de $\mathrm{NaH}_{2} \mathrm{PO}_{4} \cdot \mathrm{H}_{2} \mathrm{O}$ de $5 \mathrm{mg} / \mathrm{L}$, concentração de $\mathrm{NaNO}_{3}$ de $45 \mathrm{mg} / \mathrm{L}$ e fotoperíodo de 12: 12 horas claro: escuro, conduz ao maior teor lipídico com menor variabilidade.

Entretanto, faz-se necessária a análise estatística completa para avaliação da significância dos fatores e das interações entre eles que se pretende estudar. As Figuras 31 e 32 ilustram os gráficos dos efeitos dos fatores no que diz respeito à média e a razão sinal-ruído, respectivamente. 
Figura 31 - Gráficos dos efeitos dos fatores no que diz respeito à média do teor lipídico em cultivos submetidos à luz branca.

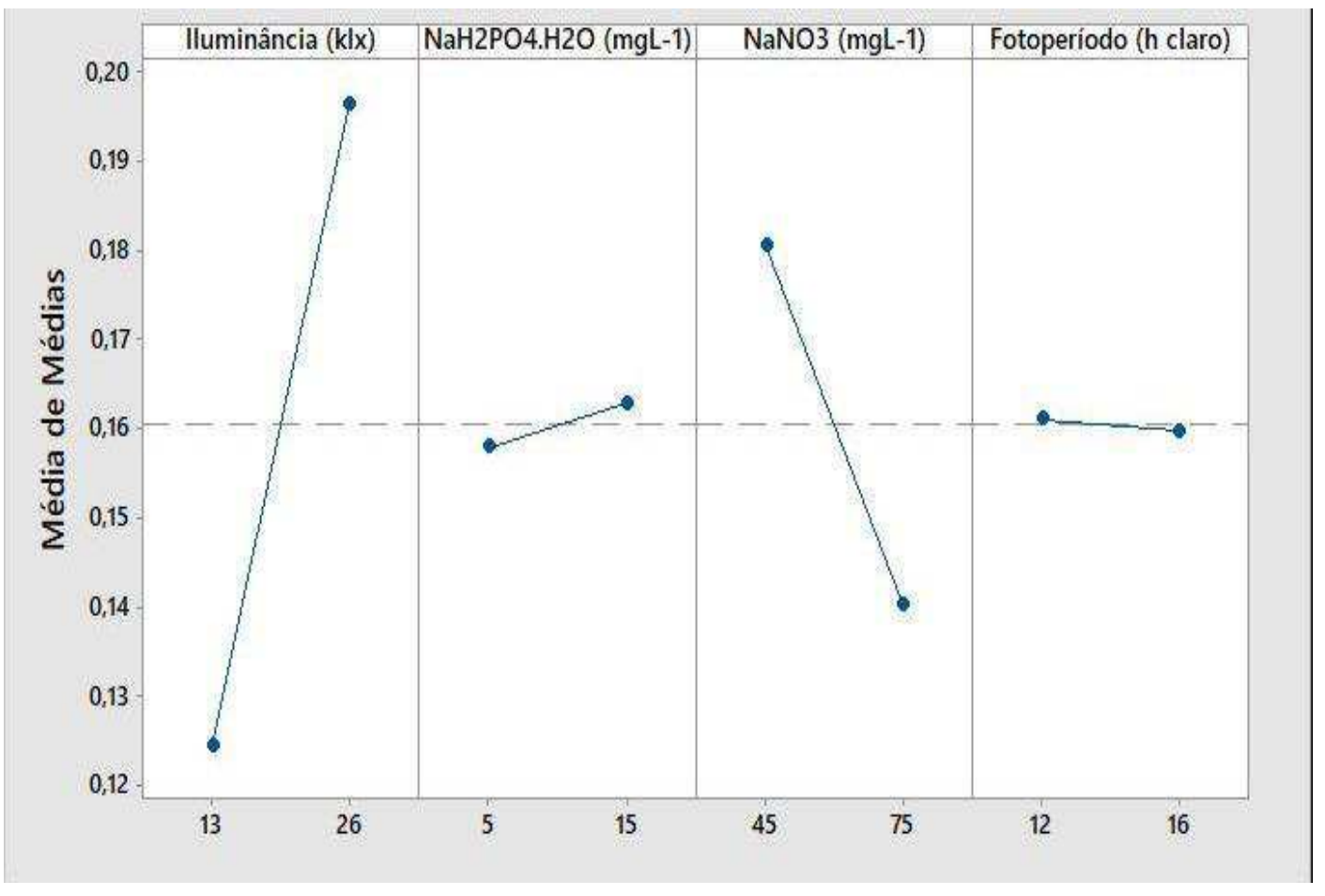

Fonte: Próprio Autor

Figura 32 - Gráficos dos efeitos dos fatores no que diz respeito à $S / N$ do teor lipídico, em cultivos submetidos à luz branca.

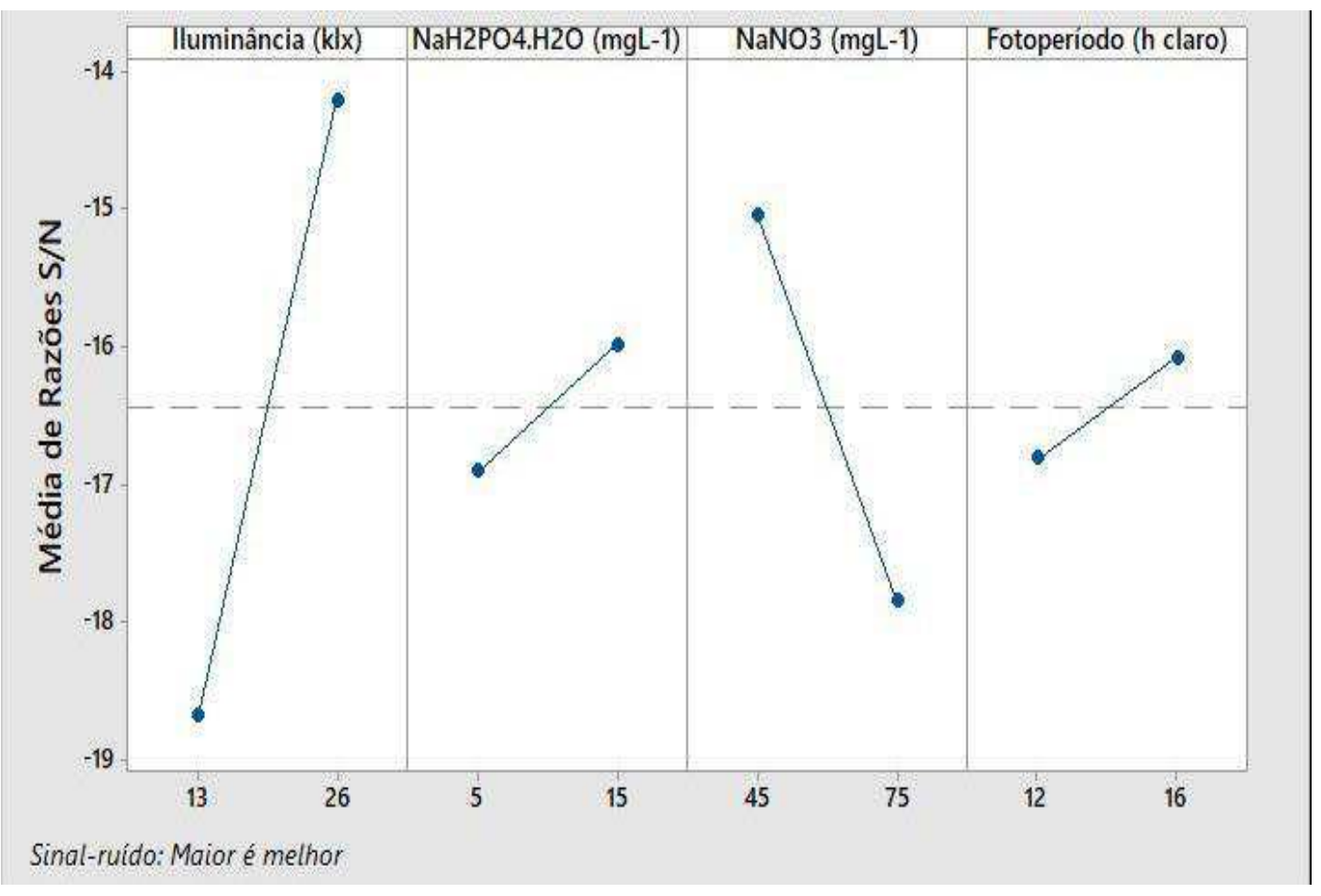

Fonte: Próprio Autor 
As Figuras 31 e 32 indicam que a iluminância e a concentração de $\mathrm{NaNO}_{3}$ devem ser os fatores críticos do processo tanto para o teor lipídico como para a variabilidade da resposta. As figuras também concordam que o ajuste dos fatores, conforme o realizado no experimento 1 , deve ser o melhor, exceto pela concentração de $\mathrm{NaH}_{2} \mathrm{PO}_{4} . \mathrm{H}_{2} \mathrm{O}$ que deve ser de $15 \mathrm{mg} / \mathrm{L} \mathrm{e}$, no que diz respeito à $\mathrm{S} / \mathrm{N}$, pelo fotoperíodo que deve ser de 8 ciclos diários de 2: 1 horas claro: escuro.

A análise das interações entre os fatores é crucial para a compreensão de um processo no qual os fatores operam em conjunto. As Figuras 33 a 35, demonstram o gráfico da interação entre a iluminância e os demais fatores no que diz respeito a média.

Figura 33 - Gráfico da interação entre a iluminância e a concentração de $\mathrm{NaH}_{2} \mathrm{PO}_{4} \cdot \mathrm{H}_{2} \mathrm{O}$, para o teor lipídico, no que diz respeito à média em cultivos submetidos à luz branca.

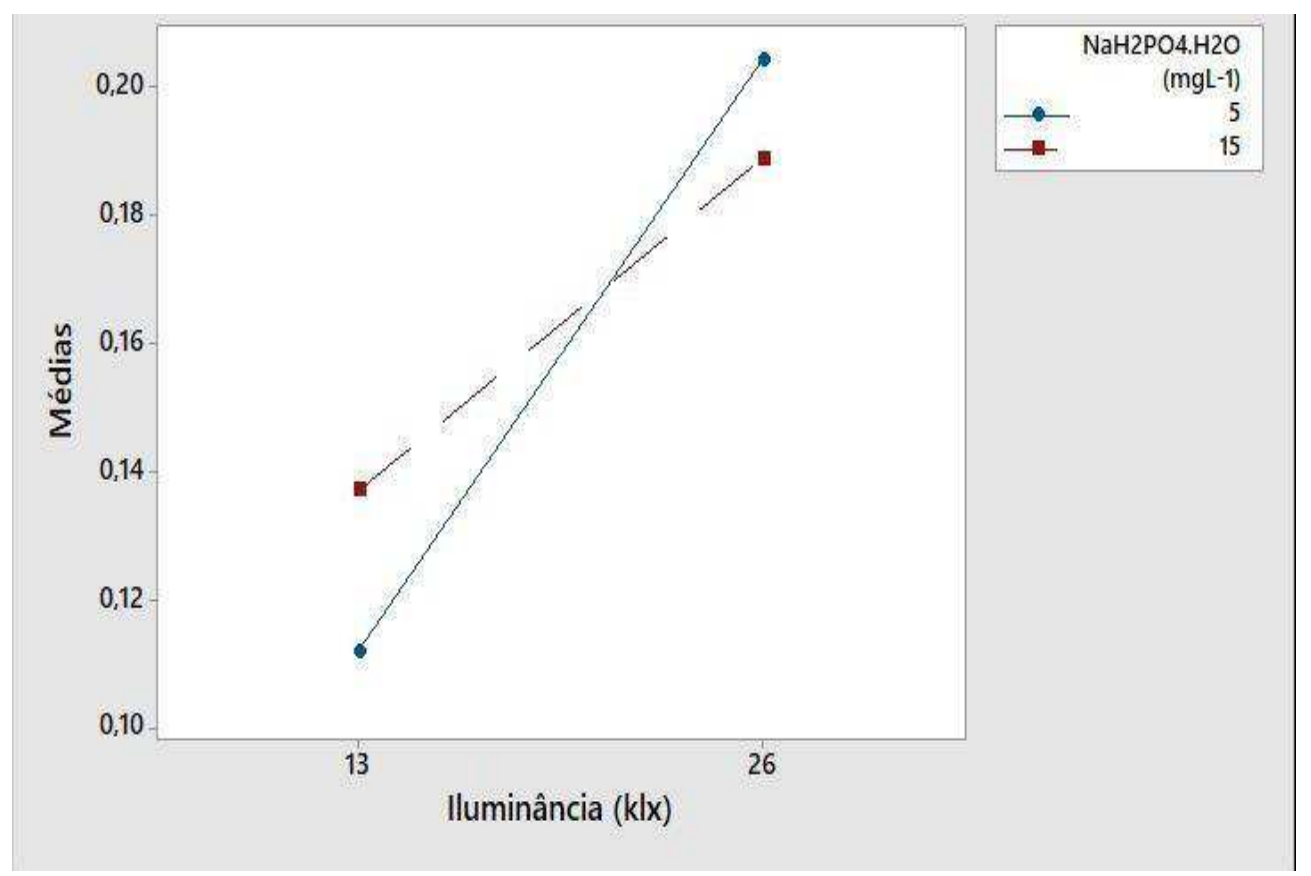

Fonte: Próprio Autor 
Figura 34 - Gráfico da interação entre a iluminância e a concentração de $\mathrm{NaNO}_{3}$, para o teor lipídico, no que diz respeito à média em cultivos submetidos à luz branca.

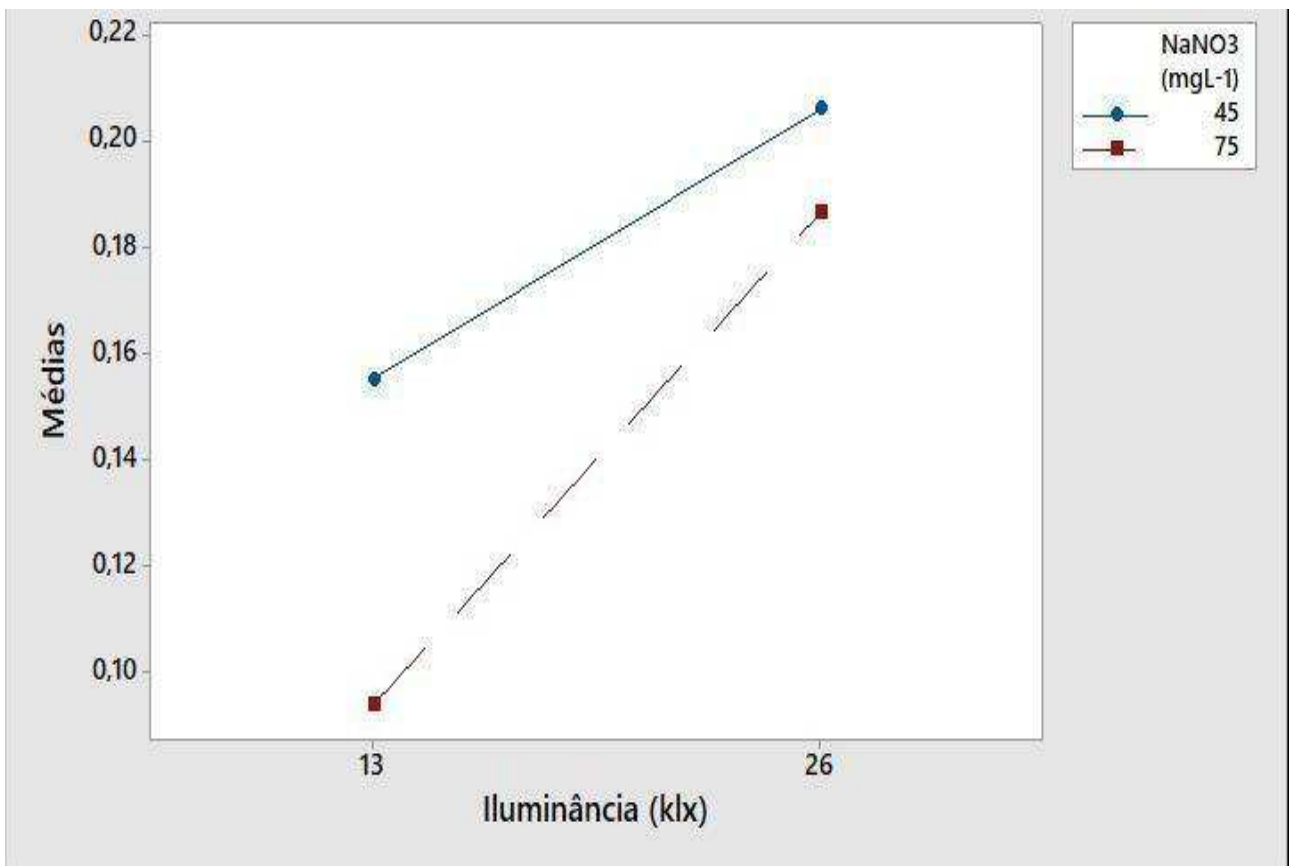

Fonte: Próprio Autor

Figura 35 - Gráfico da interação entre a iluminância e o fotoperíodo, para o teor lipídico, no que diz respeito à média em cultivos submetidos à luz branca.

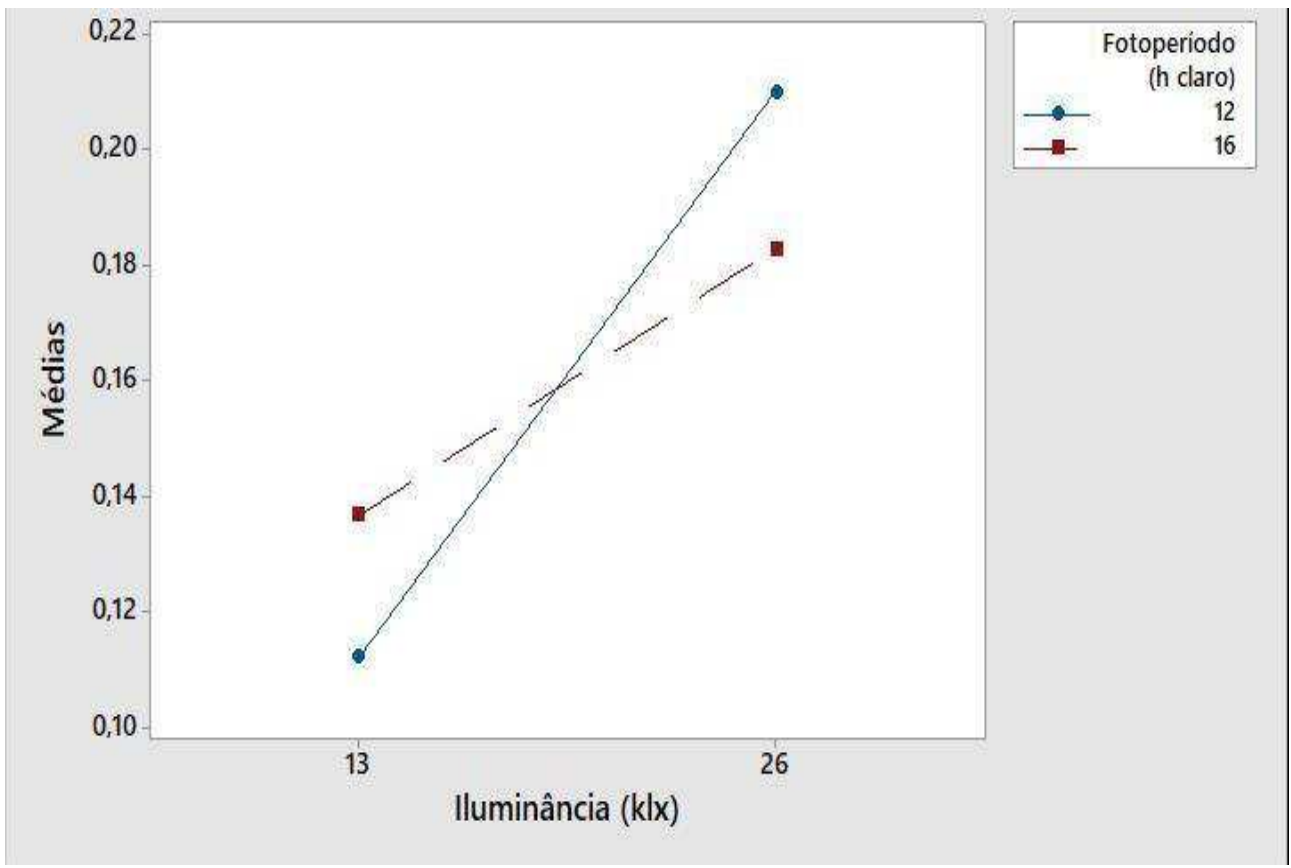

Fonte: Próprio Autor 
As Figuras 33, 34 e 35 demonstram que, para o intervalo de confiança de 95\%, não deve haver significância estatística para a interação entre a iluminância e a concentração de $\mathrm{NaNO}_{3}$.

Para as interações entre a iluminância e a concentração de $\mathrm{NaH}_{2} \mathrm{PO}_{4} \cdot \mathrm{H}_{2} \mathrm{O}$ e entre a iluminância e o fotoperíodo, apesar do indício de significância estatística, para o mesmo intervalo de confiança, não há dúvidas de que quando a iluminância é de $26 \mathrm{klx}$ a concentração de $\mathrm{NaH}_{2} \mathrm{PO}_{4} \cdot \mathrm{H}_{2} \mathrm{O}$ deve ser de $5 \mathrm{mg} / \mathrm{L}$ e o fotoperíodo de 12: 12 horas claro: escuro, visando o maior teor lipídico, visto que a intersecção entre as retas das figuras 33 e 35, respectivamente, se dá no ponto em que a iluminância equivale a 19,32 klx e 19,19 klx..

Pelas Figuras 36 a 38 é possível avaliar as interações entre os fatores no que diz respeito à razão sinal-ruído. A análise delas, permite confirmar que as conclusões obtidas quanto ao ajuste ideal dos fatores, para o maior teor lipídico, permanecem válidas para a redução da variabilidade.

Figura 36 - Gráfico da interação entre a iluminância e a concentração de $\mathrm{NaH}_{2} \mathrm{PO}_{4} \cdot \mathrm{H}_{2} \mathrm{O}$, para o teor lipídico, no que diz respeito à $\mathrm{S} / \mathrm{N}$ em cultivos submetidos à luz branca.

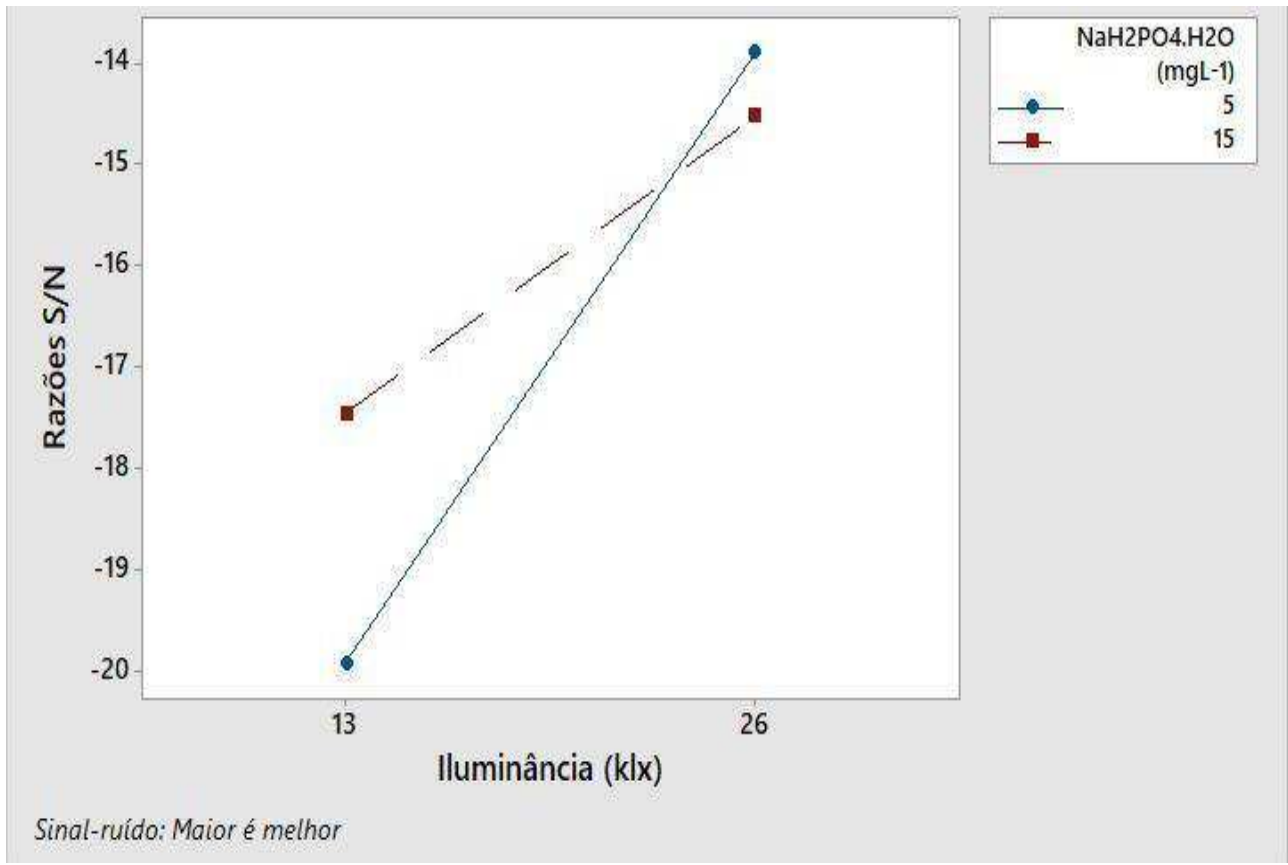

Fonte: Próprio Autor 
Figura 37 - Gráfico da interação entre a iluminância e a concentração de $\mathrm{NaNO}_{3}$, para o teor lipídico, no que diz respeito à $\mathrm{S} / \mathrm{N}$ em cultivos submetidos à luz branca.

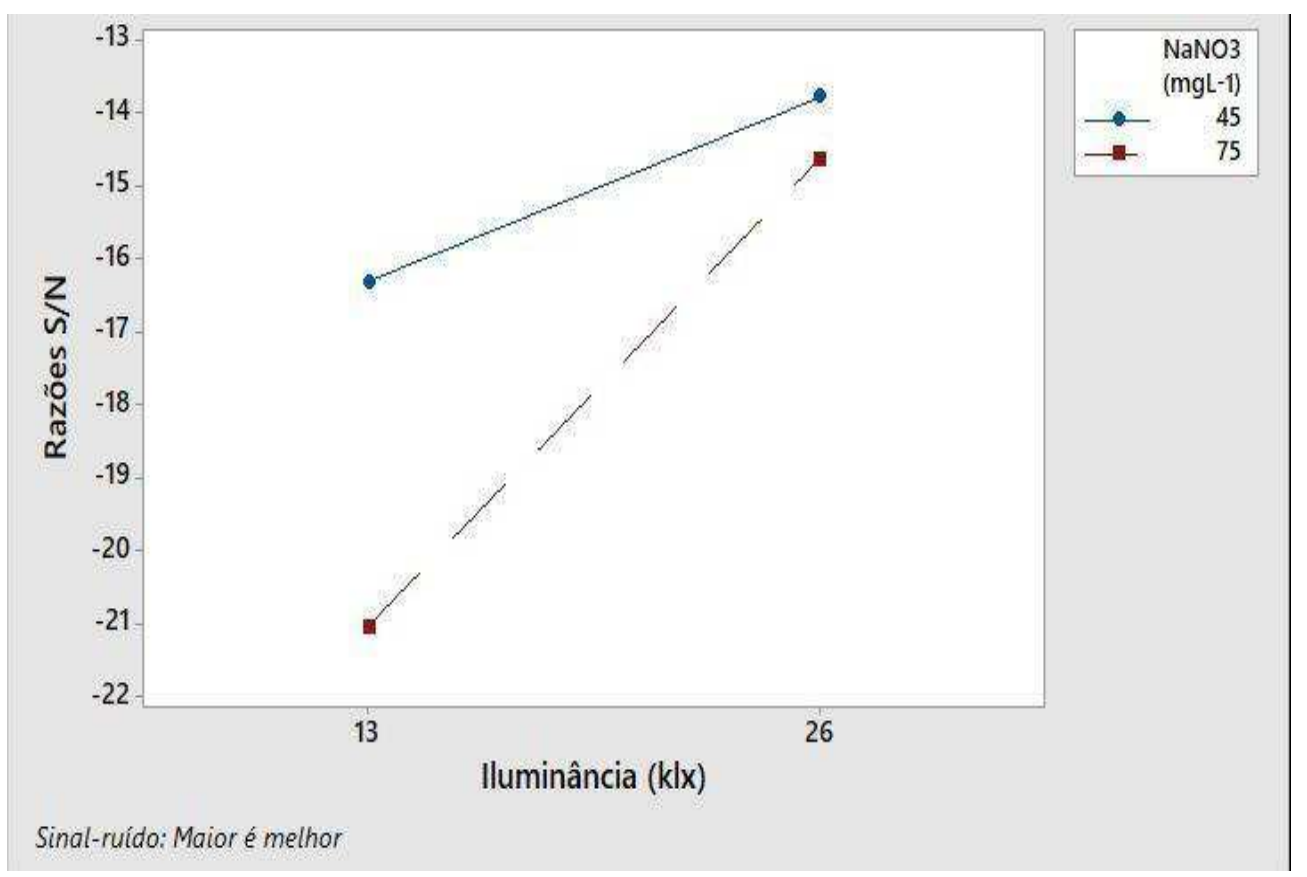

Fonte: Próprio Autor

Figura 38 - Gráfico da interação entre a iluminância e o fotoperíodo, para o teor lipídico, no que diz respeito à $\mathrm{S} / \mathrm{N}$ em cultivos submetidos à luz branca.

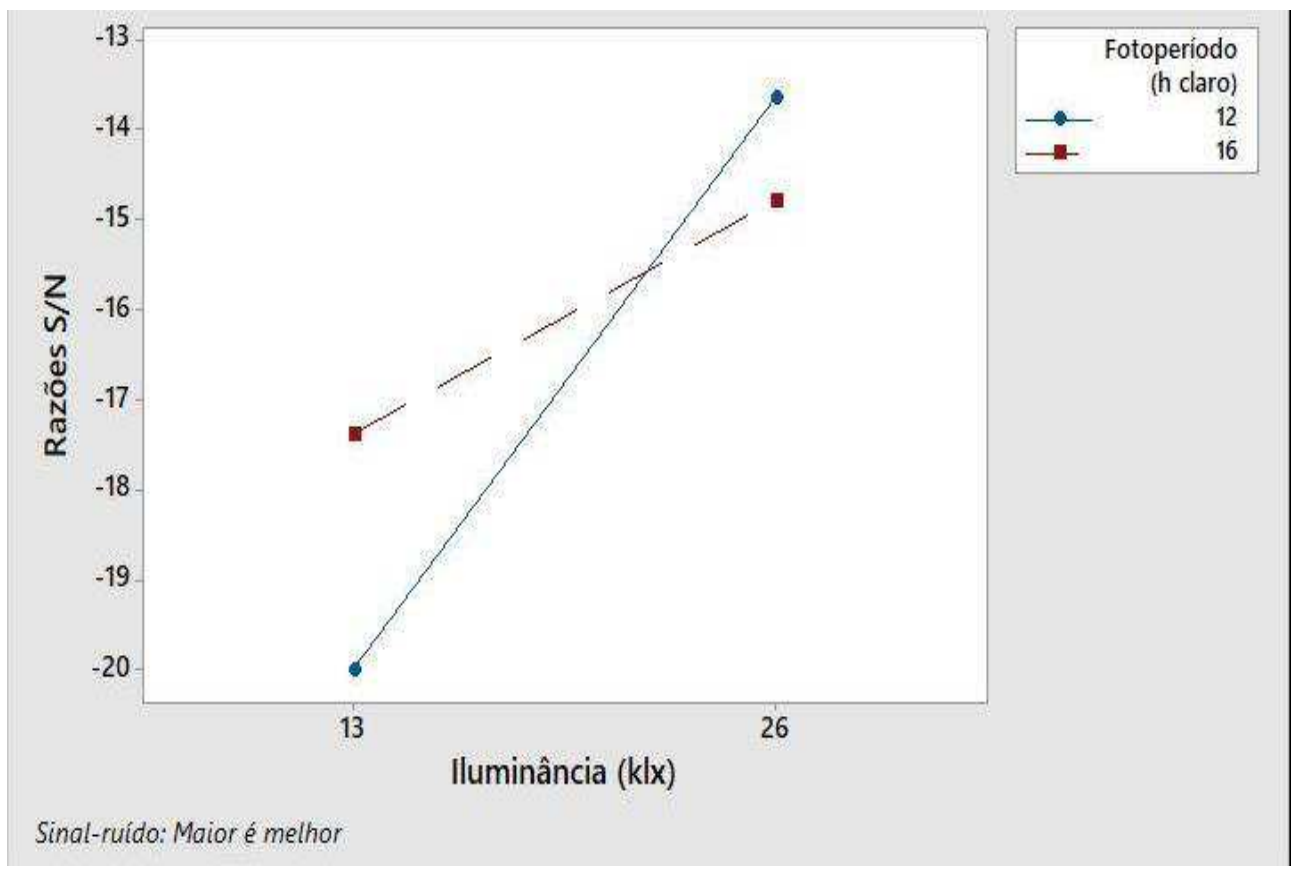

Fonte: Próprio Autor 
As Tabelas 13 e 14 apresentam a análise de variância (ANOVA) com respeito à média e à razão sinal-ruído, respectivamente. Ambas comprovam que a ilumiância e a concentração de $\mathrm{NaNO}_{3}$ são os fatores críticos do processo. Destaque para a significância estatística entre a iluminância e todos os demais fatores, contrariando a intuição da análise gráfica, que parecia não indicar significância estatística entre a iluminância e a concentração de $\mathrm{NaNO}_{3}$. Todas as conclusões são válidas para o intervalo de confiança de 95\%.

Tabela 13 - Análise de variância, para o teor lipídico, com respeito à média em cultivos submetidos à luz branca.

\begin{tabular}{|c|c|c|c|c|c|}
\hline \multicolumn{7}{|c|}{ ANÁLISE DE VARIÂNCIA } \\
\hline Média $=\mathbf{0 , 1 6 0 4 6 9}$ \\
\hline Efeito & $\mathbf{S Q}$ & $\mathbf{g l}$ & $\mathbf{S Q M}$ & $\mathbf{F}$ & $\mathbf{p}$ \\
\hline Iluminância & 0,020657 & 1 & 0,020657 & 73,68820 & 0,000026 \\
\hline $\mathrm{NaH}_{2} \mathrm{PO}_{4} \cdot \mathrm{H}_{2} \mathrm{O}$ & 0,000094 & 1 & 0,000094 & 0,33391 & 0,579260 \\
\hline Iluminância - Fosfato & 0,001646 & 1 & 0,001646 & 5,87287 & 0,041629 \\
\hline $\mathrm{NaNO}_{3}$ & 0,006541 & 1 & 0,006541 & 23,33253 & 0,001304 \\
\hline Iluminância - Nitrato & 0,001728 & 1 & 0,001728 & 6,16592 & 0,037926 \\
\hline Iluminância - Fotoperíodo & 0,002655 & 1 & 0,002655 & 9,47042 & 0,015177 \\
\hline Fotoperíodo & 0,000006 & 1 & 0,000006 & 0,02185 & 0,886140 \\
\hline Resíduo & 0,002243 & 8 & 0,000280 & & \\
\hline
\end{tabular}

Fonte: Próprio Autor

Tabela 14 - Análise de variância, para o teor lipídico, com respeito à $S / N$ em cultivos submetidos à luz branca.

\begin{tabular}{|c|c|c|c|c|c|}
\hline \multicolumn{7}{|c|}{ ANÁLISE DE VARIÂNCIA } \\
\hline Média = -16,381 & $\mathbf{S Q}$ & $\mathbf{g l}$ & $\mathbf{S Q M}$ & $\mathbf{F}$ & $\mathbf{p}$ \\
\hline Efeito & 77,07122 & 1 & 77,07122 & 65,52049 & 0,000040 \\
\hline Iluminância & 3,14627 & 1 & 3,14627 & 2,67474 & 0,140591 \\
\hline $\mathrm{NaH}_{2} \mathrm{PO}_{4} \cdot \mathrm{H}_{2} \mathrm{O}$ & 9,14623 & 1 & 9,14623 & 7,77548 & 0,023615 \\
\hline Iluminância - Fosfato & 30,56676 & 1 & 30,56676 & 25,98569 & 0,000933 \\
\hline $\mathrm{NaNO}_{3}$ & 14,83320 & 1 & 14,83320 & 12,61014 & 0,007498 \\
\hline Iluminância - Nitrato & 12,86917 & 1 & 12,86917 & 10,94045 & 0,010736 \\
\hline Iluminância - Fotoperíodo & 1,60891 & 1 & 1,60891 & 1,36778 & 0,275855 \\
\hline Fotoperíodo & 9,41034 & 8 & 1,17629 & & \\
\hline Resíduo & & & &
\end{tabular}

Fonte: Próprio Autor 


\subsubsection{Ajuste de múltiplas respostas}

Por meio da função Desirability, é possível a conjugação de um ajuste que maximize, simultaneamente, ambas as variáveis de resposta, mesmo em situações em que, individualmente, os ajustes ideais dos fatores que as maximizem sejam conflitantes. A Figura 39 traz o gráfico de otimização com os valores de desejabilidade individuais $\left(\mathrm{d}_{\mathrm{i}}\right)$ de ambas as variáveis de resposta e de desejabilidade global (D).

Figura 39 - Gráfico de otimização simultânea das variáveis de resposta, em cultivos submetidos à luz branca.

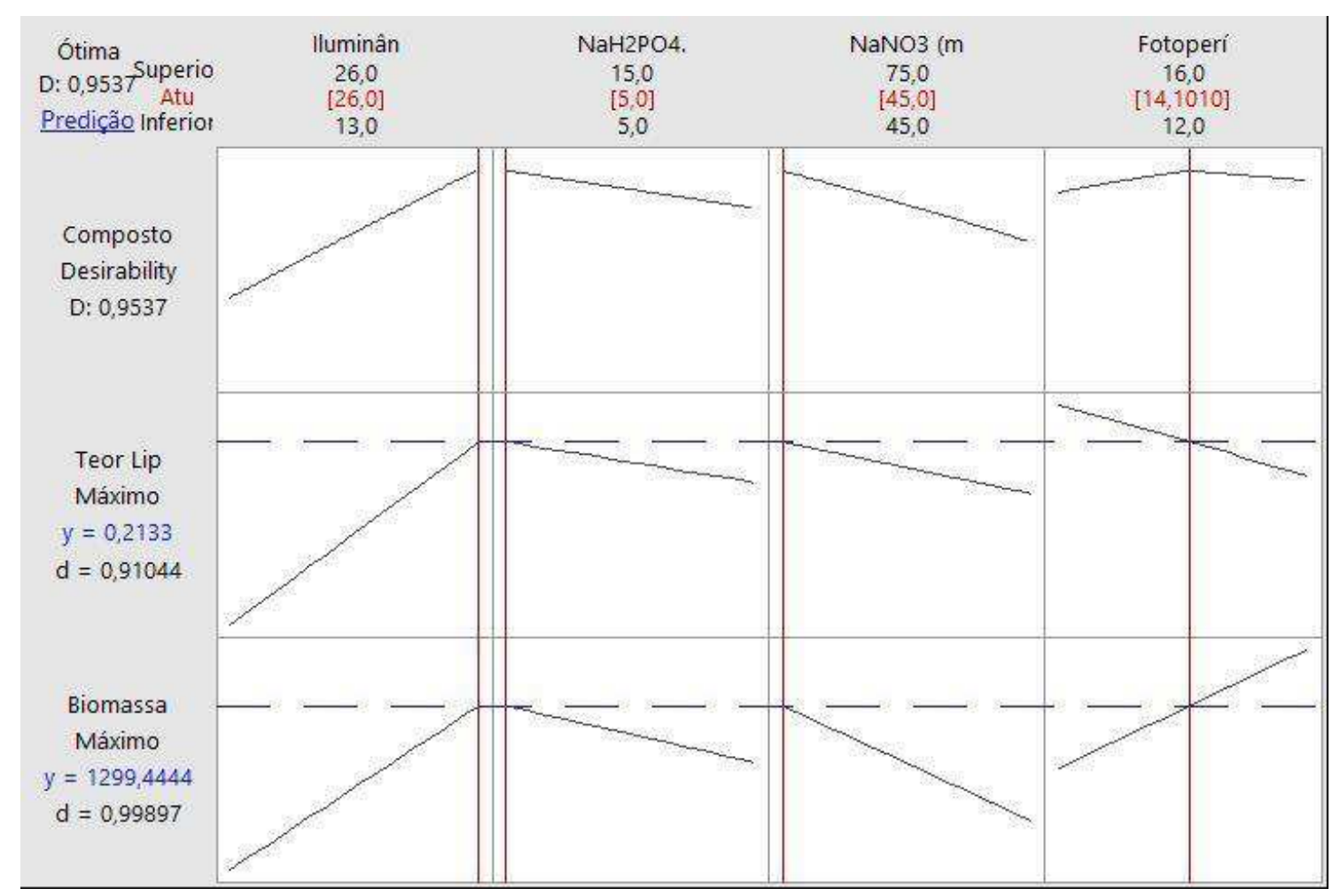

Fonte: Próprio Autor

Os gráficos da Figura 39 mostram que é possível que uma desejabilidade global (D) de 0,9537 seja atingida, por meio da média geométrica entre a desejabilidade da biomassa de 0,99897 e a desejabilidade do teor lipídico de 0,91044, com pesos unitários para ambas as variáveis de resposta, o que fica claro com o comportamento linear dos gráficos.

Para que a máxima desejabilidade global (D), dentro dos limites de estudo do presente trabalho, seja atingida, os fatores devem estar ajustados de modo que a iluminância seja de $26 \mathrm{klx}$, a concentração de $\mathrm{NaH}_{2} \mathrm{PO}_{4} \cdot \mathrm{H}_{2} \mathrm{O}$ seja de $5 \mathrm{mg} / \mathrm{L}$, a 
concentração de $\mathrm{NaNO}_{3}$ seja de $45 \mathrm{mg} / \mathrm{L}$ e o fotoperíodo seja, aproximadamente, de 14: 10 horas claro: escuro. Nessas condições, a produção de biomassa teórica atingida seria de 1299,4444 mg/L, ao passo que o teor lipídico teórico seria de 0,2133.

\subsection{A luz azul}

A luz azul, vista por sua vertente corpuscular, pode ser compreendida como um conjunto de fótons com comprimento de onda de aproximadamente $470 \mathrm{~nm}$. Com isso, baseado nas equações (1) e (2), é possível concluir que cada fóton tem uma energia equivalente a 4,22648 $\times 10^{-19} \mathrm{~m}^{2} \mathrm{~kg} / \mathrm{s}^{2}$.

\subsubsection{Teor de biomassa}

No que tange à variável de resposta "Produção de biomassa", em cultivos submetidos à luz azul, a média dos resultados, considerando todas as oito condições experimentais, realizadas em duplicata, foi de 916,875 mg/L, o que representa uma perda de 8,313\% em relação ao proposto por Shen (2014) e de $8,427 \%$ em relação à média atingida com a luz branca. A tabela 15 mostra os resultados, bem como a média e a razão sinal-ruído para cada condição experimental. 
Tabela 15 - Resultados de produção de biomassa referentes ao arranjo ortogonal L8 de Taguchi, obtidos em cultivos submetidos à luz azul.

\begin{tabular}{|c|c|c|c|c|}
\hline Experimento & \multicolumn{2}{|c|}{ Produção de Biomassa (mg/L) } & Média & S/N \\
\hline 1 & 830 & 860 & 845 & 56,721 \\
\hline 2 & 1120 & 1420 & 1270 & 59,808 \\
\hline 3 & 670 & 440 & 555 & 53,178 \\
\hline 4 & 930 & 930 & 930 & 57,609 \\
\hline 5 & 920 & 1200 & 1060 & 58,157 \\
\hline 6 & 710 & 880 & 795 & 55,801 \\
\hline 7 & 640 & 820 & 730 & 54,969 \\
\hline 8 & 1400 & 900 & 1150 & 59,479 \\
\hline
\end{tabular}

Fonte: Próprio Autor

Pela Tabela 15 é possível supor que a condição experimental condizente com o praticado no experimento 2, isto é, iluminância de $26 \mathrm{klx}$, concentração de $\mathrm{NaH}_{2} \mathrm{PO}_{4} . \mathrm{H}_{2} \mathrm{O}$ de $5 \mathrm{mg} / \mathrm{L}$, concentração de $\mathrm{NaNO}_{3}$ de $75 \mathrm{mg} / \mathrm{L}$ e fotoperíodo de 8 ciclos diários de 2: 1 horas claro: escuro, conduz à maior produção de biomassa com menor variabilidade.

Tal como anteriormente, faz-se necessária a análise estatística completa para avaliação da significância dos fatores e das interações entre eles que se pretende estudar. As Figuras 40 e 41 ilustram os gráficos dos efeitos dos fatores no que diz respeito à média e a razão sinal-ruído, respectivamente. 
Figura 40 - Gráficos dos efeitos dos fatores no que diz respeito à média de biomassa, em cultivos submetidos à luz azul.

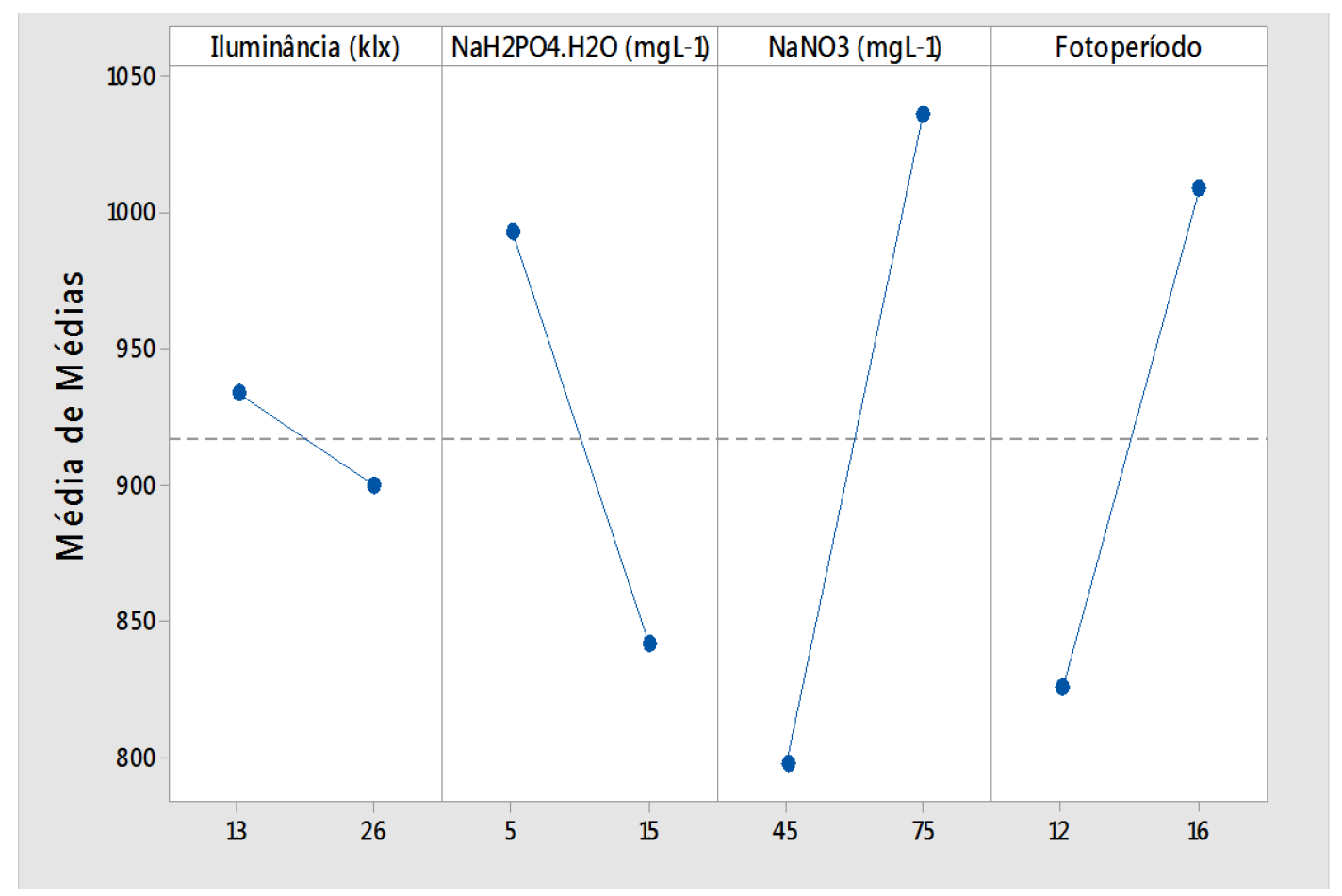

Fonte: Próprio Autor

Figura 41 - Gráficos dos efeitos dos fatores no que diz respeito à $\mathrm{S} / \mathrm{N}$ da produção de biomassa, em cultivos submetidos à luz azul.

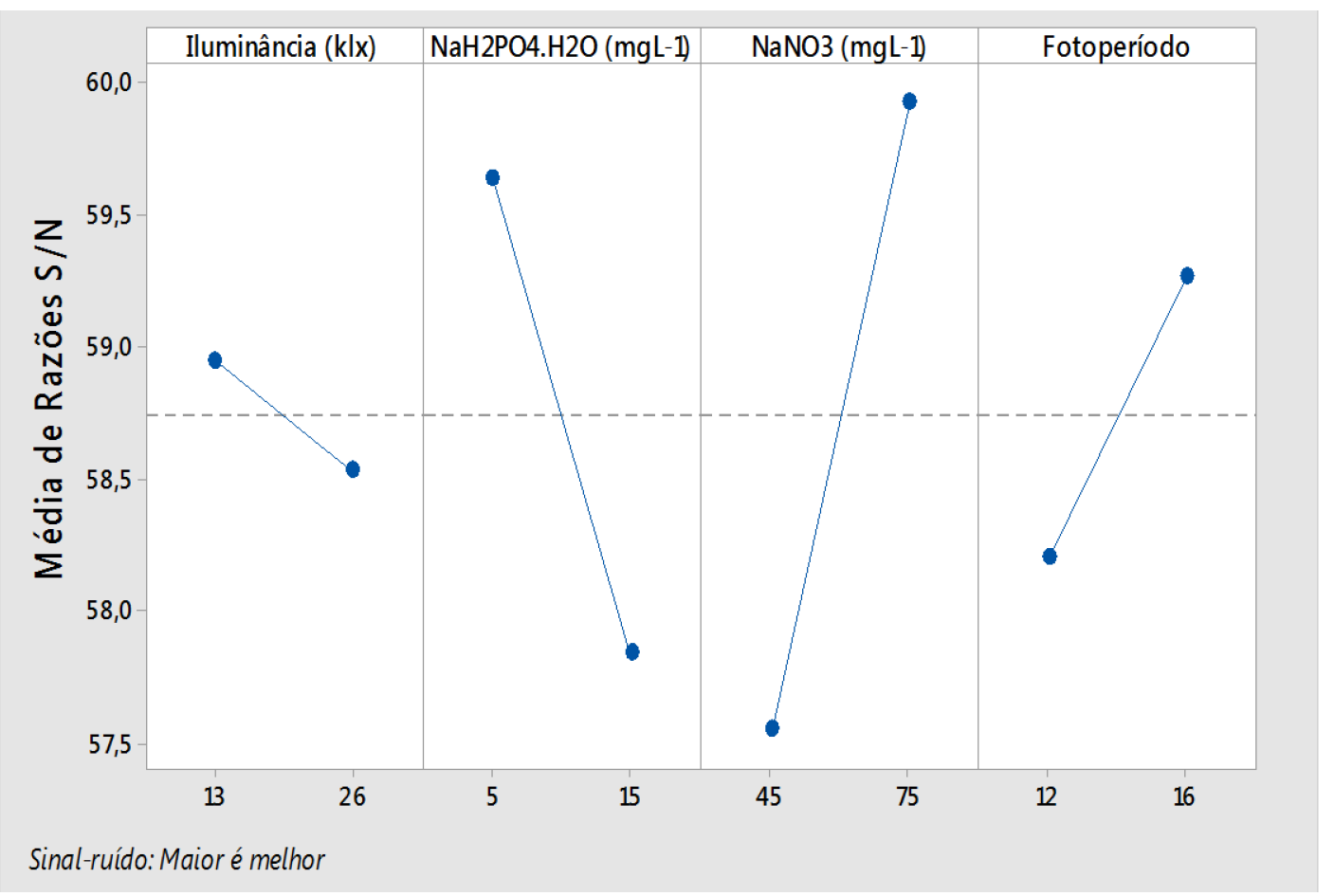

Fonte: Próprio Autor 
As Figuras 40 e 41 indicam que a concentração de $\mathrm{NaNO}_{3}$ deve ser o fator crítico do processo tanto para a produção de biomassa como para a variabilidade da resposta. Pelas Figuras também é possível inferir que o ajuste dos fatores, conforme 0 realizado no experimento 2 deve ser o melhor, exceto pela iluminância que, apesar de pouco significativa, em uma primeira análise, pareceria estar melhor ajustada no patamar de $13 \mathrm{klx}$.

As Figuras 42 a 44 demonstram o gráfico da interação entre a iluminância e os demais fatores no que diz respeito a média, já que a análise ainda pendente dessas interações, tal como tratado para a luz branca, segue sendo crucial para a compreensão do processo multivariado.

Figura 42 - Gráfico da interação entre a iluminância e a concentração de $\mathrm{NaH}_{2} \mathrm{PO}_{4} \cdot \mathrm{H}_{2} \mathrm{O}$, para a produção de biomassa, no que diz respeito à média em cultivos submetidos à luz azul.

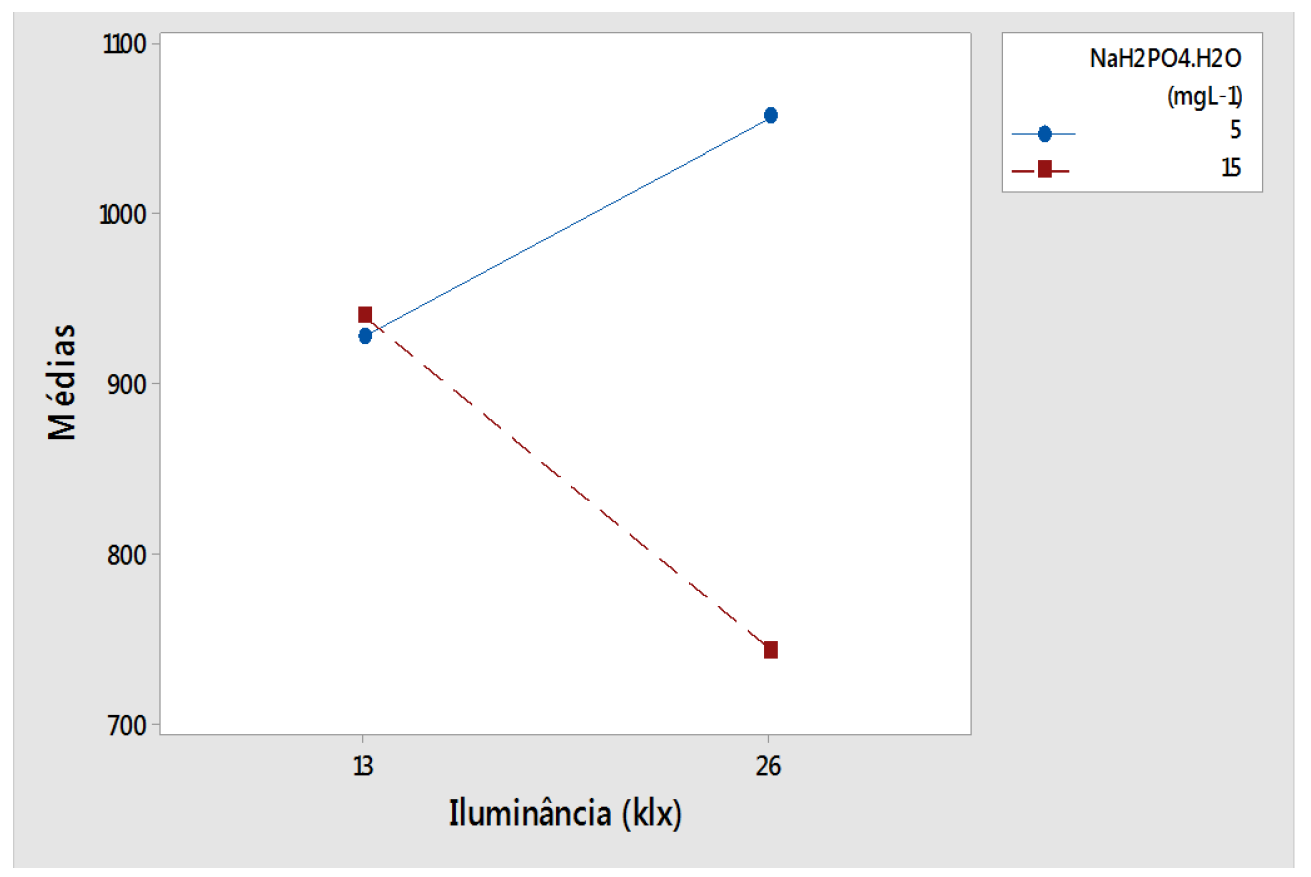

Fonte: Próprio Autor 
Figura 43 - Gráfico da interação entre a iluminância e a concentração de $\mathrm{NaNO}_{3}$, para a produção de biomassa no que diz respeito à média em cultivos submetidos à luz azul.

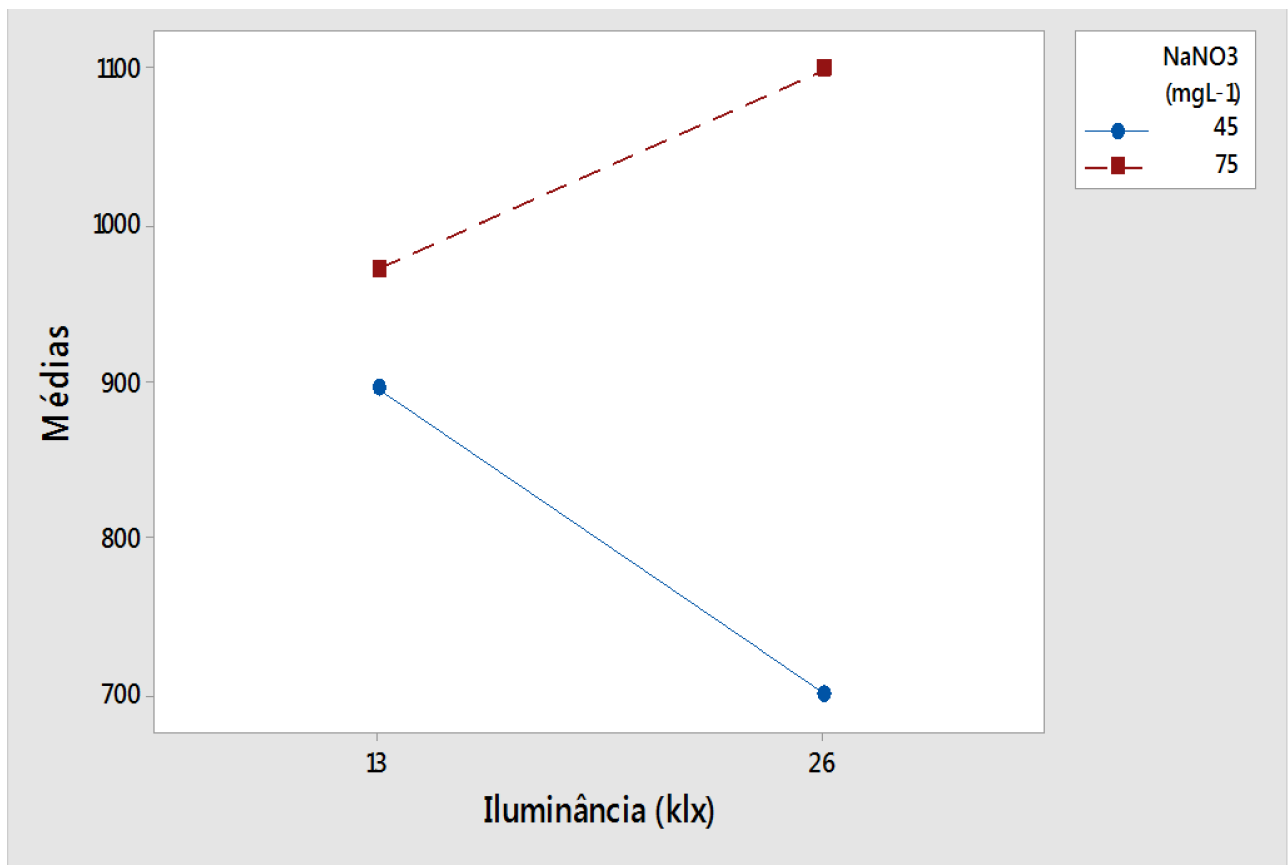

Fonte: Próprio Autor

Figura 44 - Gráfico da interação entre a iluminância e o fotoperíodo, para a produção de biomassa, no que diz respeito à média em cultivos submetidos à luz azul.

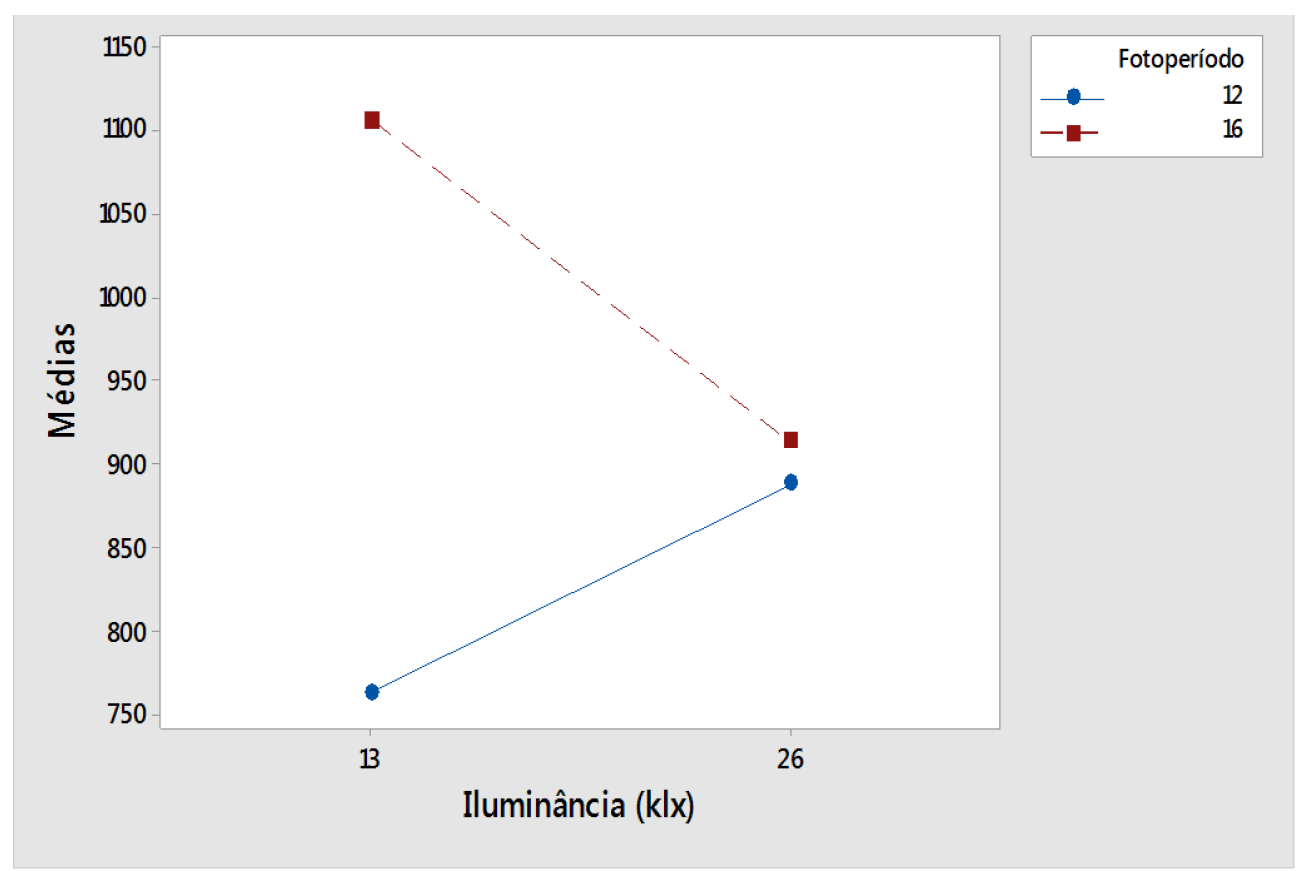

Fonte: Próprio Autor 
As Figuras 42, 43 e 44 demonstram que as interações entre a iluminância e a concentração de $\mathrm{NaH}_{2} \mathrm{PO}_{4} \cdot \mathrm{H}_{2} \mathrm{O}$, entre a iluminância e a concentração de $\mathrm{NaNO}_{3}$ e entre a iluminância e o fotoperíodo, apesar do indício de significância estatística, para o intervalo de confiança de 95\%, não há dúvidas de que quando a iluminância é de $26 \mathrm{klx}$ a concentração de $\mathrm{NaH}_{2} \mathrm{PO}_{4}$ deve ser de $5 \mathrm{mg} / \mathrm{L}$, a concentração de $\mathrm{NaNO}_{3}$ deve ser de $75 \mathrm{mg} / \mathrm{L}$ e o fotoperíodo de 8 ciclos diários de 2: 1 horas claro: escuro, visando a maior produção de biomassa, visto que a intersecção entre as retas das Figuras 42, 43 e 44, respectivamente, se dá no ponto em que a iluminância equivale a 13,50 klx, 9,88 klx e 27,02 klx.

As Figuras 45 a 47 permitem avaliar as interações entre os fatores no que diz respeito à razão sinal-ruído. É possível confirmar que as conclusões obtidas quanto ao ajuste ideal dos fatores, para a maior produção de biomassa, permanecem válidas para a redução da variabilidade, exceto pelo fotoperíodo que estaria melhor ajustado no nível de 12: 12 horas claro: escuro, quando a iluminância fosse de $26 \mathrm{klx}$.

Figura 45 - Gráfico da interação entre a iluminância e a concentração de $\mathrm{NaH}_{2} \mathrm{PO}_{4} \cdot \mathrm{H}_{2} \mathrm{O}$, para a produção de biomassa, no que diz respeito à $\mathrm{S} / \mathrm{N}$ em cultivos submetidos à luz azul.

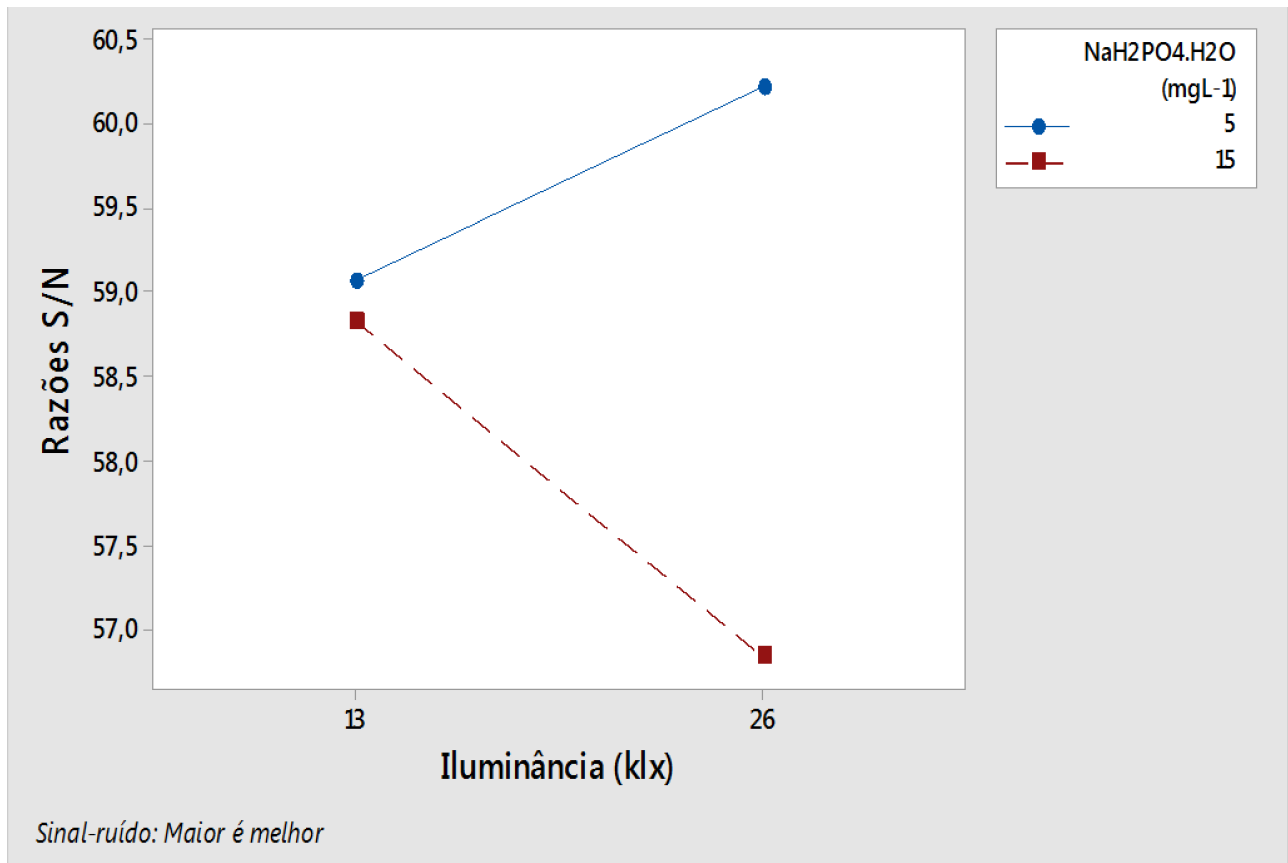

Fonte: Próprio Autor 
Figura 46 - Gráfico da interação entre a iluminância e a concentração de $\mathrm{NaNO}_{3}$, para a produção de biomassa, no que diz respeito à $\mathrm{S} / \mathrm{N}$ em cultivos submetidos à luz azul.

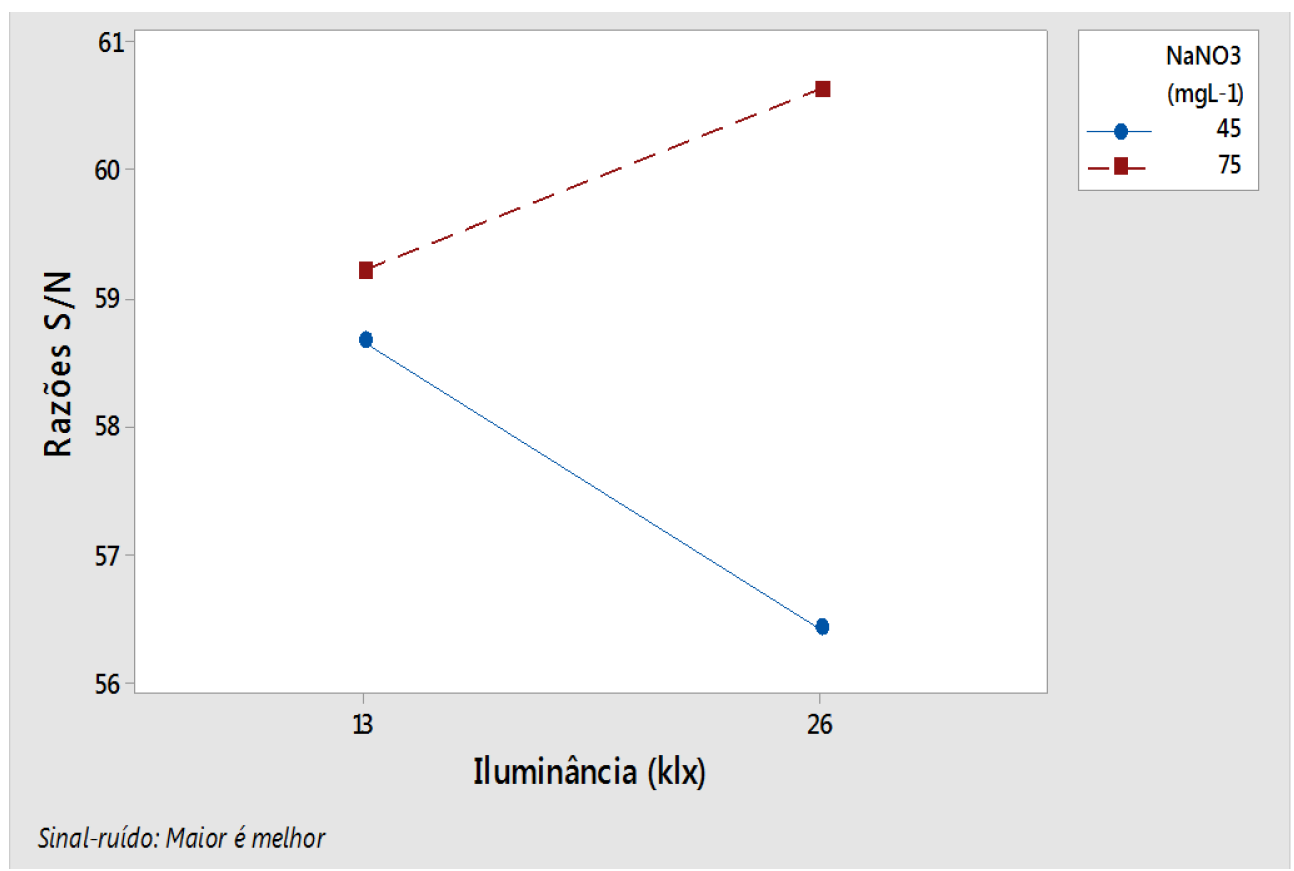

Fonte: Próprio Autor

Figura 47 - Gráfico da interação entre a iluminância e o fotoperíodo, para a produção de biomassa, no que diz respeito à $\mathrm{S} / \mathrm{N}$ em cultivos submetidos à luz azul.

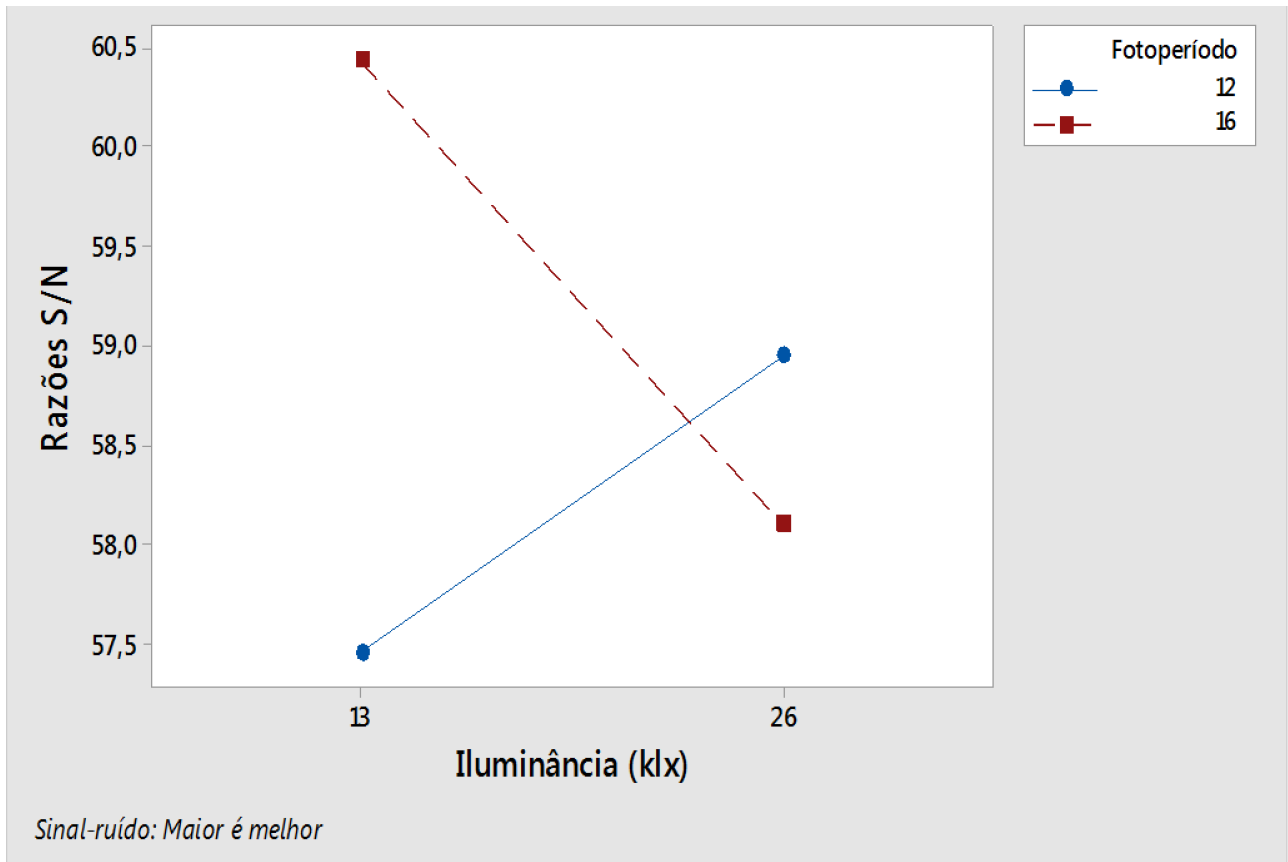

Fonte: Próprio Autor 
As Tabelas 16 e 17 trazem a análise de variância (ANOVA) com respeito à média e à razão sinal-ruído, respectivamente. Ambas comprovam que a concentração de $\mathrm{NaNO}_{3}$ é o único parâmetro que apresenta significância estatística, observado o intervalo de confiança de $95 \%$.

Tabela 16 - Análise de variância, para a produção de biomassa, com respeito à média em cultivos submetidos à luz azul.

\begin{tabular}{|c|c|c|c|c|c|}
\hline \multicolumn{7}{|c|}{ ANÁLISE DE VARIÂNCIA } \\
\hline Média = 916,875 & $\mathbf{S Q}$ & gl & SQM & $\mathbf{F}$ & $\mathbf{p}$ \\
\hline Efeito & 4556,3 & 1 & 4556,3 & 0,136645 & 0,721233 \\
\hline Iluminância & 91506,3 & 1 & 91506,3 & 2,744330 & 0,136191 \\
\hline $\mathrm{NaH}_{2} \mathrm{PO}_{4} \cdot \mathrm{H}_{2} \mathrm{O}$ & 107256,3 & 1 & 107256,3 & 3,216682 & 0,110645 \\
\hline Iluminância - Fosfato & 228006,3 & 1 & 228006,3 & 6,838051 & 0,030891 \\
\hline $\mathrm{NaNO}_{3}$ & 104006,3 & 1 & 104006,3 & 3,119213 & 0,115365 \\
\hline Iluminância - Nitrato & 100806,3 & 1 & 100806,3 & 3,023243 & 0,120273 \\
\hline Iluminância - Fotoperíodo & 135056,3 & 1 & 135056,3 & 4,050422 & 0,078964 \\
\hline Fotoperíodo & 266750,0 & 8 & 33343,8 & & \\
\hline Resíduo & & & & \\
\hline
\end{tabular}

Fonte: Próprio Autor

Tabela 17 - Análise de variância, para a produção de biomassa, com respeito à $\mathrm{S} / \mathrm{N}$ em cultivos submetidos à luz azul.

\begin{tabular}{|c|c|c|c|c|c|}
\hline \multicolumn{7}{|c|}{ ANÁLISE DE VARIÂNCIA } \\
\hline Média = 58,9008 & $\mathbf{S Q}$ & $\mathbf{g l}$ & $\mathbf{S Q M}$ & $\mathbf{F}$ & $\mathbf{p}$ \\
\hline Efeito & 0,97514 & 1 & 0,97514 & 0,340292 & 0,575733 \\
\hline Iluminância & 11,12007 & 1 & 11,12007 & 3,880549 & 0,084355 \\
\hline $\mathrm{NaH}_{2} \mathrm{PO}_{4} \cdot \mathrm{H}_{2} \mathrm{O}$ & 9,93018 & 1 & 9,93018 & 3,465317 & 0,099695 \\
\hline Iluminância - Fosfato & 22,49211 & 1 & 22,49211 & 7,849029 & 0,023140 \\
\hline NaNO & 11,63559 & 1 & 11,63559 & 4,060450 & 0,078659 \\
\hline Iluminância - Nitrato & 13,95446 & 1 & 13,95446 & 4,869662 & 0,058378 \\
\hline luminância - Fotoperíodo & 6,45404 & 1 & 6,45404 & 2,252255 & 0,171813 \\
\hline Fotoperíodo & 22,92473 & 8 & 2,86559 & & \\
\hline Resíduo & & & &
\end{tabular}

Fonte: Próprio Autor

\subsubsection{Teor lipídico}

No que diz respeito à variável de resposta "Teor lipídico", em cultivos submetidos à luz azul, a média dos resultados, considerando todas as oito condições experimentais, realizadas em duplicata, foi de $15,07 \%$, o que está de acordo com 
os dados da Tabela 4, apresentada no item 2.5. A Tabela 18 mostra os resultados, bem como a média e a razão sinal-ruído para cada condição experimental.

Tabela 18 - Resultados de teor lipídico referentes ao arranjo ortogonal $L_{8}$ de Taguchi, obtidos em cultivos submetidos à luz azul.

\begin{tabular}{|c|c|c|c|c|}
\hline Experimento & \multicolumn{2}{|c|}{ Teor Lipídico } & Média & S/N \\
\hline 1 & 0,1902 & 0,1903 & 0,1903 & $-16,18$ \\
\hline 2 & 0,1600 & 0,1958 & 0,1779 & $-17,17$ \\
\hline 3 & 0,1500 & 0,1564 & 0,1532 & $-18,12$ \\
\hline 4 & 0,1488 & 0,1753 & 0,1621 & $-17,88$ \\
\hline 5 & 0,1124 & 0,1914 & 0,1519 & $-19,68$ \\
\hline 6 & 0,0841 & 0,0904 & 0,0873 & $-23,07$ \\
\hline 7 & 0,1997 & 0,1327 & 0,1662 & $-17,28$ \\
\hline 8 & 0,1241 & 0,1097 & 0,1169 & $-20,27$ \\
\hline
\end{tabular}

Fonte: Próprio Autor

Pela tabela 18 é possível supor que a condição experimental condizente com o praticado no experimento 1 , isto é, iluminância de $26 \mathrm{klx}$, concentração de $\mathrm{NaH}_{2} \mathrm{PO}_{4} . \mathrm{H}_{2} \mathrm{O}$ de $5 \mathrm{mg} / \mathrm{L}$, concentração de $\mathrm{NaNO}_{3}$ de $45 \mathrm{mg} / \mathrm{L}$ e fotoperíodo de 12: 12 horas claro: escuro, conduz ao maior teor lipídico com menor variabilidade.

Tal como anteriormente, faz-se necessária a análise estatística completa para avaliação da significância dos fatores e das interações entre eles que se pretende estudar. As Figuras 48 e 49 ilustram os gráficos dos efeitos dos fatores no que diz respeito à média e a razão sinal-ruído, respectivamente. 
Figura 48 - Gráficos dos efeitos dos fatores no que diz respeito à média do teor lipídico em cultivos submetidos à luz azul.

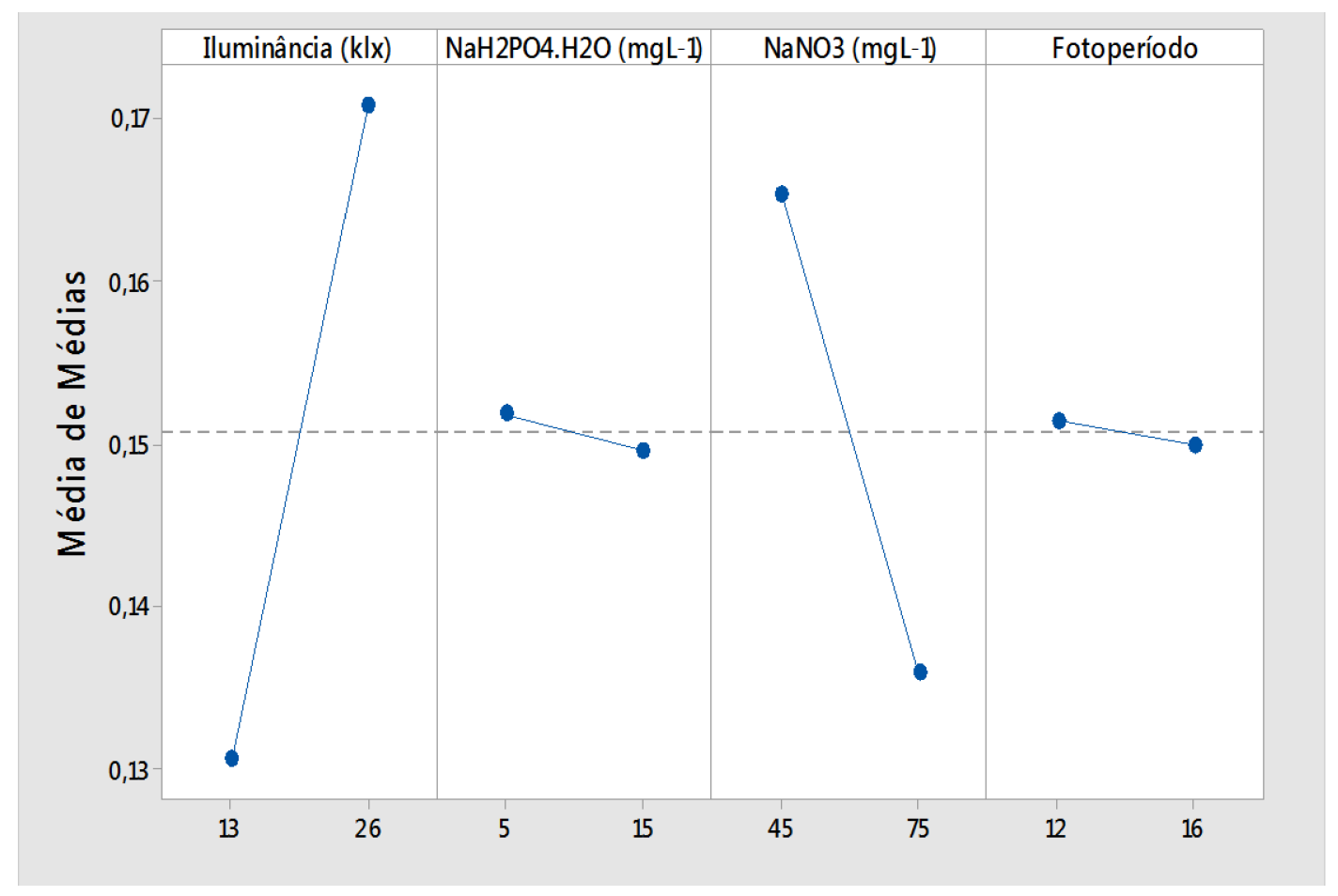

Fonte: Próprio Autor

Figura 49 - Gráficos dos efeitos dos fatores no que diz respeito à $S / N$ do teor lipídico, em cultivos submetidos à luz azul.

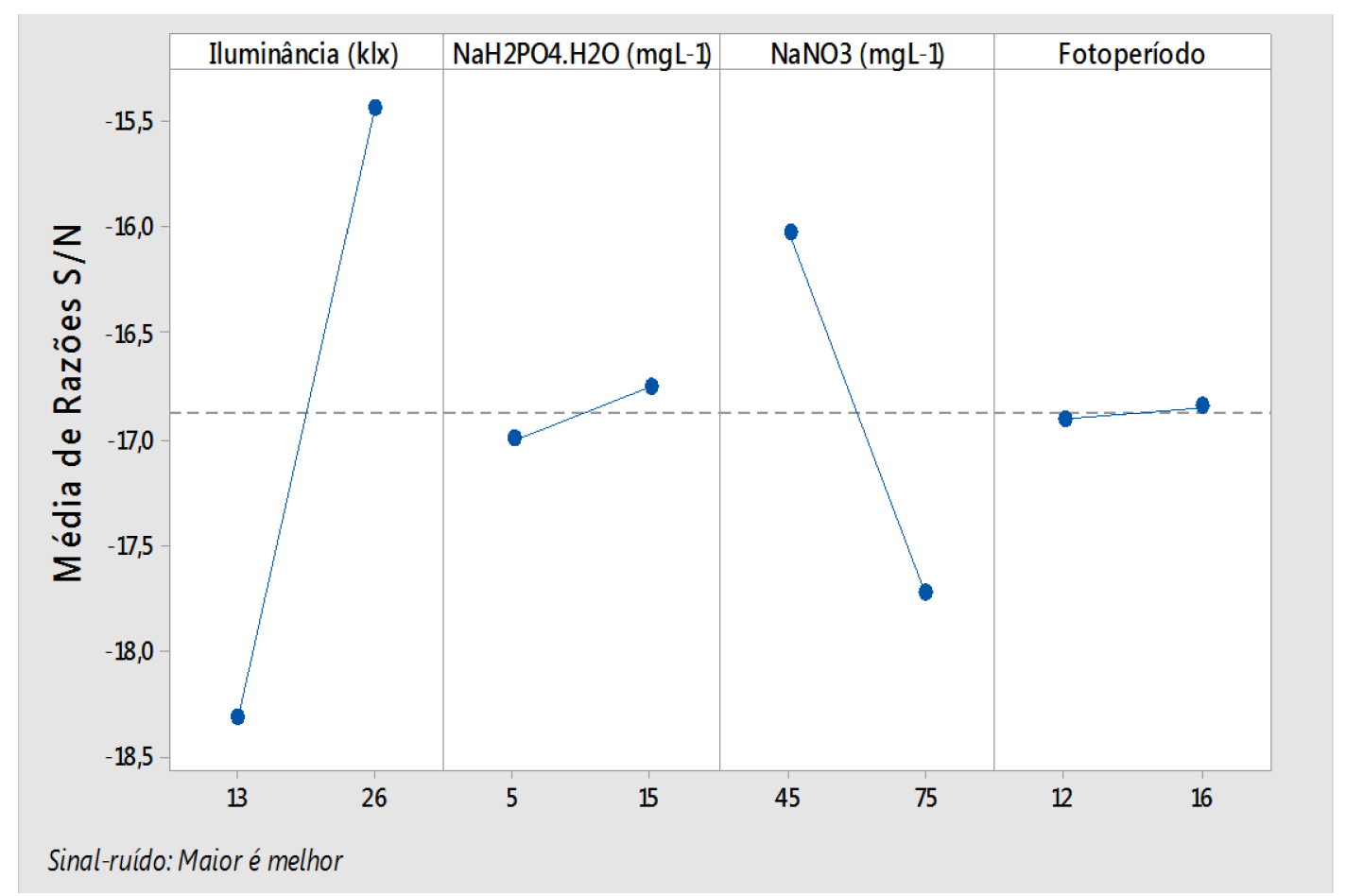

Fonte: Próprio Autor 
As Figuras 48 e 49 indicam que a iluminância e a concentração de $\mathrm{NaNO}_{3}$ devem ser os fatores críticos do processo tanto para o teor lipídico como para a variabilidade da resposta. As figuras também concordam que o ajuste dos fatores, conforme o realizado no experimento 1 , deve ser o melhor, exceto, no que diz respeito à $\mathrm{S} / \mathrm{N}$ pela concentração de $\mathrm{NaH}_{2} \mathrm{PO}_{4} \cdot \mathrm{H}_{2} \mathrm{O}$ que deve ser de 15 $\mathrm{mg} / \mathrm{L}$ e pelo fotoperíodo que deve ser de 8 ciclos diários de 2: 1 horas claro: escuro, entretanto, ambos os fatores de discordância, parecem não apresentar criticidade.

As Figuras 50 a 52, apresentam o gráfico da interação entre a iluminância e os demais fatores no que diz respeito a média, já que a análise ainda pendente dessas interações, tal como tratado anteriormente, segue sendo crucial para a compreensão do processo multivariado.

Figura 50 - Gráfico da interação entre a iluminância e a concentração de $\mathrm{NaH}_{2} \mathrm{PO}_{4} \cdot \mathrm{H}_{2} \mathrm{O}$, para o teor lipídico, no que diz respeito à média em cultivos submetidos à luz azul.

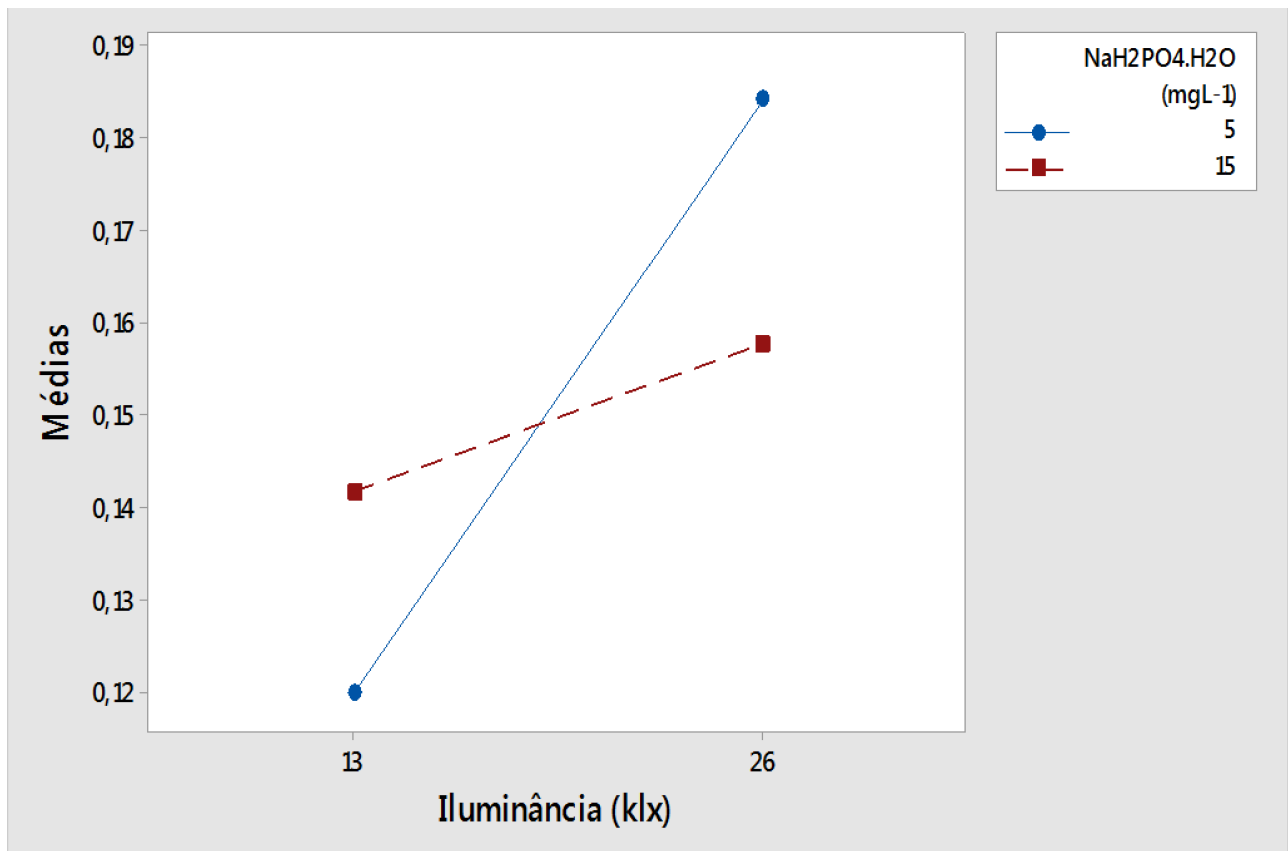

Fonte: Próprio Autor 
Figura 51 - Gráfico da interação entre a iluminância e a concentração de $\mathrm{NaNO}_{3}$, para o teor lipídico, no que diz respeito à média em cultivos submetidos à luz azul.

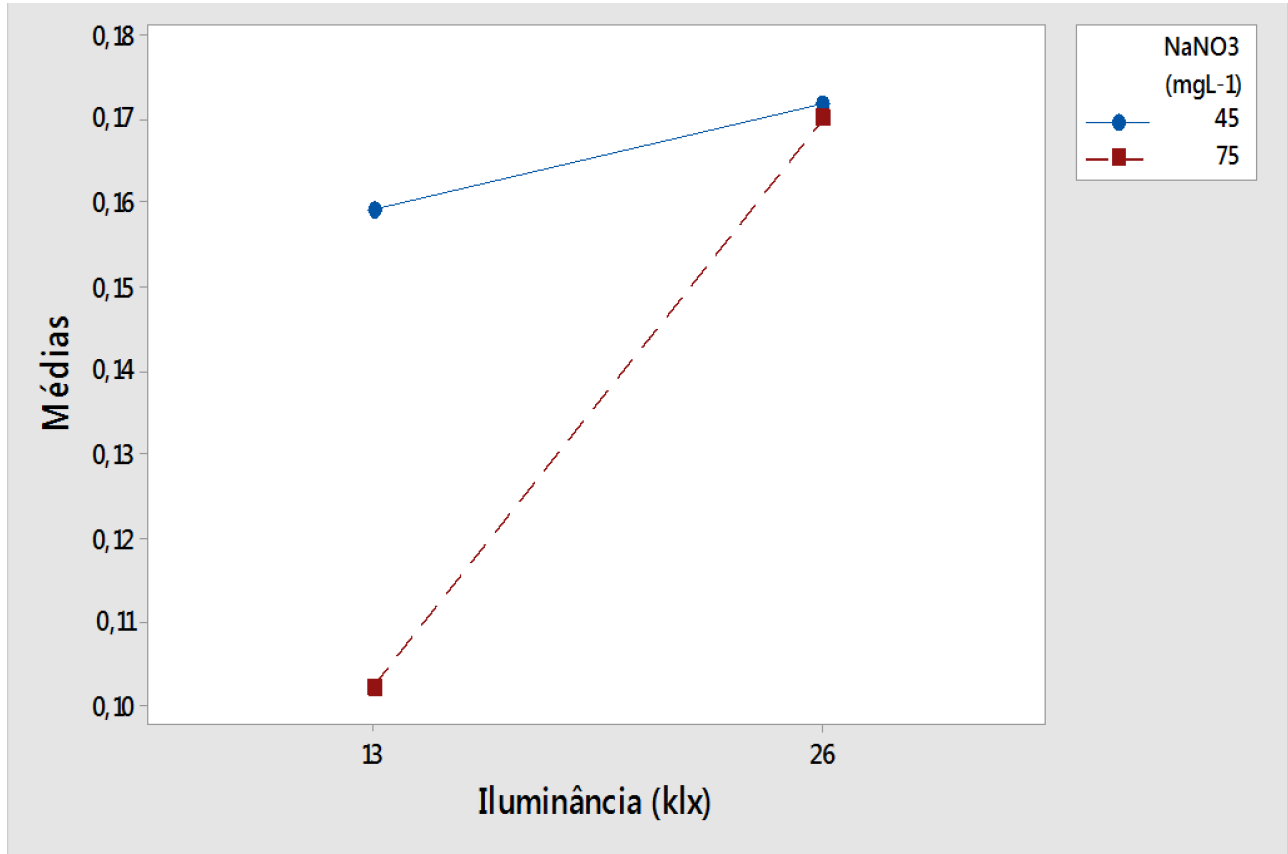

Fonte: Próprio Autor

Figura 52 - Gráfico da interação entre a iluminância e o fotoperíodo, para o teor lipídico, no que diz respeito à média em cultivos submetidos à luz azul.

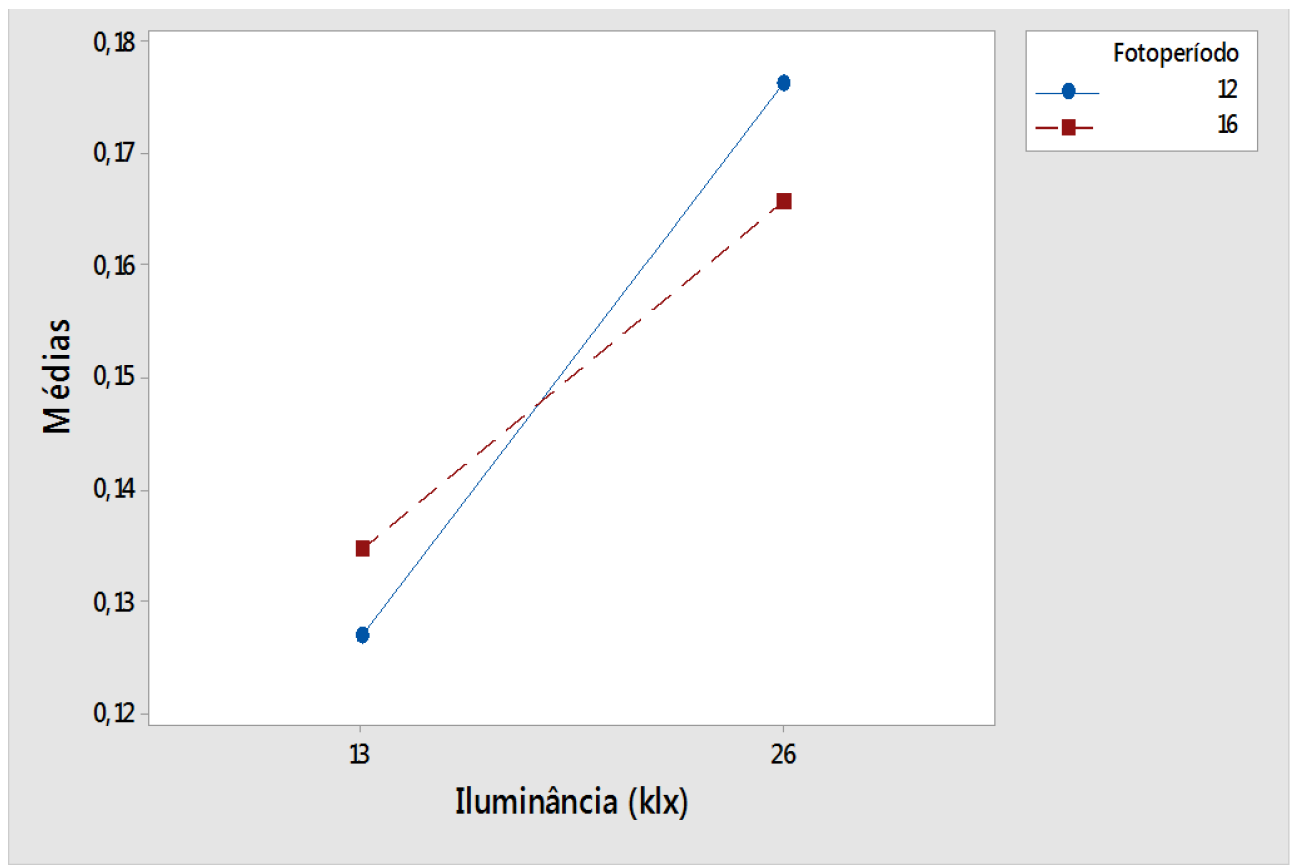

Fonte: Próprio Autor 
As Figuras 50, 51 e 52 demonstram que as interações entre a iluminância e a concentração de $\mathrm{NaH}_{2} \mathrm{PO}_{4} \cdot \mathrm{H}_{2} \mathrm{O}$, entre a iluminância e a concentração de $\mathrm{NaNO}_{3}$ e entre a iluminância e o fotoperíodo, apesar do indício de significância estatística, para o mesmo intervalo de confiança, quando a iluminância é de 26 klx a concentração de $\mathrm{NaH}_{2} \mathrm{PO}_{4}$ deve ser de $5 \mathrm{mg} / \mathrm{L}$, a concentração de $\mathrm{NaNO}_{3}$ deve ser de $45 \mathrm{mg} / \mathrm{L}$ e o fotoperíodo de 12: 12 horas claro: escuro, visando o maior teor lipídico, visto que a intersecção entre as retas das figuras 50, 51 e 52, respectivamente, se dá no ponto em que a iluminância equivale a 18,90 klx, 26,41 klx e 18,46 klx..

As Figuras 53 a 55 permitem avaliar as interações entre os fatores no que diz respeito à razão sinal-ruído. É possível confirmar que as conclusões obtidas quanto ao ajuste ideal dos fatores, para o maior teor lipídico, permanecem válidas para a redução da variabilidade.

Figura 53 - Gráfico da interação entre a iluminância e a concentração de $\mathrm{NaH}_{2} \mathrm{PO}_{4} \cdot \mathrm{H}_{2} \mathrm{O}$, para o teor lipídico, no que diz respeito à $\mathrm{S} / \mathrm{N}$ em cultivos submetidos à luz azul.

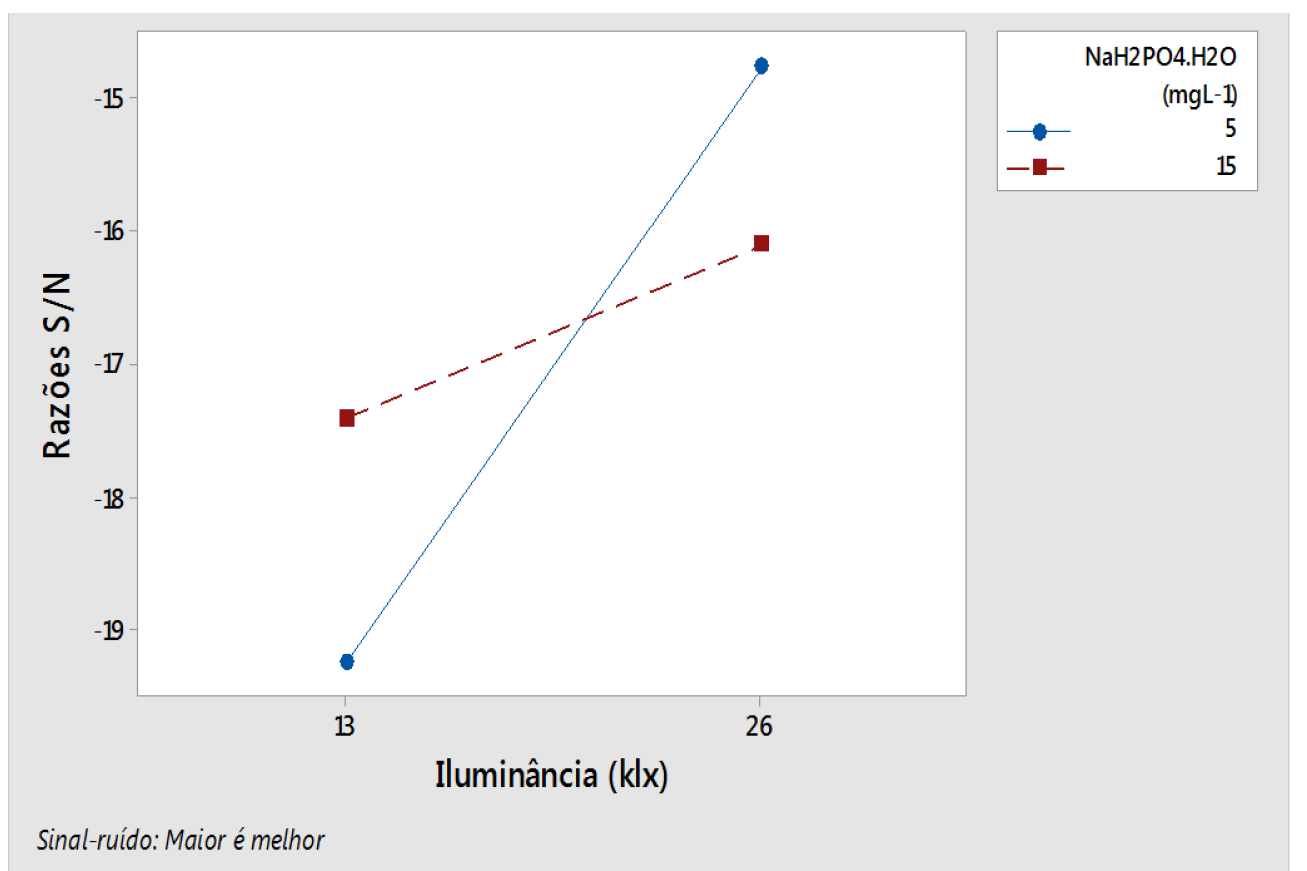

Fonte: Próprio Autor 
Figura 54 - Gráfico da interação entre a iluminância e a concentração de $\mathrm{NaNO}_{3}$, para o teor lipídico, no que diz respeito à $\mathrm{S} / \mathrm{N}$ em cultivos submetidos à luz azul.

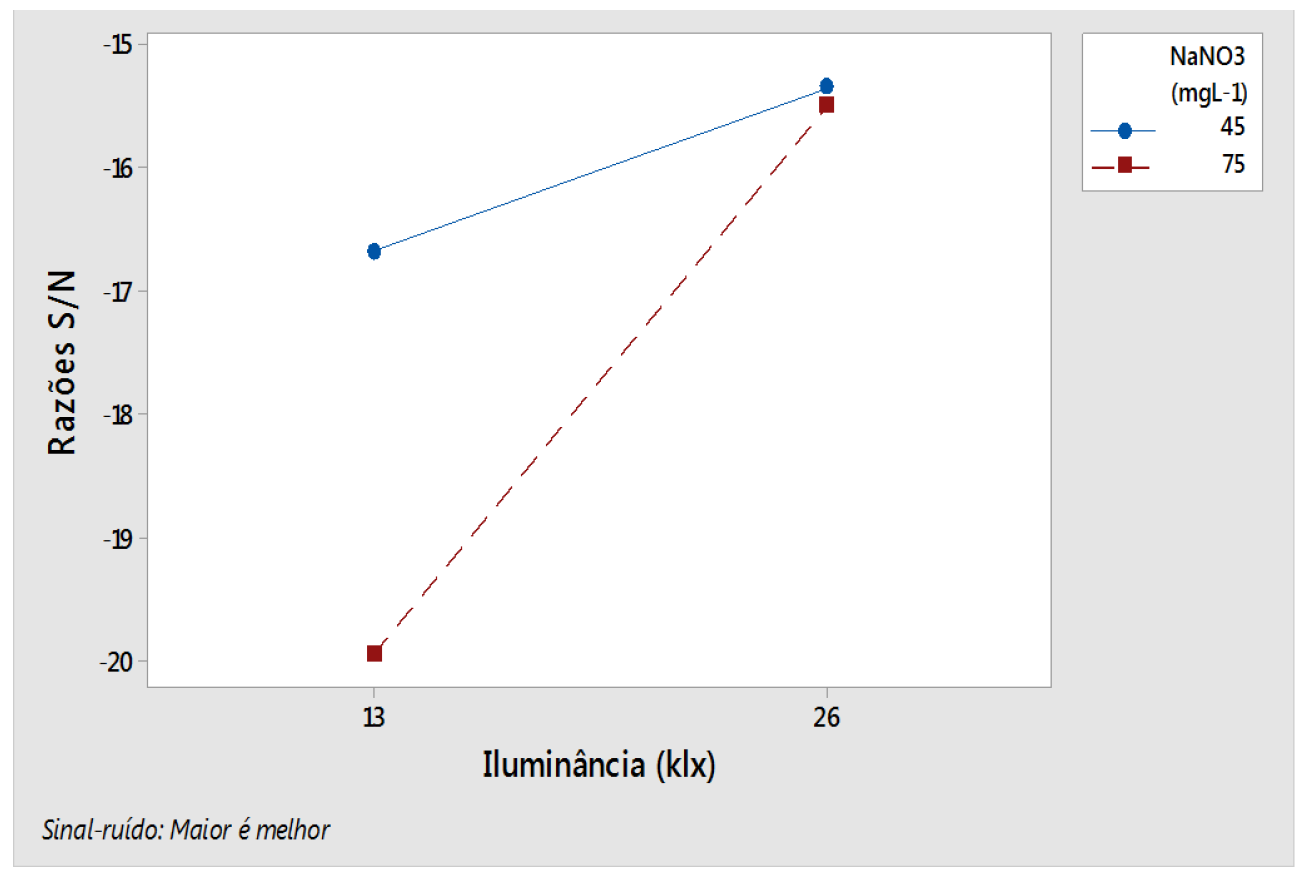

Fonte: Próprio Autor

Figura 55 - Gráfico da interação entre a iluminância e o fotoperíodo, para o teor lipídico, no que diz respeito à $\mathrm{S} / \mathrm{N}$ em cultivos submetidos à luz azul.

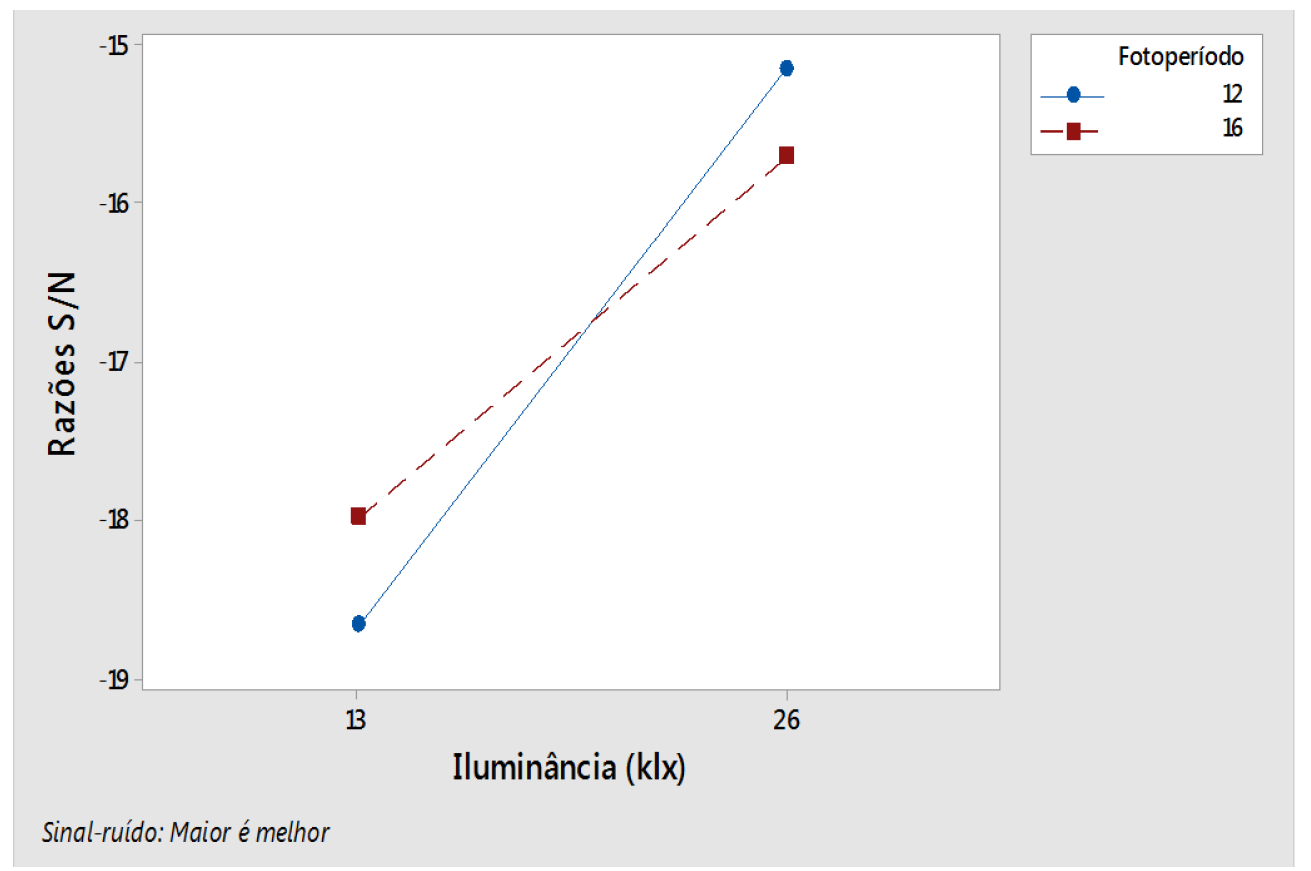

Fonte: Próprio Autor 
As Tabelas 19 e 20 apresentam a análise de variância (ANOVA) com respeito à média e à razão sinal-ruído, respectivamente. O único parâmetro que apresenta significância estatística, observado o intervalo de confiança de 95\%, em ambas as Tabelas é a iluminância.

Tabela 19 - Análise de variância, para o teor lipídico, com respeito à média em cultivos submetidos à luz azul.

\begin{tabular}{|c|c|c|c|c|c|}
\hline \multicolumn{7}{|c|}{ ANÁLISE DE VARIÂNCIA } \\
\hline Média = 0,150706 & $\mathbf{S Q}$ & $\mathbf{g l}$ & $\mathbf{S Q M}$ & $\mathbf{F}$ & $\mathbf{p}$ \\
\hline Efeito & 0,00649 & 1 & 0,00649 & 7,989387 & 0,022268 \\
\hline Iluminância & 0,00002 & 1 & 0,00002 & 0,024643 & 0,879149 \\
\hline $\mathrm{NaH}_{2} \mathrm{PO}_{4} \cdot \mathrm{H}_{2} \mathrm{O}$ & 0,00234 & 1 & 0,00234 & 2,885706 & 0,127797 \\
\hline Iluminância - Fosfato & 0,00345 & 1 & 0,00345 & 4,243839 & 0,073353 \\
\hline $\mathrm{NaNO}_{3}$ & 0,00305 & 1 & 0,00305 & 3,753049 & 0,088718 \\
\hline Iluminância - Nitrato & 0,00033 & 1 & 0,00033 & 0,410987 & 0,539396 \\
\hline Iluminância - Fotoperíodo & 0,00001 & 1 & 0,00001 & 0,010528 & 0,920799 \\
\hline Fotoperíodo & 0,00650 & 8 & 0,00081 & & \\
\hline Resíduo & & & &
\end{tabular}

Fonte: Próprio Autor

Tabela 20 - Análise de variância, para o teor lipídico, com respeito à $\mathbf{S} / \mathbf{N}$ em cultivos submetidos à luz azul.

\begin{tabular}{|c|c|c|c|c|c|}
\hline \multicolumn{7}{|c|}{ ANÁLISE DE VARIÂNCIA } \\
\hline Média = -16,735 & SQ & gl & SQM & F & p \\
\hline Efeito & 28,64362 & 1 & 28,64362 & 11,244900 & 0,010030 \\
\hline Iluminância & 0,14321 & 1 & 0,14321 & 0,056220 & 0,818532 \\
\hline $\mathrm{NaH}_{2} \mathrm{PO}_{4} \cdot \mathrm{H}_{2} \mathrm{O}$ & 9,34598 & 1 & 9,34598 & 3,669040 & 0,091754 \\
\hline Iluminância - Fosfato & 14,35175 & 1 & 14,35175 & 5,634205 & 0,044990 \\
\hline $\mathrm{NaNO}_{3}$ & 13,11724 & 1 & 13,11724 & 5,149560 & 0,052951 \\
\hline Iluminância - Nitrato & 1,83937 & 1 & 1,83937 & 0,722099 & 0,420158 \\
\hline lluminância - Fotoperíodo & 0,07209 & 1 & 0,07209 & 0,028302 & 0,870577 \\
\hline Fotoperíodo & 20,37804 & 8 & 2,54726 & & \\
\hline Resíduo & & & &
\end{tabular}

Fonte: Próprio Autor

\subsubsection{Ajuste de múltiplas respostas}

Tal como realizado para a luz branca, por meio da função Desirability, é possível a conjugação de um ajuste que maximize, simultaneamente, ambas as variáveis de resposta, mesmo em situações em que, individualmente, os ajustes ideais 
dos fatores que as maximizem sejam conflitantes. A Figura 56 traz o gráfico de otimização com os valores de desejabilidade individuais $\left(\mathrm{d}_{\mathrm{i}}\right)$ de ambas as variáveis de resposta e de desejabilidade global (D).

Figura 56 - Gráfico de otimização simultânea das variáveis de resposta, em cultivos submetidos à luz azul.

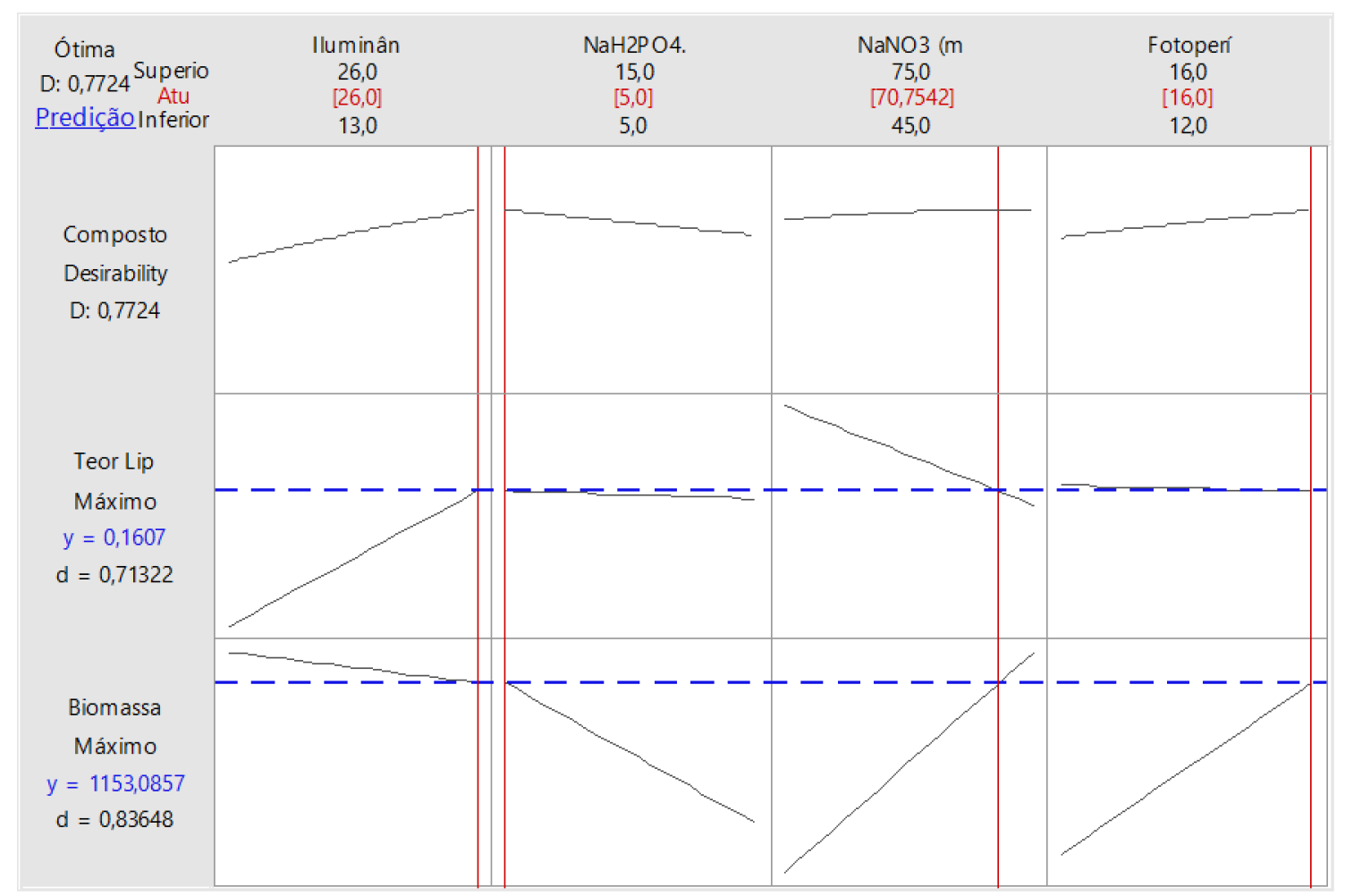

Fonte: Próprio Autor

Os gráficos da Figura 56 mostram que é possível que uma desejabilidade global (D) de 0,7724 seja atingida, por meio da média geométrica entre a desejabilidade da biomassa de 0,83648 e a desejabilidade do teor lipídico de 0,71322, com pesos unitários para ambas as variáveis de resposta, o que fica claro com o comportamento linear dos gráficos.

Para que a máxima desejabilidade global (D), dentro dos limites de estudo do presente trabalho, seja atingida, os fatores devem estar ajustados de modo que a iluminância seja de $26 \mathrm{klx}$, a concentração de $\mathrm{NaH}_{2} \mathrm{PO}_{4} \cdot \mathrm{H}_{2} \mathrm{O}$ seja de $5 \mathrm{mg} / \mathrm{L}$, a concentração de $\mathrm{NaNO}_{3}$ seja de aproximadamente $71 \mathrm{mg} / \mathrm{L}$ e o fotoperíodo seja de 8 ciclos diários de 2: 1 horas claro: escuro. Nessas condições, a produção de biomassa teórica atingida seria de 1153,0857 mg/L, ao passo que o teor lipídico teórico seria de 0,1607. 


\section{CONCLUSÃO}

Diante do que foi tratado ao longo de todos os capítulos anteriores da presente pesquisa, pode-se observar a importância comprovada de parâmetros luminosos no desenvolvimento de cultivos de microalgas marinhas Chlorella minutissima.

Em face dos objetivos considerados no capítulo 1, foi possível analisar e concluir que a iluminância é um fator evidentemente crítico em cultivos submetidos à luz branca e à luz com comprimento de onda equivalente a $470 \mathrm{~nm}$, no que tange ao teor lipídico, devendo ser cuidadosamente controlado, sob pena de redução drástica na produção de biomassa e no teor lipídico, além de uma elevação na variabilidade das respostas.

Para o caso da luz de comprimento de onda igual a $470 \mathrm{~nm}$, composta dos fótons mais energéticos entre os que compuseram o presente estudo, a iluminância perde significância no que tange a produção de biomassa com menor variabilidade, fato que se deve justamente ä maior energia absorvida de seus fótons na fotossíntese.

Verifica-se ainda, para cultivos submetidos à luz branca, que o nível de menor concentração de $\mathrm{NaNO}_{3}(45 \mathrm{mg} / \mathrm{L})$ mostrou-se ideal para a maior produção de biomassa e para o maior teor lipídico, ambos com menor variabilidade. Este fato, pode estar relacionado a uma queda no $\mathrm{pH}$, provocada pela adição de ânions $\mathrm{NO}_{3}^{-}$, prejudicial ao desenvolvimento dos cultivos.

Ressalta-se que, para os cultivos submetidos à luz no comprimento de onda equivalente a $470 \mathrm{~nm}$, a condição em que a concentração de $\mathrm{NaNO}_{3}$ equivale a $45 \mathrm{mg} / \mathrm{L}$ se mantem favorável para o maior teor lipídico com menor variabilidade. Entretanto, nestes cultivos, o stress por nitrogênio tendeu a minimizar o rendimento global da biomassa.

A diluição da luz, por meio de ciclos curtos de luz e escuridão, compatível com a fotossíntese, conduziram a uma maior produção de biomassa, entretanto, condições de stress ambiental, conduzem à um maior teor lipídico, de modo que ciclos mais longos de luz e escuridão favorecem a maximização dessa variável de resposta. 
A adaptação dos cultivos às condições de luminosidade propostas foi satisfatória, levando a uma produção de biomassa teórica máxima de 1299,4444 $\mathrm{mg} / \mathrm{L}$, superando em $29,94 \%$ o patamar de $1000 \mathrm{mg} / \mathrm{L}$, e a um teor lipídico teórico máximo de 0,2133 , valores obtidos por meio da otimização simultânea das variáveis de resposta, realizada pela função Desirability, em cultivos submetidos à luz branca.

Para cultivos submetidos à luz no comprimento de onda equivalente a $470 \mathrm{~nm}$, a produção de biomassa teórica máxima também ultrapassa o patamar de 1000 $\mathrm{mg} / \mathrm{L}$, sendo de $1153,0857 \mathrm{mg} / \mathrm{L}$, ao passo que o teor lipídico teórico máximo, ainda para cultivos submetidos à luz com comprimento de onda equivalente a $470 \mathrm{~nm}$, é de $16,07 \%$, otimizando simultaneamente ambas as variáveis de resposta por meio da função Desirability. 


\section{SUGESTÃO DE PRÓXIMAS ETAPAS DE PESQUISA}

De posse do debatido ao longo dos capítulos do presente trabalho e tendo em vista o espectro de absorção das clorofilas a e b, além de aspectos técnicos documentados por Khalili et al. (2015), que relatam que o espectro de emissão vermelho se encaixa perfeitamente com o fóton necessário para atingir os primeiros estados excitados das clorofilas a e b, faz-se relevante a condução de um estudo que permita observar os comportamentos das variáveis de resposta deste trabalho, quando os cultivos forem submetidos à luz cujo comprimento de onda seja de $700 \mathrm{~nm}$.

Por outro lado, um estudo no comprimento de onda de $540 \mathrm{~nm}$ evidenciaria a diferença observada nas variáveis de resposta em uma região de predominante reflexão da luz por parte das clorofilas a e b, o que justificaria a inclusão deste como parâmetro adicional de estudo futuro. 


\section{REFERÊNCIAS}

ABDO, Sayeda M. et al., Preliminary economic assessment of biofuel production from microalgae. Renewable and Sustainable Energy Reviews, v. 55, p. 11471153, 2016.

ABOMOHRA, Abd El-Fatah et al., Microalgal biomass production as a sustainable feedstock for biodiesel: Current status and perspectives. Renewable and Sustainable Energy Reviews, v. 64, p. 596-606, 2016.

AMARAL, Mateus de Souza. Cultivo da microalga marinha Chlorella minutissima em fotobiorreator integrado (coluna de bolhas - tubular) internamente iluminado visando à obtenção de biomassa para a produção de biodiesel. 2018. Tese (Doutorado em Ciências) - Escola de Engenharia de Lorena, Universidade de São Paulo, Lorena, 2018.2 Disponível em: http://www.teses.usp.br/teses/disponiveis/97/97131/tde-03122018-183830/. Acesso em: 22 dez. 2018.

AMARAL, M.S., Cultivo da microalga marinha Chlorella sp. como fonte de matéria-prima para a produção de biodiesel. 2014.109p:il. Dissertação (Mestrado em Ciências) - Escola de Engenharia de Lorena da Universidade de São Paulo, Lorena, 2014.

ARENAS, E. G. et al., Microalgae as a potential source for biodiesel production: techniques, methods, and other challenges. International Journal of Energy Research, v. 41, n. 6, p. 761-789, 2017.

BAJHAIYA, Amit K.; MOREIRA, Javiera Ziehe; PITTMAN, Jon K. Transcriptional engineering of microalgae: prospects for high-value chemicals. Trends in Biotechnology, v. 35, n. 2, p. 95-99, 2017.

BARTLEY, Meridith L. et al., Effects of salinity on growth and lipid accumulation of biofuel microalga Nannochloropsis salina and invading organisms. Biomass and Bioenergy, v. 54, p. 83-88, 2013.

BECKER, E. Wolfgang. Microalgae: biotechnology and microbiology. Cambridge University Press, 1994. 
BHOLA, Virthie et al., Effects of parameters affecting biomass yield and thermal behaviour of Chlorella vulgaris. Journal of Bioscience and Bioengineering, $v$. 111, n. 3, p. 377-382, 2011.

BLIGH, E. Graham; DYER, W. Justin. A rapid method of total lipid extraction and purification. Canadian Journal of Biochemistry and Physiology, v. 37, n. 8, p. 911-917, 1959.

BOUZID, Lakhdar et al., Simultaneous optimization of surface roughness and material removal rate for turning of $\mathrm{X} 20 \mathrm{Cr} 13$ stainless steel. The International Journal of Advanced Manufacturing Technology, v. 74, n. 5-8, p. 879-891, 2014.

BURLEW, John S. Algal culture. From Laboratory to Pilot Plant, Carnegie Inst. Washington Publ, v. 600, n. 1, 1953.

BOROWITZKA, Michael Armin; MOHEIMANI, Navid Reza. Sustainable biofuels from algae. Mitigation and Adaptation Strategies for Global Change, v. 18, n. 1, p. 13-25, 2013.

BOROWITZKA, Michael A. Commercial production of microalgae: ponds, tanks, tubes and fermenters. Journal of biotechnology, v. 70, n. 1, p. 313-321, 1999.

CARBAS, Ricardo João Camilo et al., Estudo paramétrico de juntas adesivas pelo método de Taguchi. 2012.

CARDOZO, Karina HM et al., Metabolites from algae with economical impact. Comparative Biochemistry and Physiology Part C: Toxicology \& Pharmacology, v. 146, n. 1, p. 60-78, 2007.

CARLSSON, Anders S. (Ed.). Micro-and macro-algae: utility for industrial applications: outputs from the EPOBIO project. CPL Press, 2007.

CARON, David A. et al., Probing the evolution, ecology and physiology of marine protists using transcriptomics. Nature Reviews Microbiology, v. 15, n. 1, p. 6$20,2017$.

CARVALHO, Ana P. et al., Light requirements in microalgal photobioreactors: an overview of biophotonic aspects. Applied Microbiology and Biotechnology, v. 89, n. 5, p. 1275-1288, 2011. 
CASTRO, P.M.M. Método de taguchi: controlo de qualidade com recurso não convencional ao desenho estatístico de experiências (DOE). 2001.

CHABBI, Amel et al., Predictive modeling and multi-response optimization of technological parameters in turning of Polyoxymethylene polymer (POM C) using RSM and desirability function. Measurement, v. 95, p. 99-115, 2017.

CHATSUNGNOEN, Tawan; CHISTI, Yusuf. Harvesting microalgae by flocculation-sedimentation. Algal Research, v. 13, p. 271-283, 2016.

CHEN, Chun-Yen et al., Cultivation, photobioreactor design and harvesting of microalgae for biodiesel production: a critical review. Bioresource technology, v. 102, n. 1, p. 71-81, 2011.

CHISTI, Yusuf. Biodiesel from microalgae. Biotechnology Advances, v. 25, n. 3, p. 294-306, 2007.

CONNOR, R. et al., Water in a changing world. The United Nations World Water Development report. 2009;3. Disponível em: http://webworld.unesco.org/water/wwap/wwdr/wwdr3/pdf/WWDR3_Water_in_a_ Changing_World.pdf. Acesso em: 01 maio 2016.

CONVERTI, A. et al., Effect of temperature and nitrogen concentration on the growth and lipid content of nannochloropsis oculata and chlorella vulgaris for biodiesel production. Chemical Engineering and Processing: Process Intensification, v. 48, n. 6, p. 1146-1151, 2009.

D'ALESSANDRO, E. B.; ANTONIOSI FILHO, N. R. Concepts and studies on lipid and pigments of microalgae: a review. Renewable and Sustainable Energy Reviews, v. 58, p. 832-841, 2016.

DA SILVA, Helder Antônio; DA SILVA, Messias Borges. Aplicação de um projeto de experimentos (DOE) na soldagem de tubos de zircaloy-4. Revista Produção e Engenharia, v. 1, n. 1, p. 41-52, 2016.

DE FARIAS SILVA, Carlos Eduardo; BERTUCCO, Alberto. Bioethanol from microalgae and cyanobacteria: a review and technological outlook. Process Biochemistry, v. 51, n. 11, p. 1833-1842, 2016. 
DEMIRBAS, Ayhan; DEMIRBAS, Muhammet Fatih. Algae energy: algae as a new source of biodiesel. Springer Science \& Business Media, 2010.

DEMIRBAS, M. Fatih. Biorefineries for biofuel upgrading: a critical review. Applied Energy, v. 86, p. S151-S161, 2009.

DEPARTMENT OF ENERGY. Alternative fuel transportation program; replacement fuel goal modification. Office of Energy Efficiency and Renewable Energy. Department of Energy; 2007.

DERRINGER, G.; SUICH, R. Simultaneous Optimization of Several Response Variables. Journal of Quality Technology, v.12, p. 214-219, 1980.

DO CARMO ARAÚJO, Saulo Alberto; DEMINICIS, Bruno Borges. Fotoinibição da fotossíntese. Revista Brasileira de Biociências, v. 7, n. 4, 2009.

DU, Zhenyi et al., Catalytic pyrolysis of microalgae and their three major components: carbohydrates, proteins, and lipids. Bioresource technology, v. 130, p. 777-782, 2013.

DUBINSKY, Z.; MATSUKAWA, R.; KARUBE, I. Photobiological aspects of algal mass culture. J. Mar. Biotechnol, v. 2, p. 61-65, 1995.

ELSEVIER. Disponível em: http://www.scopus.com. Acesso em: 29 dez. 2018.

ENAMALA, Manoj Kumar et al., Production of biofuels from microalgae-A review on cultivation, harvesting, lipid extraction, and numerous applications of microalgae. Renewable and Sustainable Energy Reviews, v. 94, p. 49-68, 2018.

ERIKSSON, L. et al., Design of experiments. Principles and Applications, p. 172-174, 2000.

FAROOQ, Muhammad Arsalan et al., An innovative approach for planning and execution of pre-experimental runs for Design of Experiments. European Research on Management and Business Economics, v. 22, n. 3, p. 155-161, 2016.

FERNÁNDEZ, FG Acién et al., Cost-effective production of $13 \mathrm{C}, 15 \mathrm{~N}$ stable isotope-labelled biomass from phototrophic microalgae for various 
biotechnological applications. Biomolecular Engineering, v. 22, n. 5, p. 193200, 2005.

FUNDAÇÃO UNIVERSITÁRIA PARA O VESTIBULAR. Disponível em: https://blogdoenem.com.br/biologia-enem-velocidade-fotossintese. Acesso em: 07 set. 2017.

FURIAN, P. H. Disponível em: https://www.infoescola.com/fisica/espectroeletromagnetico/. Acesso em: 18 set. 2017.

GERDE, Jose A. et al., Microalgae flocculation: impact of flocculant type, algae species and cell concentration. Algal Research, v. 3, p. 30-35, 2014.

GHERNAOUT, Djamel; GHERNAOUT, Badiaa. On the concept of the future drinking water treatment plant: algae harvesting from the algal biomass for biodiesel production-a review. Desalination and Water Treatment, v. 49, n. 13, p. 1-18, 2012.

GOUVEIA, L; A.C. OLIVEIRA. Microalgae as a raw material for biofuels production. Journal of Industrial Microbiology \& Biotechnology, v. 36, n. 2, p. 269-274, 2009.

GRIMA, E. Molina et al., Photobioreactors: light regime, mass transfer, and scaleup. Journal of Biotechnology, v. 70, n. 1, p. 231-247, 1999.

GU, Na et al., Effect of salinity on growth, biochemical composition, and lipid productivity of Nannochloropsis oculata CS 179. Engineering in Life Sciences, v. 12, n. 6, p. 631-637, 2012.

GUILLARD, Robert RL. Culture of phytoplankton for feeding marine invertebrates. In: Culture of marine invertebrate animals. Springer US, 1975. p. 29-60.

HALIM, R.; DANQUAH, M. K.; WEBLEY, P. A. Extraction of oil from microalgae for biodiesel production: a review. Biotechnology Advances, v. 30, n. 3, p. 70932, jan. 2012.

HAN, F.; PEI, H.; HU, W.; SONG, M.; MA,G.; PEI, R. Optimization and lipid production enhancement of microalgae culture by efficiently changing the 
conditions along with the growthstate. Energy Convers. Manage. v. 19, pp. 315322, 2015.

HANSEL, Philip A.; RIEFLER, R. Guy; STUART, Benjamin J. Efficient flocculation of microalgae for biomass production using cationic starch. Algal Research, v. 5, p. 133-139, 2014.

HARRINGTON, E. C. The desirability function. Industrial quality control, v. 21, n. 10, p. 494-498, 1965.

HATTAB, M.; GHALY, A. Production of Biodiesel from Marine and Freshwater Microalgae: A Review. Advances in Research, v. 3, n. 2, p. 107-155, 2015.

HODGSON, Paul A. et al., Patterns of variation in the lipid class and fatty acid composition of Nannochloropsis oculata (Eustigmatophyceae) during batch culture. Journal of Applied Phycology, v. 3, n. 2, p. 169-181, 1991.

INTERNATIONAL ENERGY AGENCY. Key World Energy Statistics, 2014.

ISHIKA, Tasneema; MOHEIMANI, Navid R.; BAHRI, Parisa A. Sustainable saline microalgae co-cultivation for biofuel production: A critical review. Renewable and Sustainable Energy Reviews, v. 78, p. 356-368, 2017.

ISLAM, Muhammad Aminul; HEIMANN, Kirsten; BROWN, Richard J. Microalgae biodiesel: Current status and future needs for engine performance and emissions. Renewable and Sustainable Energy Reviews, v. 79, p. 1160-1170, 2017.

JAUBERT, Marianne et al., Light sensing and responses in marine microalgae. Current Opinion in Plant Biology, v. 37, p. 70-77, 2017.

JEONG, Hakgeun; LEE, Junghoon; CHA, Misun. Energy efficient growth control of microalgae using photobiological methods. Renewable energy, v. 54, p. 161165, 2013.

JUANTORENA, A. U. et al., Hydrogen production by microorganisms and its application in a PEMFC. International Journal of Energy Research, v. 36, n. 8, p. 902-910, 2012. 
JUNGANDREAS, Anne et al., The acclimation of Phaeodactylum tricornutum to blue and red light does not influence the photosynthetic light reaction but strongly disturbs the carbon allocation pattern. PloS one, v. 9, n. 8, p. e99727, 2014.

KANEMOTO, F. T. Otimização do sistema de cultivo de baixo custo de Nannochloropsis gaditana Lubián 1982 para produção de biodiesel. 2012. Dissertação (Mestrado em Ciências) - Instituto Oceanográfico, Universidade de São Paulo, São Paulo, 2012.

KAWAROE, Mujizat et al., Marine microalgae Tetraselmis suecica as flocculant agent of bio-flocculation method. HAYATI Journal of Biosciences, v. 23, n. 2, p. 62-66, 2016.

KE, Bacon. Photosynthesis photobiochemistry and photobiophysics. Springer Science \& Business Media, 2001.

KHALILI, Arezoo et al., Influence of nutrients and LED light intensities on biomass production of microalgae Chlorella vulgaris. Biotechnology and Bioprocess Engineering, v. 20, n. 2, p. 284-290, 2015.

KLEIN, Bruno Colling; BONOMI, Antonio; MACIEL FILHO, Rubens. Integration of microalgae production with industrial biofuel facilities: A critical review. Renewable and Sustainable Energy Reviews, v. 82, p. 1376-1392, 2018.

KOLLER, M., MUHR, A., BRAUNEGG, G. Microalgae as versatile cellular factories for valued products. Algal Res., v. 6, p. 52-63, 2014.

KWIETNIEWSKA, E. et al., Microalgae: cultivation and application of biomass as a source of energy: a review. [s.l.] Instytut Agrofizyki, 2012.

LEE, H. S. et al., Determining the best specific light uptake rates for the lumostatic cultures in bubble column photobioreactors. Enzyme Microb. Technol. v. 39, pp. 447-452, 2006.

LEE, Young-Chul et al., Harvesting of oleaginous Chlorella sp. by organoclays. Bioresource technology, v. 132, p. 440-445, 2013. 
LIONARD, Marie et al., Influence of changes in salinity and light intensity on growth of phytoplankton communities from the Schelde river and estuary (Belgium/The Netherlands). Hydrobiologia, v. 540, n. 1-3, p. 105-115, 2005.

LIU, Jiexia et al., Effective flocculation of target microalgae with self-flocculating microalgae induced by $\mathrm{pH}$ decrease. Bioresource Technology, v. 167, p. 367375, 2014.

LOURES, C.C.A. Otimização do processo de cultivo da microalga chlorella minutissima como fonte de matéria-prima para a produção de biodiesel 2016. 153 f. Tese (Doutorado em Engenharia Mecânica) - Faculdade de Engenharia do Campus de Guaratinguetá, Universidade Estadual Paulista, Guaratinguetá, 2016.

MADIGAN, M. T.; MARTINKO, J. M.; PARKER, J. Sulfate-and sulfur-reducing Proteobacteria. 2006.

MAEDA, Yoshiaki et al., Marine microalgae for production of biofuels and chemicals. Current opinion in biotechnology, v. 50, p. 111-120, 2018.

MATA, T. M.; MARTINS, A. A.; CAETANO, N. S. Microalgae for biodiesel production and other applications: A review. Renewable and Sustainable Energy Reviews, v. 14, p. 217-232, 2010.

MATTHIJS, Hans CP et al., Application of light-emitting diodes in bioreactors: Flashing light effects and energy economy in algal culture (Chlorella pyrenoidosa). Biotechnology and Bioengineering, v. 50, n. 1, p. 98-107, 1996. MESKO, F.; JACOB-LOPES, E. Biodiesel derived from microalgae: Advances and perspectives. Química Nova, v. 35p. 2013-2018, 2012.

METTING, F. B. Biodiversity and application of microalgae. Journal of industrial microbiology, v. 17, n. 5-6, p. 477-489, 1996.

MILANO, Jassinnee et al., Microalgae biofuels as an alternative to fossil fuel for power generation. Renewable and Sustainable Energy Reviews, v. 58, p. 180$197,2016$.

MONTGOMERY, D.C. Design and Analysis of Experiments. 5th ed. New York: John Wiley and Sons, 2001. 684 p. 
NAGARAJAN, Sanjay et al., An updated comprehensive techno-economic analysis of algae biodiesel. Bioresource technology, v. 145, p. 150-156, 2013.

NEOFOTIS, P. et al., Characterization and classification of highly productive microalgae strains discovered for biofuel and bioproduct generation. Algal Research, v. 15, p. 164-178, 2016.

ONUMAEGBU, C. et al., Pre-treatment methods for production of biofuel from microalgae biomass. Renewable and Sustainable Energy Reviews, v. 93, p. 16-26, 2018.

PENG. H. E, et al., A Review of Novel Materials and Technologies for the Sustainable Development of Microalgae Biofuel. 2016.

PILON, Laurent; BERBEROĞLU, Halil; KANDILIAN, Razmig. Radiation transfer in photobiological carbon dioxide fixation and fuel production by microalgae. Journal of Quantitative Spectroscopy and Radiative Transfer, v. 112, n. 17, p. 2639-2660, 2011.

RAHEEM, Abdul et al., A review on sustainable microalgae based biofuel and bioenergy production: Recent developments. Journal of Cleaner Production, $v$. 181, p. 42-59, 2018.

RAO, Ravella Sreenivas et al., The Taguchi methodology as a statistical tool for biotechnological applications: a critical appraisal. Biotechnology Journal, v. 3, n. 4, p. 510-523, 2008.

RATHA, S. K.; PRASANNA, R. Bioprospecting microalgae as potential sources of "green energy"-challenges and perspectives. Applied Biochemistry and Microbiology, v. 48, n. 2, p. 109-125, 2012.

RATLEDGE, Colin. Regulation of lipid accumulation in oleaginous microorganisms. 2002.

RICHARDSON, James W.; OUTLAW, Joe L.; ALLISON, Marc. The economics of microalgae oil. 2010.

RICHMOND, Amos; CHENG-WU, Zhang; ZARMI, Yair. Efficient use of strong light for high photosynthetic productivity: interrelationships between the optical 
path, the optimal population density and cell-growth inhibition. Biomolecular Engineering, v. 20, n. 4, p. 229-236, 2003.

RODEN, Eric E.; ZACHARA, John M. Microbial reduction of crystalline iron (III) oxides: Influence of oxide surface area and potential for cell growth. Environmental Science \& Technology, v. 30, n. 5, p. 1618-1628, 1996.

ROSS, P. J. Taguchi techniques for quality engineering, 2nd ed., New York. McGraw-Hill Professional, 1995. 329 p.

ROSSI, F. Blending Response Surface Methodology and Principal Components Analysis to Match a Target Product. Food Quality and Preference, v. 12, p. 457465, 2001.

ROY, Ranjit K. Design of experiments using the Taguchi approach: 16 steps to product and process improvement. John Wiley \& Sons, 2001.

SALAM, K. A.; VELASQUEZ-ORTA, S. B.; HARVEY, A. P. A sustainable integrated in situ transesterification of microalgae for biodiesel production and associated co-products: a review. Renewable and Sustainable Energy Reviews, v. 65, p. 1179-1198, 2016.

SALAMA, El-Sayed et al., Recent progress in microalgal biomass production coupled with wastewater treatment for biofuel generation. Renewable and Sustainable Energy Reviews, v. 79, p. 1189-1211, 2017.

SANTILLAN-JIMENEZ, Eduardo et al., Extraction, characterization, purification and catalytic upgrading of algae lipids to fuel-like hydrocarbons. Fuel, v. 180, p. 668-678, 2016.

SANTOS, R. R. et al., Comparison between several methods of total lipid extraction from Chlorella vulgaris biomass. Ultrasonics Sonochemistry, v. 22, p. 95-99, 2015.

SCRAGG, A. H. et al., Growth of microalgae with increased calorific values in a tubular bioreactor. Biomass and Bioenergy, v. 23, n. 1, p. 67-73, 2002.

SHEN, Yafei. Carbon dioxide bio-fixation and wastewater treatment via algae photochemical synthesis for biofuels production. RSC Advances, v. 4, n. 91, p. 49672-49722, 2014. 
SHUBA, Eyasu Shumbulo; KIFLE, Demeke. Microalgae to biofuels:'Promising'alternative and renewable energy, review. Renewable and Sustainable Energy Reviews, v. 81, p. 743-755, 2018.

SHURTZ, Benjamin K.; WOOD, Byard; QUINN, Jason C. Nutrient resource requirements for large-scale microalgae biofuel production: Multi-pathway evaluation. Sustainable Energy Technologies and Assessments, v. 19, p. 51$58,2017$.

SIGAUD, Teresa Cristina Siqueira; AIDAR, Elizabeth. Salinity and temperature effects on the growth and chlorophyll- $\alpha$ content of some planktonic aigae. Boletim do Instituto Oceanográfico, v. 41, n. 1-2, p. 95-103, 1993.

SMITH, Sarah R. et al., Transcriptional orchestration of the global cellular response of a model pennate diatom to diel light cycling under iron limitation. PLoS genetics, v. 12, n. 12, p. e1006490, 2016.

SOUZA, Marciléa Machado de et al., Um estudo da luz: construindo com materiais de baixo custo uma Antiluneta Polarizadora e o Sistema Solar. 2017.

SPOEHR, H. A.; MILNER, Harold W. The chemical composition of Chlorella; effect of environmental conditions. Plant physiology, v. 24, n. 1, p. 120, 1949.

SPOLAORE, Pauline et al., Commercial applications of microalgae. Journal of bioscience and bioengineering, v. 101, n. 2, p. 87-96, 2006.

SRIRAM, S.; SEENIVASAN, R. Biophotonic perception on Desmodesmus sp. VIT growth, lipid and carbohydrate content. Bioresource Technology, v. 198, pp. 626-633, 2015.

SUALI, Emma; SARBATLY, Rosalam. Conversion of microalgae to biofuel. Renewable and Sustainable Energy Reviews, v. 16, n. 6, p. 4316-4342, 2012. SUGANYA et al., Macroalgae and microalgae as a potential source for commercial applications along with biofuels production: A biorefinery approach. Renewable and Sustainable Energy Reviews, v. 55, p. 909-941,2016. 
SWAN, D. A.; SAVAGE, G. J. Continuous Taguchi-a model-based approach to Taguchi's 'quality by design'with arbitrary distributions. Quality and Reliability Engineering International, v. 14, n. 1, p. 29-41, 1998.

TAKAGI, Mutsumi et al., Effect of salt concentration on intracellular accumulation of lipids and triacylglyceride in marine microalgae Dunaliella cells. Journal of bioscience and bioengineering, v. 101, n. 3, p. 223-226, 2006.

THEODOROU, Maria E. et al., Effects of phosphorus limitation on respiratory metabolism in the green alga Selenastrum minutum. Plant Physiology, v. 95, n. 4, p. 1089-1095, 1991.

UDUMAN, Nyomi et al., Dewatering of microalgal cultures: a major bottleneck to algae-based fuels. Journal of renewable and sustainable energy, v. 2, n. 1, p. $012701,2010$.

UNIVERSIDADE ESTADUAL DE CAMPINAS. Disponivel em: http://www.mc.unicamp.br/index.php/noticias/prog-fds-snm2016. Acesso em: 18 set. 2017.

US ENERGY INFORMATION ADMINISTRATION (EIA). Disponível em: http://www.eia.gov/forecasts/aeo/section_energyconsump.cfm. Acesso em: 12 nov. 2016.

VALLE, Kristin Collier et al., System responses to equal doses of photosynthetically usable radiation of blue, green, and red light in the marine diatom Phaeodactylum tricornutum. PloS one, v. 9, n. 12, p. e114211, 2014.

VAN GYSEGHEM,E. et al., Selection of reversed-phase liquid chromatographic columns with diverse selectivity towards the potential separation of impurities in drugs. Journal of Chromatography A, n. 1042, p. 69-80, 2004.

VERMUË, M. H. et al., Cationic polymers for successful flocculation of marine microalgae. Bioresource technology, v. 169, p. 804-807, 2014.

VIDYASHANKAR, Srivatsan et al., Characterization of fatty acids and hydrocarbons of chlorophycean microalgae towards their use as biofuel source. Biomass and Bioenergy, v. 77, p. 75-91, 2015. 
WANG, Shi-Kai et al., Microalgae cultivation in photobioreactors: An overview of light characteristics. Engineering in Life Sciences, v. 14, n. 6, p. 550-559, 2014. YAN, C.; ZHAO, Y.; ZHENG, Z.; LUO, X. Effects of various LED light wavelengths and light intensity supply strategies on synthetic high-strength wastewater purification by Chlorella vulgaris. Biodegradation. v. 24, pp. 721-732, 2013.

YANG, H.J.; HWANG, P.J.; LEE, S.H. A study on shrinkage compensation of the SLS process by using the Taguchi method. International Journal of Machine Tools \& Manufacture, v.42, p. 1203-1212, 2002.

ZHANG, Liping; HAPPE, Thomas; MELIS, Anastasios. Biochemical and morphological characterization of sulfur-deprived and $\mathrm{H}$ 2-producing Chlamydomonas reinhardtii (green alga). Planta, v. 214, n. 4, p. 552-561, 2002. ZHAO, Yongjun et al., Effects of various LED light wavelengths and intensities on microalgae-based simultaneous biogas upgrading and digestate nutrient reduction process. Bioresource Technology, v. 136, p. 461-468, 2013.

ZHEN, Guangyin et al., Anaerobic co-digestion on improving methane production from mixed microalgae (Scenedesmus sp., Chlorella sp.) and food waste: kinetic modeling and synergistic impact evaluation. Chemical Engineering Journal, v. 299, p. 332-341, 2016.

ZORN, S. M. F. E. Desenvolvimento do processo de extração de lipídios da biomassa de microalgas marinhas. 2017. 124 p. Dissertação (Mestrado em Ciências) - Escola de Engenharia de Lorena, Universidade de São Paulo, Lorena, 2017. 